
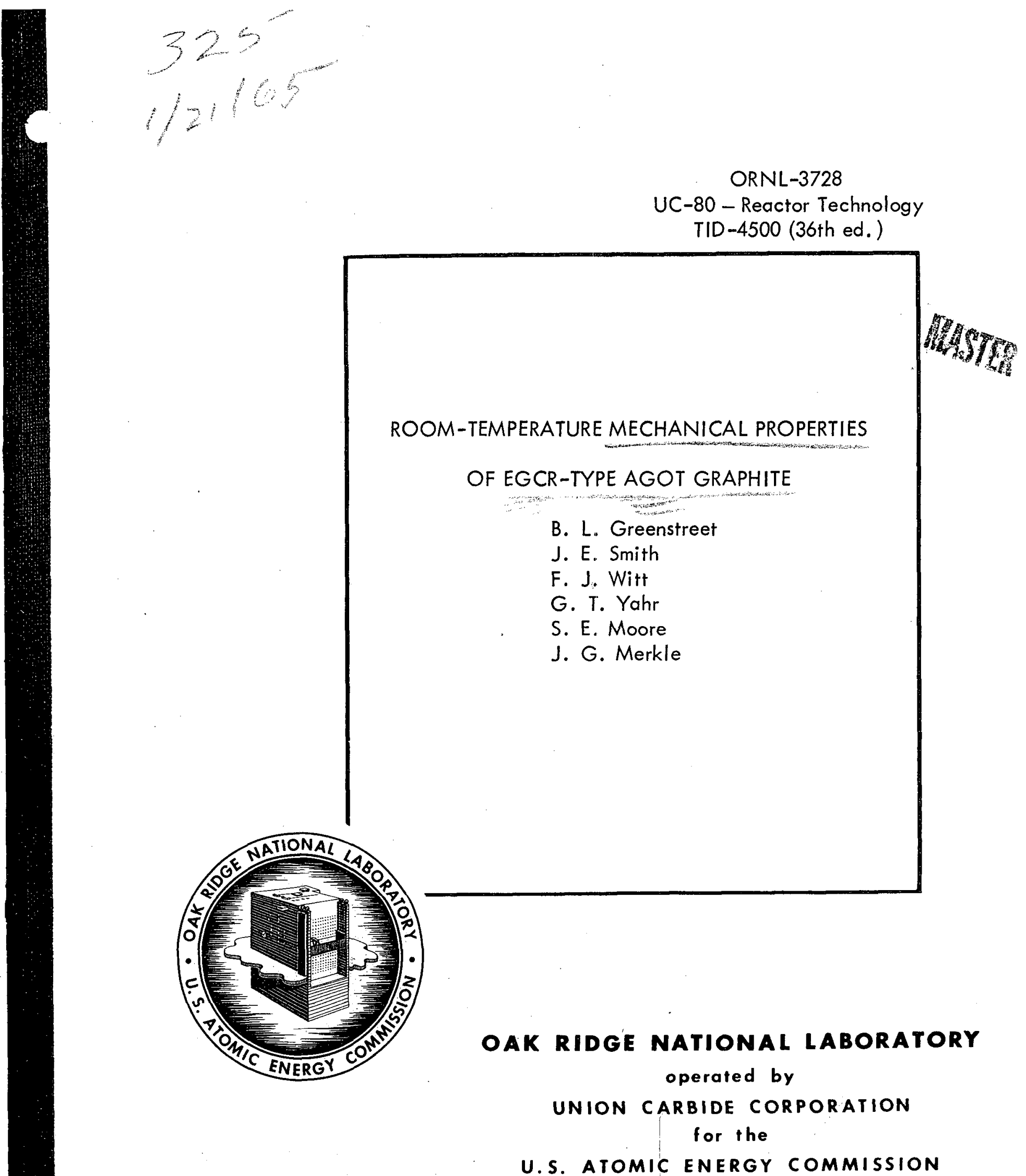
Contract No. W-7405-eng-26

Reactor Division

ROOM-TEMPERATURE MECHANICAI PROPERTIES

OF EGCR-TYPE AGOT GRAPHITE

B. I. Greenstreet

J. E. Smith

F. J. Witt
G. T. Yahr

S. E. Moore

J. G. Merkle

\title{
JANUARY 1965
}

\author{
OAK RIDGE IIATIONAL IABORATORY \\ Oak Ridge, Tennessee \\ operated by \\ UNION CARBIDE CORPORATION \\ for the \\ U.S. ATOMIC ENERGY COMMISSION
}




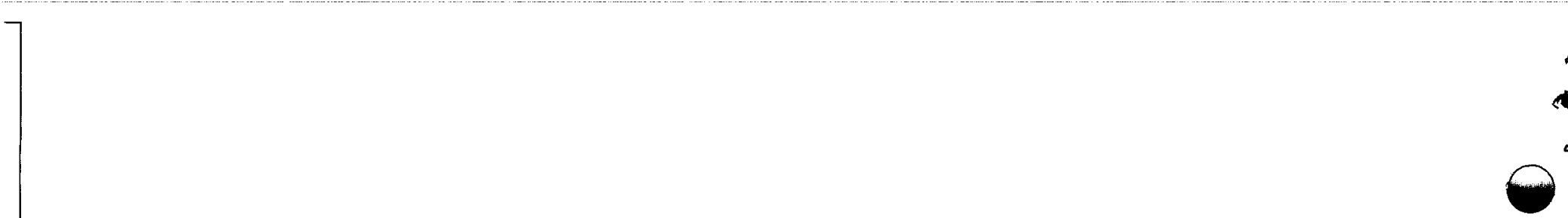




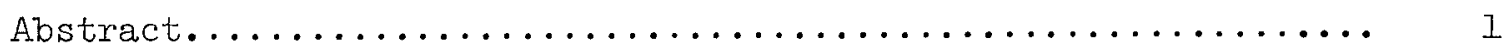

Introduction...................................... 1

Description of Material and Test Specimens................. 4

Test Procedure..................................... 9

Data Collection and Reduction......................... 13

Test Results..................................... 18

Uniaxial Tests.................................. 18

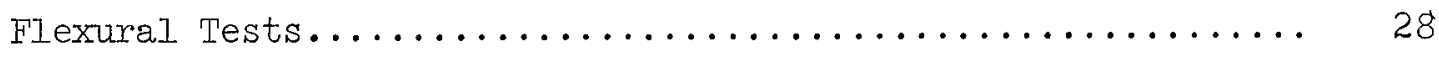

Comparison of Uniaxial and Flextural Specimens........... 37

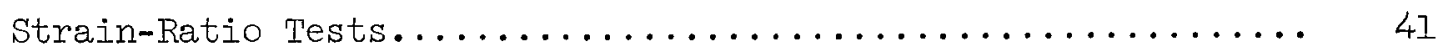

Fxamination of Data Distributions....................... 49

Stress Distributions for a Given Strain................. 49

Statistical Examination of Fracture Stress Data............ 51

Analytical Representations of the Stress-Strain Relationships.... 58

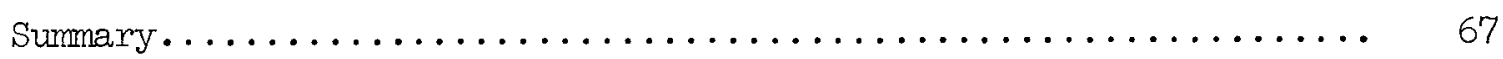

Appendix. Hooke's Law for a Transversely Isotropic Material..... 69 
ROOM-TEMPERATURE MECHANICAL

PROPERTIES OF EGCR-TYPE AGOT GRAPHITE
B. I. Greenstreet
G. T. Yahr
J. E. Smith
S. E. Moore
F. J. Witt
J. G. Merkle

Abstract

Numerous uniaxial and flexural tests were performed on EGCR-type AGOT graphite at room temperature. Moduli of elasticity, fracture stresses, fracture strains, stress-strain diagrams, ultimate strain energies, and strain ratios were obtained. The two most important conclusions reached from comparisons of the data are that (I) size effects, including volume and cross-sectional area, are small or nonexistent within the size range investigated, and (2) the behavior is the same in flexural and in uniaxial tests. The analyses provide a first step in establishing failure criteria.

Significant differences exist between the tensile and compressive results; however, the material conforms fairly well to the assumption of transverse isotropy. The data distributions for the stress-strain diagrams are shown, in the main, to be normal, and analytical expressions characterizing the relationship between stress and strain are presented. The fracture stresses were examined according to Weibull's statistical theory of failure, and it was shown that the more important implications of the theory are not supported by the data.

\section{Introduction}

The problems involved in investigating the structural integrity of a graphite body are twofold. First, data must be available that adequately describe the mechanical and physical properties characteristic of the graphite, and second, a means must exist for generalizing the properties data to the complex conditions that usually exist in the body under consideration. In particular, a satisfactory solution to the second problem dictates that adequate failure criteria exist whereby uniaxial stressstrain data may be used to correctly predict rupture of a graphite body under a more complex stress state.

Surprisingly, proven failure criteria (i.e., stress or strain states governing the failure of the material) are not available even in the 
simplest case of loading (other than a uniform uniaxial stress) such as pure bending of a beam. If it is assumed that failure in flexure occurs when the maximum stress in the beam reaches the rupture stress obtained from a uniaxial tensile test, the moments calculated on an elastic basis are, on the average, only about $73 \%$ of those causing failure. When such discrepancies exist in the simplest case of loading, rupture predictions for structures wherein complex multiaxial stress states exist may be even more deceptive.

The commonly observed differences between the uniaxial tensile strength and the flexural strength of graphite may be due in whole or in part to the following three factors:

1. Graphite exhibits brittle behavior. The failure of many brittle materials has reportedly been found to be dependent upon the stress distribution within a body rather than upon the attainment of a critical stress. Among the prominent explanations is Weibull's statistical theory, according to which the probability of fracture of a given body depends on the volume under stress and on the stress distribution. Thus, when the entire volume is under a given maximum stress, as in the case of a tensile specimen, the probability of fracture is greater than when only a fraction of the volume is under the same maximum stress, as in the case of a flexural specimen. Based on the same type of reasoning, a large tensile specimen has a greater probability of fracture under a designated stress than does a smaller specimen. This latter supposition is the size effect associated with brittle materials.

2. Both the tensile and compressive stress-strain diagrams for graphite are nonlinear even at low strain levels. Thus, the ordinary linear elastic stress-strain relationships cannot be used to accurately obtain strains when stresses are known or to obtain stresses when strains are known. Furthermore, even in the simple case of pure bending, the proper stress-strain relations must be used to obtain the stresses in the beam; if the stress-strain relations are nonlinear, the stress does not vary linearly across the beam as is presumed in deriving the simple elastic formula.

3. The tensile and compressive stress-strain diagrams for a particular type of graphite are not the same. For example, it is known that the 
compressive strength of graphite is from three to four times larger than the tensile strength, and it has been reported ${ }^{*}$ that the resistance to deformation in compression is significantly different from that in tension. A difference in tensile and compressive behavior has a marked effect on the stress and strain distributions within a body.

In adition to the above three factors that affect rupture predictions for pure bending, the analysis of graphite components under multiaxial stress states is further complicated by the anisotropy of graphite and the absence of proven failure criteria. A significant error can be introduced if anisotropy is neglected, or if incorrect failure criteria are employed.

In order to determine the mechanical behavior of EGCR-type AGOT graphite, a series of room-temperature tests was conducted. These tests were designed to provide mechanical properties data, to examine size effects in uniaxial tests, and to clear up the previously reported discrepancies between bend and uniaxial test results. Because of the variability of graphite, a large sampling was used in each case so that the data could be compared and examined on statistical bases. The methods used and the data obtained are described in this report.

Since the data given were obtained on pieces from only two of the 120 extrusions used in making the core columns for the EGCR (Experimental GasCooled Reactor), they are not to be construed as representative for all the graphite used in the reactor core. However, the behaviors observed and reported are representative of EGCR-type AGOT graphite.

The work reported here was originally initiated and supported under the Experimental Gas-Cooled Reactor Program at Oak Ridge National Laboratory. In November 1963, the work came under the auspices of Advanced Graphite Research and Technology Portion of the Nuclear Rocket Program (J. E. Morrissey, Space Nuclear Propulsion Office, U. S. Atomic Energy Commission). This and other work was subsequently to be carried out in close contact with Los Alamos Scientific Laboratory and Westinghouse Astronuclear Laboratory. J. C. Rowley, N-7 Group, N Division, Los Alamos Scientific Laboratory, served as Technical Director of the work for USAEC.

\footnotetext{
* Superscripts refer to numbered references in the Bibliography.
} 
The authors wish to acknowledge the contributions of J. M. Corum, who assisted in planning the testing program, H. D. Curtis and W. J. McAfee, who assisted in the experimental work, D. T. Godwin, who assisted in the data reduction, and $\mathrm{R}$. B. Bullock, who wrote the computer programs.

\section{Description of Material and Test Specimens}

The graphite for the Experimental Gas-Cooled Reactor, ${ }^{2}$ designated EGCR-type AGOT, was made from calcined Continental-Lake Charles petroleum coke. This coke has a needle-type particle structure. The maximum particle size was limited to $1 / 32$ in. A coal-tar pitch was used as the binder, and the graphitizing temperatures ranged from $2800^{\circ} \mathrm{C}$ to about $3100^{\circ} \mathrm{C}$, with an average of about $2840^{\circ} \mathrm{C}$. Additional information on the material, as determined by the sampling procedure given by the purchase specification, is listed in Table 1.

Table 1. Manufacturer's Data on EGCR-Type AGOT Graphite

\begin{tabular}{|c|c|c|c|}
\hline Quantity & Average & Maximum & Minimum \\
\hline Density, $\mathrm{g} / \mathrm{cm}^{3}$ & 1.71 & 1.73 & 1.68 \\
\hline Ash content, wt $\%$ & 0.015 & 0.024 & 0.008 \\
\hline Boron content, ppm & 0.26 & 0.50 & 0.10 \\
\hline \multicolumn{4}{|c|}{$\begin{array}{l}\text { Coefficient of thermal } \\
\text { expansion, }{ }^{\circ} \mathrm{C}^{-1}\end{array}$} \\
\hline Longitudinal & $0.70 \times 10^{-6}$ & $0.89 \times 10^{-6}$ & $0.58 \times 10^{-6}$ \\
\hline Transverse & $2.34 \times 10^{-6}$ & $2.66 \times 10^{-6}$ & $2.14 \times 10^{-6}$ \\
\hline \multicolumn{4}{|c|}{$\begin{array}{l}\text { Thermal conductivity, } \\
\text { Btu/hr} \cdot \mathrm{ft} \cdot{ }^{\circ} \mathrm{F}\end{array}$} \\
\hline Longitudinal & 131.3 & 137.9 & 113.7 \\
\hline Transverse & 87.2 & 104.0 & 74.5 \\
\hline
\end{tabular}

The graphite was manufactured by Union Carbide Corporation, Carbon Products Division, in the form of extrusions about $18 \mathrm{in}$. square by $20 \mathrm{ft}$ Iong. These extrusions were then machined to form the graphite core columns. A typical moderator column is shown in Fig. 1, in which the 


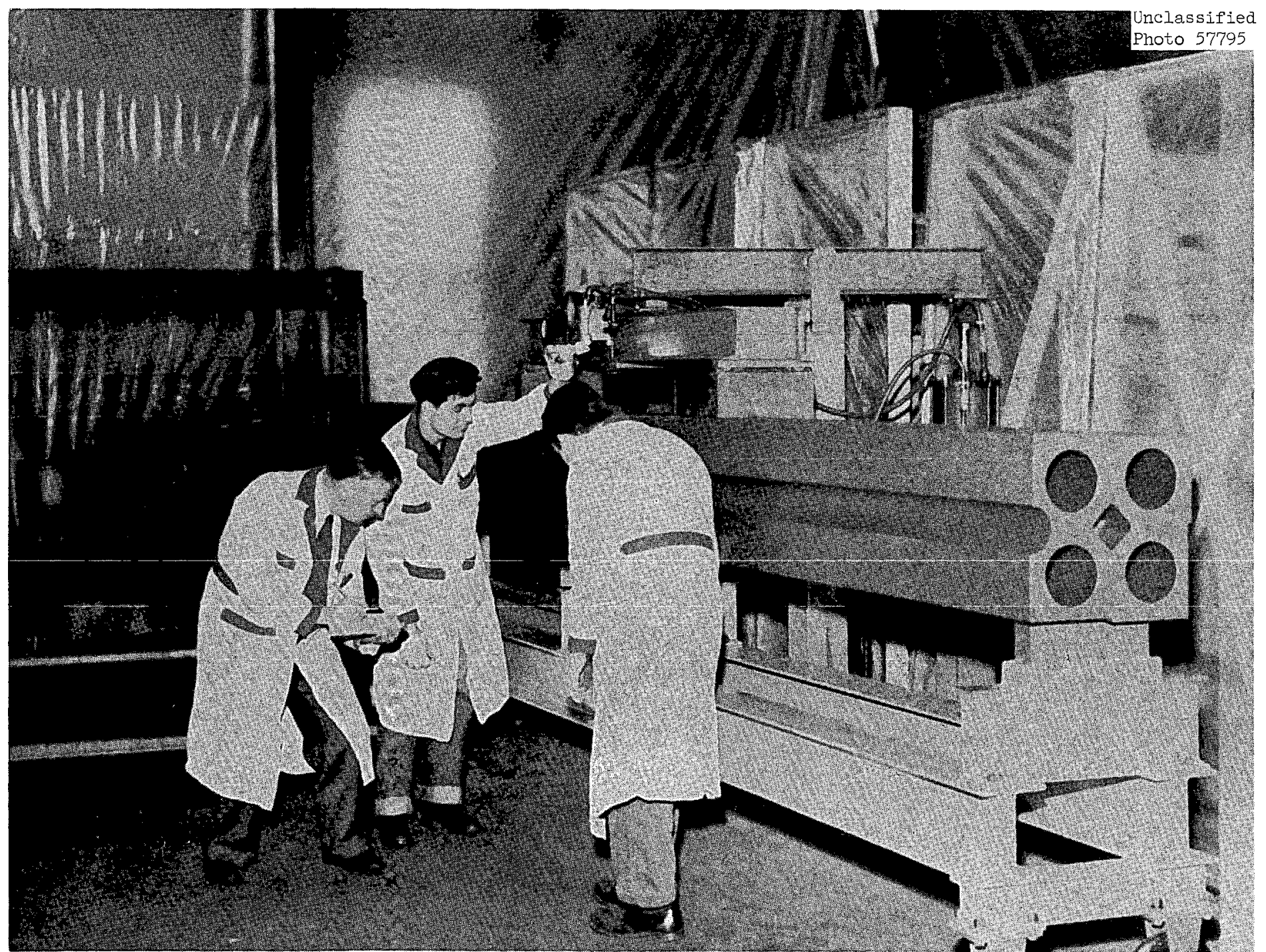

Fig. 1. EGCR Moderator Colum Being Machined. 
four 5 1/4-in.-diam fuel channels and half of a 4-in.-diam control rod channel along one side of the column may be seen. The square recess in the end is for engaging a positioning lug on the core support plate. The sides are stepped to reduce neutron streaming, and the cross-sectional dimension is nominally 16 in.

The specimens used to obtain the data given in this report came from pieces removed in machining two of the columns. The extrusions from which these pieces came were identified by the manufacturer as File Numbers 252 and 266. The column machined from extrusion 252 was used in the core of the EGCR, while the one machined from extrusion 266 was an extra column which passed all acceptance tests but was not used in the reactor. The data on these columns, as supplied by the manufacturer, are listed in Table 2. The average of all the tensile-strength data given by the manufacturer for the EGCR columns was 752 psi transverse to the extrusion direction and 1104 psi parallel to the extrusion direction, with coefficients

Table 2. Manufacturer's Data on Extrusions

Designated File Nos. 252 and 266

\begin{tabular}{|c|c|c|}
\hline & File No. 252 & File No. 266 \\
\hline \multicolumn{3}{|l|}{ Graphitizing data } \\
\hline Run No. & $\mathrm{G}-76$ & $G-72$ \\
\hline Date & $2-10-61$ & $1-31-61$ \\
\hline Temperature, ${ }^{\circ} \mathrm{C}$ & 2832 & 2800 \\
\hline Density, $\mathrm{g} / \mathrm{cm}^{3}$ & 1.72 & 1.71 \\
\hline Ash content, $\%$ & 0.019 & 0.018 \\
\hline Boron content, ppm & 0.3 & 0.2 \\
\hline Transverse tensile strength, psi & 739 & 726 \\
\hline $\begin{array}{l}\text { Transverse coefficient of thermal } \\
\text { expansion, }{ }^{\circ} \mathrm{C}^{-1}\end{array}$ & $2.27 \times 10^{-6}$ & $2.43 \times 10^{-6}$ \\
\hline $\begin{array}{l}\text { Transverse thermal conductivity, } \\
\mathrm{cal} / \mathrm{cm} \cdot \mathrm{sec} \cdot{ }^{\circ} \mathrm{C}\end{array}$ & 0.397 & 0.342 \\
\hline Transverse Young's modulus, psi & $0.85 \times 10^{6}$ & $0.82 \times 10^{6}$ \\
\hline
\end{tabular}


of variation of 7 and $6 \%$, respectively. The sampling procedure for determining properties of the graphite are given in EGCR specifications $\mathrm{RC}-2 .^{3}$

Throughout the testing program, the graphite was assumed to be transversely isotropic; that is, the properties in a plane normal to the extrusion direction are independent of direction, but the properties in the direction normal to this plane differ from those in the plane. Five constants are required to describe the elastic behavior of such a material; they are defined here as follows:

$$
\begin{aligned}
& E_{1}=\text { the modulus of elasticity normal to the extrusion direction, } \\
& \mathrm{E}_{3}=\text { the modulus of elasticity parallel to the extrusion direction, } \\
& -v_{12}=\text { the ratio of the strain induced normal to the extrusion axis } \\
& \text { and normal to the direction of loading to the strain in the } \\
& \text { direction of the load when the specimen is loaded normal to } \\
& \text { the extrusion axis, } \\
& -v_{13}=\text { the ratio of the strain induced parallel to the extrusion di- } \\
& \text { rection to the strain in the direction of the load when the } \\
& \text { specimen is loaded normal to the extrusion direction, } \\
& \mathrm{G}_{4}=\text { the ratio of the shear stress on a plane parallel to the ex- } \\
& \text { trusion direction to the corresponding shear strain. }
\end{aligned}
$$
given by

$$
v_{31}=\frac{E_{3}}{E_{1}} v_{13} .
$$

Since graphite does not exhibit linear elastic behavior, complete stress-strain and strain-ratio diagrams that describe the material behavior in the same sense as the elastic constants describe a purely elastic material were obtained, with one exception. Shear-stress versus shear-strain diagrams corresponding to $\mathrm{G}_{4}$ were not obtained.

The major study was conducted on specimens that had Iongitudinal axes oriented parallel to the extrusion direction. The specimen configurations 
used are designated a through $\mathrm{h}$ in the schematic drawings of Fig. 2. Specimens a through $f$ were designed to examine the effects of volume and stress gradient upon the fracture characteristics. The volume of the reduced section of the small tensile and small flexural specimens was 0.115 in. $^{3}$. The volume of the reduced section of the large tensile and large flexural specimens was 0.920 in. ${ }^{3}$ : eight times that of the small specimens. The surface areas of the large flexural and tensile specimens and small flexural and tensile specimens were similarly matched. The larger specimens had a surface area of $5.890 \mathrm{in} .^{2}$, while the small specimens had a surface area of 1.472 in. ${ }^{2}$, differing by a factor of 4 from the large specimens. The ratio of the length of the reduced section to the diameter was 1:l for both sizes of compressive specimens, as may be seen from the table of Fig. 2 .

In order to further study size effects, specimens of type $g$ in Fig. 2 were tested. Using these specimens, the effect of minimum cross-sectional


b SMALL TENSILE

c LARGE COMPRESSIVE

d SMALL COMPRESSIVE

a LARGE FLEXURAL

f SMALL FLEXURAL

$g$ AREA - EFFECT

h POISSON'S RATIO

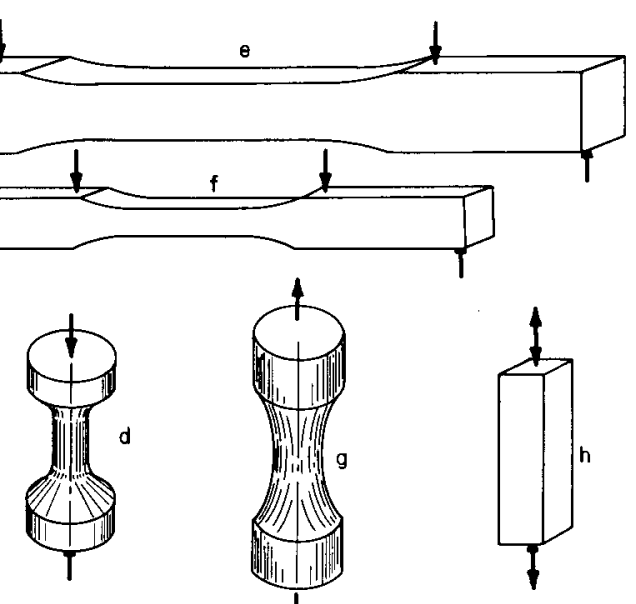

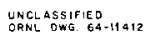

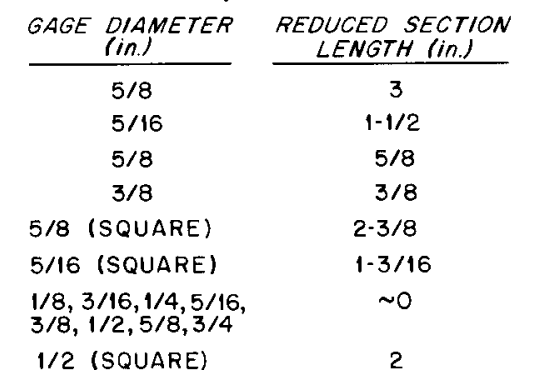

Fig. 2. Test Specimen Configurations. 
dimension on the failure characteristics under tensile load were examined. The reduced section of the specimens was designed to have a minimum cross section with essentially zero length to minimize the effect of volume as a parameter. In tests on this type of specimen the overall length, as well as the diameter of the minimum section, was varied.

Except for the strain-ratio specimens (designated $h$ in Fig. 2), tests on specimens with longitudinal axes oriented perpendicular to the extrusion direction were made only on those labeled a through d in Fig. 2. Thus, only volume effects were examined for this direction.

Detailed drawings of the specimens are shown in Fig. 3. The specimens had a machined finish of $63 \mu \mathrm{in.}$, and no sanding or polishing was permitted. in the reduced section. The transitions from the ends of the specimens to the reduced sections had generous radii in order to reduce the stress concentrations. Reduction of the stress concentration in this region to a minimum value is extremely important with graphite, since no appreciable local yielding occurs.

The tensile, compressive, and flexural specimens cut in the parallel direction were all taken from the 4 1/4-in.-diam cores that were trepanned from the fuel channels in extrusion 266. A set of specimens including one of each size and type was taken from each 10-in. length of core, as indicated in Fig. 4. The tensile and compressive specimens with axes normal to the extrusion axis were taken from solid blocks cut from the ends of extrusion 266. The same was true for the strain-ratio specimens. Cores that were trepanned from the fuel channels of extrusion 252 were used to make the area-effect specimens.

\section{Test Procedure}

All but about 15\% of the specimens were radiographed prior to testing to provide information for later fractographical examinations. After testing the specimens were filed individually.

Loads were applied to the specimens with a BLW Universal Testing Machine. Although the ambient conditions under which the tests were conducted may be unimportant, it is perhaps interesting to note that the laboratory area was maintained at a temperature of $72^{\circ} \mathrm{F} \pm 4^{\circ} \mathrm{F}$ and the relative 
UNCLASS1FIED
ORNL DWG. $64-11413$

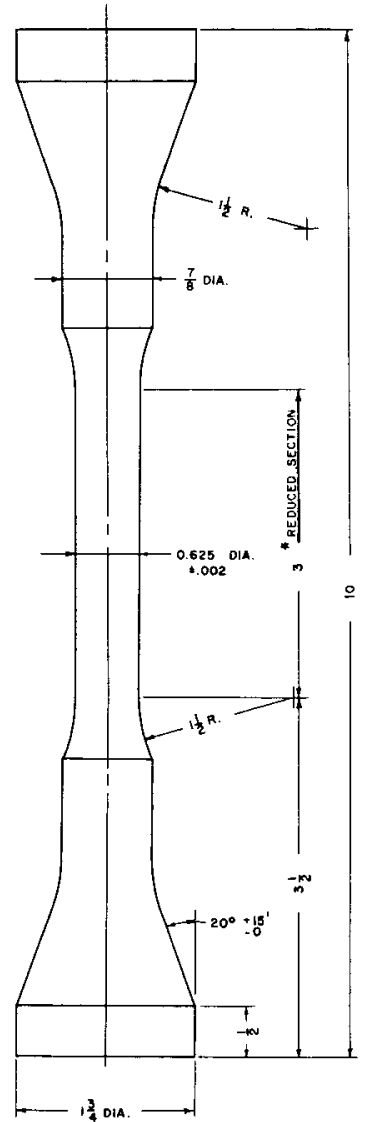

LARGE TENSILE SPECIMEN

"REDUCED SECTION ON TRANSVERSE
SPECIMENS TO BE $2-3 / 4$.

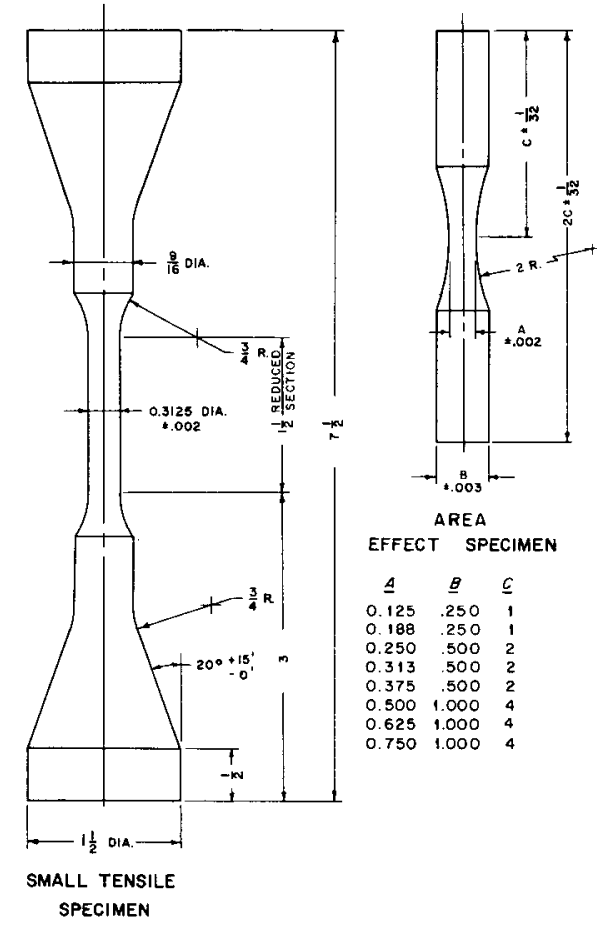

GENERAL NOTES:

TOLERANCES UNLESS OTHERWISE SPECIFIED: $\begin{array}{lll}\text { FRACTIONS : } & \frac{1}{54} \\ \text { DECIMALS }:: 0.005 & 0.005\end{array}$

SURFACE FINISH TO 63

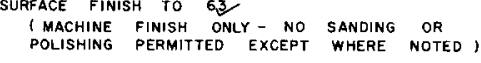
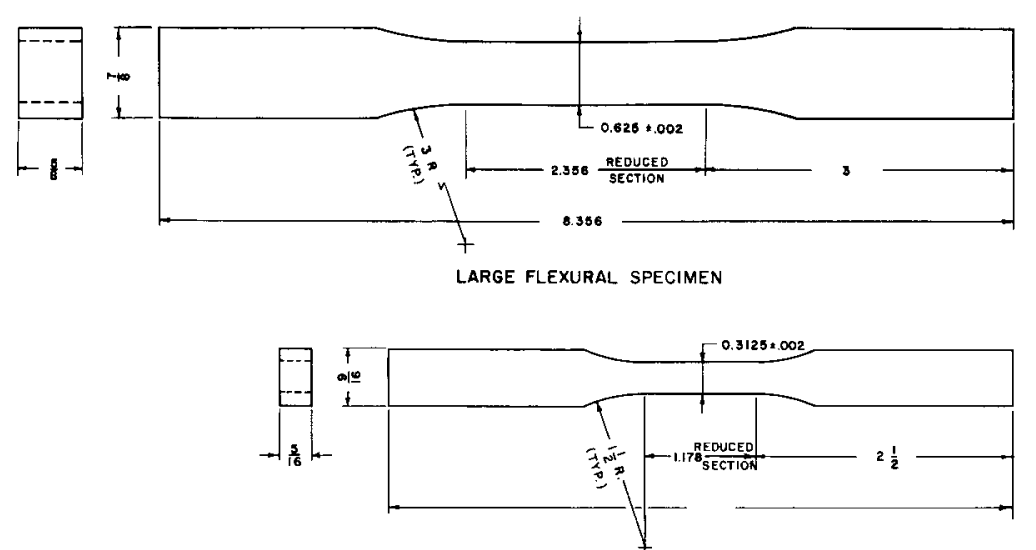

SMALL FLEXURAL SPECIMEN

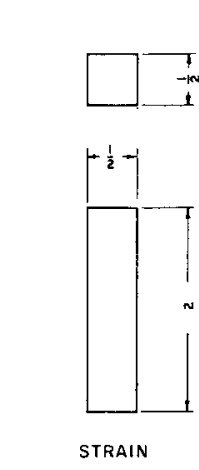

RATIO SPECIMEN
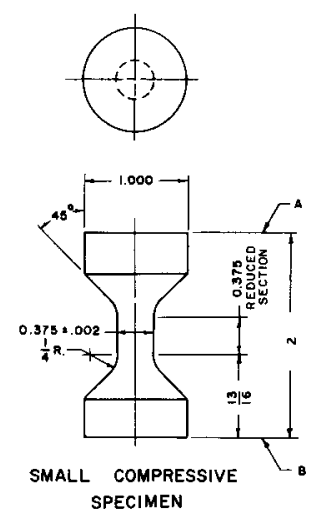
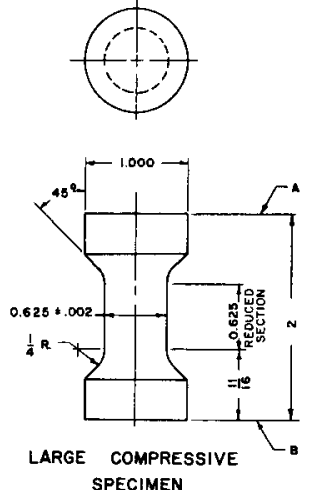
SPECIMEN

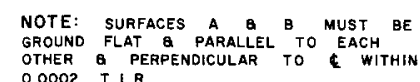

Fig. 3. Test Specimen Configurations. 




Fig. 4. Sampling Scheme for Cores. 
humidity did not exceed $60 \%$ throughout the test period. The applied loads for the uniaxial specimens were measured with Baldwin strain-gage-based load cells, and the applied loads on the flexural specimens were measured with the specially designed transducer shown in Fig. 5. Platen rates of 0.010 and $0.025 \mathrm{in.} / \mathrm{min}$ were used for the uniaxial and flexural tests, respectively. On all but the area-effect specimens, the strains were measured with $66-121$ foil strain gages having a nominal gage length of 0.125 in. Type C6-1ll metalfilm gages with a length of 0.063 in. were used in the area-effect tests.

Two diametrically opposed gages were mounted on each uniaxial specimen. These gages were wired in series to form one leg of the measuring

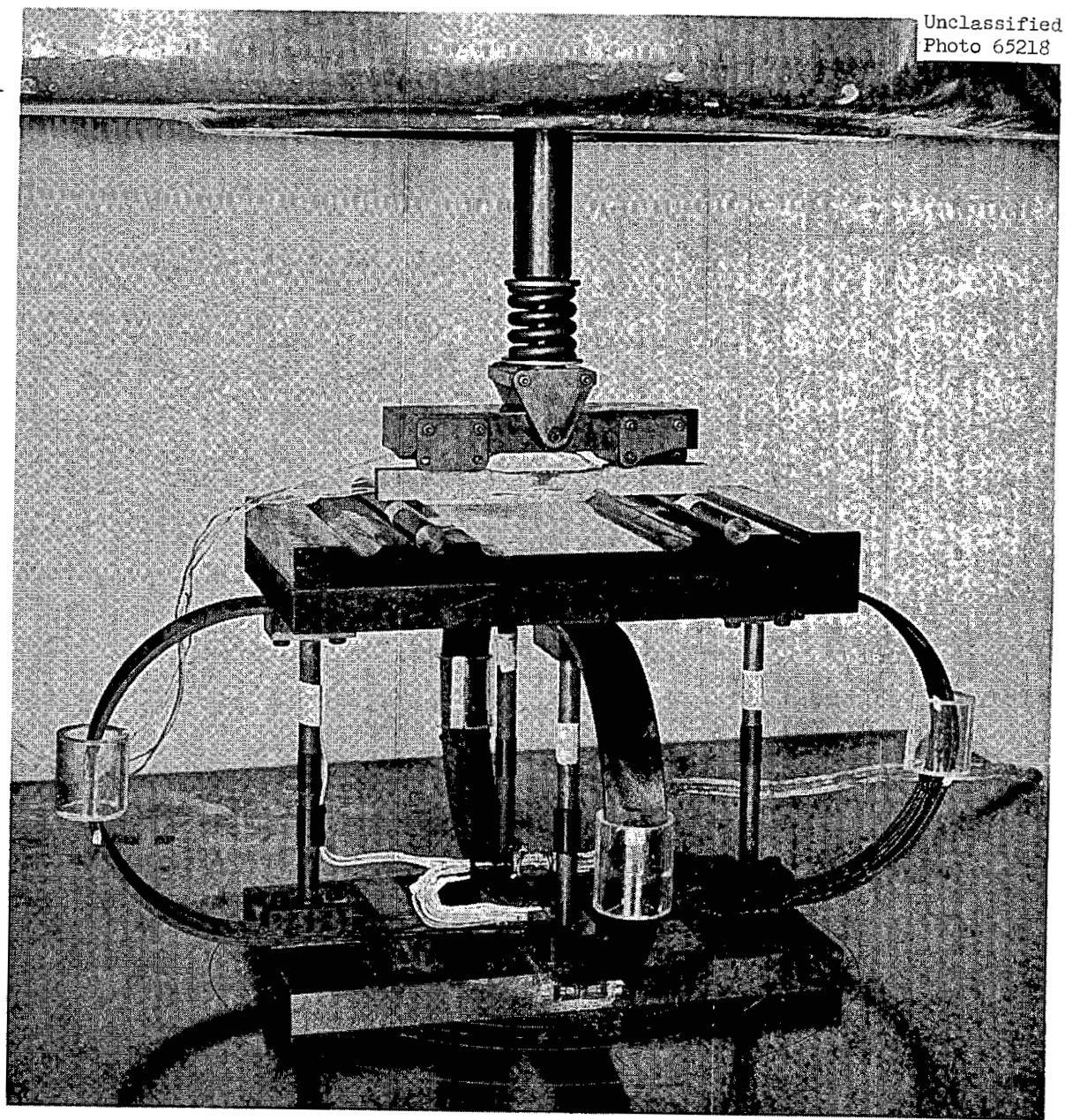

Fig. 5. Transducer Used in Flexural Tests. 
bridge. Such an arrangement gave the average output for the two gages and cancelled any differences in strains at the two points due to moments induced by bending or to variation of properties with the material. In the flexural tests, the gages were positioned on the extreme surfaces of a single cross section.

A very difficult problem in making tensile tests is that of eliminating moment loadings due to misalignments in load application. This difficulty was largely overcome in the cases of specimen types $a$ and $b$ of Fig. 2 by using round metal disks with centrally mounted cables for applying the load to the specimen. These metal disks, or end caps, were carefully aligned with and glued to the ends of the specimens. The pulling cables were as small in diameter as was compatible with the strengths required. Thus, the moments were greatly reduced by promoting self alignment. Cable grippers were used in pulling the area-effect specimens.

A standard fixture, commercially available, was used for the compression tests. The specimen end surfaces were ground parallel during fabrication and lapped in with the fixture to achieve uniform loading.

The strain-ratio specimens were cut with three different orientations. Two had longitudinal axes that were normal to the extrusion direction and perpendicular to each other. The third was aligned parallel to the extrusion direction. Specimens of each orientation were tested in both tension and compression. Two adjacent sides of each specimen were gaged with one gage parallel to and one gage normal to the longitudinal axis of the specimen.

\section{Data Collection and Reduction}

The electrical signals from the load cell and strain gages were fed into a TR-10 analog computer. When uniaxial tests were made, stress-strain diagrams were obtained directly on an X-Y plotter, with the analog computer being used only to amplify the electrical signals from the load cell and the strain gages. The signals from the flexural tests were treated somewhat differently by the analog computer. Because of the complications resulting from such things as nonlinear stress-strain behavior, differences in stress-strain diagrams in tension and compression, and the shift of the 
neutral surface from the midplane of the beam, the analog computer was used to calculate the extreme fiber stresses.

The equations used for calculating the stresses are based on the following assumptions:

1. The material is homogeneous.

2. The beam is subjected to pure bending.

3. Transverse sections remain plane and normal to the longitudinal fibers after bending.

These assumptions together with the two conditions that

1. The summation of forces in the longitudinal direction is zero,

$$
\Sigma F_{X}=0 \text { or } \quad \int \sigma d A=0
$$

2. The summation of internal and applied moments is zero,

$$
\Sigma \mathrm{M}=0 \quad \text { or } \quad \int \sigma \mathrm{y} \mathrm{dA}=\mathrm{M}
$$

yield the following expressions: ${ }^{4}$

$$
\sigma_{\mathrm{T}}=\frac{2 \mathrm{M}+\mathrm{K} \frac{\partial \mathrm{M}}{\partial \mathrm{K}}}{\mathrm{bd} \frac{\partial \epsilon_{\mathrm{T}}}{\partial \mathrm{K}}},
$$

and

$$
\sigma_{C}=\frac{2 M+K \frac{\partial M}{\partial K}}{b d \frac{{ }^{C}}{\partial K}},
$$

where $\mathrm{K}$ is the curvature of the neutral surface, and is given by

$$
K=\frac{\left|\epsilon_{T}\right|+\left|\epsilon_{C}\right|}{d} .
$$

The shift in neutral surface from the midplane is expressed by 


$$
\eta=\frac{\mathrm{d}}{2} \frac{\left|\epsilon_{\mathrm{T}}\right|-\left|\epsilon_{\mathrm{C}}\right|}{\left|\epsilon_{\mathrm{T}}\right|+\left|\epsilon_{\mathrm{C}}\right|}=\frac{\left|\epsilon_{\mathrm{T}}\right|-\left|\epsilon_{\mathrm{C}}\right|}{2 \mathrm{~K}} .
$$

In these expressions $\mathrm{A}$ is the cross-sectional area; $\mathrm{y}$ is the distance from the midplane; $\sigma$ and $\epsilon$ are the stresses and strains, respectively, with subscripts $\mathrm{C}$ and $\mathrm{T}$ indicating compression or tension; $\mathrm{b}$ is the breadth of the specimen; and $d$ is the depth. The stresses for the flexural tests, obtained from the above equations, were plotted versus strains on $\mathrm{X}-\mathrm{Y}$ plotters.

Amplified moment and strain signals and the stress signals generated by the TR-10 computer were sent by telephone lines to a multichannel digitizer or stored on magnetic tape by a Mnemotron four-channel tape recorder for later transmission to the digitizer. Finally, these data were placed on punched cards by the digitizer. In some cases, however, data were taken from the plots and punched on cards by hand.

For the strain ratio specimens, the strain transverse to the longitudinal axis of a specimen was plotted as a function of the strain parallel to the axis on an X-Y plotter. A plot was made for each of the two instrumented sides of the specimen. The ratio of transverse to longitudinal strain was calculated at specified intervals in each case, and the data were punched on cards along with the corresponding longitudinal strain values.

Enough samples were tested in each case to permit examination of all data on statistical bases. Since numerous statistical analyses were required, digital computer techniques were developed for processing the raw data from the punched cards. Eight interrelated programs were written to assist in the analysis of the data. Three of the programs accept the data from the punched cards as input; one of these uses Eqs. (1) and (2) to compute the stresses from the flexural test data. The stresses and strains are then plotted and also punched on cards so that additional studies of the data may be made. A similar program was written to process the tensile and compressive data. Comparisons of the stress-strain diagrams obtained. from these computer programs and those from the X-Y plotters showed excellent agreement. 
These programs treat either individual specimen data or data from all specimens of a given type. They also compute the area under the stressstrain diagram or the ultimate strain energy per unit volume, the complimentary energy, and the modulus of elasticity. A representative curve for each type of specimen was obtained by computing a mean curve for the data from all specimens of that type.

Since the number of data points placed on cards by the digitizer was far greater than required to fully describe the behavior of a specimen, a means was devised for extracting representative data for each specimen. A brief description of the methods used follows. The data for computing the individual stress-strain curves were obtained by selecting small, constant, strain intervals and averaging the stresses and strains in each interval. These averages were then used in all subsequent data analysis. The strain interval width was $150 \mu \mathrm{in}$. for all tensile data and for the compressive data from flexural tests. An interval width of $500 \mu \mathrm{in}$. was used for the uniaxial compressive tests when the entire curve was analyzed. Interval widths of 150 and $300 \mu \mathrm{in}$., respectively, were used for portions of the uniaxial compressive data when elastic modulus computations (described below) and comparisons with flexural test data were made. As a result of using these methods, essentially only variations in stress are associated with the points on the curves.

Although the above stress-strain averaging procedures were used in some cases the preferred method for obtaining data from uniaxial tests was that of selecting stress values for the specified strain intervals from the X-Y plotter curves. The strain intervals were selected so that the values of strain would be consistent with those from the above method. These data were then punched on cards for use in the computer programs. The modulus of elasticity, $E$, defined as the slope of the stressstrain curve at the origin, was found by least-squares fitting of data from the first four 150- $\mu$ in. strain intervals by the parabola

$$
\sigma=a \epsilon^{2}+b \epsilon
$$

The coefficient $\mathrm{b}$ is the value of $\mathrm{E}$. The basic data were uniformly selected so that meaningful modulus comparisons could be made. 
A third program used the flexural data to compute and plot the shift of the neutral surface from the midale surface as a function of tensile strain. Another program computed the arithmetic mean, the standard deviation, and the confidence intervals at the 90, 95, and 99\% levels for discrete strain intervals along the stress-strain curve, as well as for the fracture point. The confidence interval is defined as that interval within which the true mean is thought to exist with the designated percentage probability or confidence. Thus, with the use of the codes described, the data from different specimens could be compared on statistical bases.

Four additional programs were written to accept the card output data obtained from the above programs. These programs fit, using a least-squares method, all the data from any given number of tests by curves of the form

$$
\begin{gathered}
\epsilon=\frac{\sigma}{E}+\left(\frac{\sigma}{A}\right)^{n}, \\
\epsilon=\frac{\sigma}{E}+\left(\frac{\sigma}{A}\right)^{n}+\left[\epsilon_{f}-\frac{\sigma_{f}}{E}-\left(\frac{\sigma_{f}}{A}\right)^{n}\right] \frac{\sigma^{2}}{\sigma_{f}^{2}}, \\
\sigma=E \epsilon+\left(\frac{\sigma_{f}-E \epsilon_{f}}{\epsilon_{f}^{2}}\right) \epsilon^{2}+\epsilon \sum_{j=1}^{k} a_{j} \sin \frac{j \jmath \epsilon}{\epsilon_{f}}, \\
\sigma=\sum_{j=1}^{k} a_{j} \sin j \pi \epsilon .
\end{gathered}
$$

The subscript $f$ denotes the representative fracture stress or strain value; $E$ is the modulus of elasticity; and $A, n$, and $a_{j}$ are parameters obtained by the fitting procedure. The representative values for fracture stress and fracture strain are obtained by averaging the values from the individual tests. The value of $E$, the modulus of elasticity or slope of the curve at zero strain, is obtained from the polynomial fit to the first four data points of each test. The forms of $\mathrm{Eq}$. (5) and (6) require the use of nonlinear fitting techniques. The slope of the curve from either Eq. (6) or 
(7) is equal to $\mathrm{E}$ at zero strain, and the curves pass through the fracture point $\left(\sigma_{f}, \epsilon_{f}\right)$.

Test Results

\section{Uniaxial Tests}

The envelopes that give the range of stress as a function of strain for each type of uniaxial specimen (a through d in Fig. 2) are shown in Figs. 6 and 7. All the fracture points are also plotted. From these figures the scatter of the experimental data may be seen. The extreme values were often for single specimens that gave results much different from those for the remaining specimens. The standard deviations, the confidence intervals at the 90, 95, and 99\% levels, and the mean curves are plotted in Figs. 8 and 9. These mean curves were obtained by averaging the data from all the specimens of each type, and they are therefore the representative curves. The standard deviations on both stresses and strains at fracture are also shown. The small, abrupt variations in confidence intervals are due to the reductions in numbers of unbroken specimens with increasing strain. The confidence limits on the fracture points are denoted by $\bullet$ 's for both stresses and strains. The variations in strain data at other than the fracture points are very small and are not depicted in the figures.

All the comparisons here are based on the mean data for each specimen type. Strength data representative of each uniaxial specimen type are given in Table 3, where the number of specimen tested, the fracture stress and strain, the modulus of elasticity, and the ultimate strain energy are listed. These data show that the tensile fracture stress in the perpendicular direction is about $60 \%$ of that in the parallel direction, but the ultimate compressive stresses are about the same. The tensile fracture strains are slightly larger in the transverse than the parallel direction, and the compressive failure strains in the transverse direction are about double those in the parallel direction. The moduli are uniformly lower in the transverse direction, and in all cases the compressive moduli exceed the corresponding tensile values. 
Table 3. Strength Data From Uniaxial Tests on EGCR-Type AGOP Graphite

\begin{tabular}{|c|c|c|c|c|c|}
\hline Type of Specimen & $\begin{array}{l}\text { Number of } \\
\text { Specimens }\end{array}$ & $\begin{array}{l}\text { Fracture Stress } \\
\text { (psi) }\end{array}$ & $\underset{(\%)}{\text { Fracture Strain }}$ & $\begin{array}{l}\text { Modulus of } \\
\text { Elasticity } \\
\text { (psi) }\end{array}$ & $\begin{array}{c}\text { Ultimate Strain } \\
\text { Energy } \\
\left(\text { in. }-1 \mathrm{~b} / \text { in. }^{3}\right)\end{array}$ \\
\hline & & & & $\times 10^{6}$ & \\
\hline Parallel small tensile & 31 & $1610(20)^{\mathrm{a}}$ & $0.141(19)$ & $1.67(11)$ & $1.21(37)$ \\
\hline Parallel small compressive & 29 & $5000(8)$ & $1.286(15)$ & $2.19(18)$ & $47.11(22)$ \\
\hline Parallel large tensile & 30 & $1540(18)$ & $0.135(20)$ & $1.79(6)$ & $1.11(40)$ \\
\hline Parallel large compressive & 29 & $4600(7)$ & $1.311(20)$ & $1.88(14)$ & $44.64(26)$ \\
\hline Transverse small tensile & 19 & $880(22)$ & $0.164(32)$ & $0.90(9)$ & $0.87(53)$ \\
\hline Transverse small compressive & 17 & $5210(6)$ & $2.703(17)$ & $0.99(11)$ & $97.90(26)$ \\
\hline Transverse large tensile & 20 & $980(24)$ & $0.171(28)$ & $1.00(8)$ & $0.96(58)$ \\
\hline Transverse large compressive & 17 & $4650(6)$ & $2.553(14)$ & $1.21(21)$ & $80.53(20)$ \\
\hline All parallel tensile & 61 & $1570(19)$ & $0.138(19)$ & $1.73(9)$ & $1.16(38)$ \\
\hline All parallel compressive & 58 & $4800(9)$ & $1.299(18)$ & $2.04(20)$ & $45.89(24)$ \\
\hline All transverse tensile & 39 & $930(24)$ & $0.167(30)$ & $0.95(10)$ & $0.92(56)$ \\
\hline All transverse compressive & 34 & $4930(8)$ & $2.628(16)$ & $1.10(20)$ & $89.23(26)$ \\
\hline
\end{tabular}

\footnotetext{
athe numbers in parentheses are the coefficients of variation in percent.
} 



Fig. 6. Mean Stress-Strain Curves, Ranges of the Data, and Fracture Points for Parallel Uniaxial Specimens.

Although compressive strengths for the graphite are given in the table, compressive failures were not observed. In testing the compressive specimens, it was found that the failures actually occurred in tension. During loading, the compressive strain increased until the transverse 

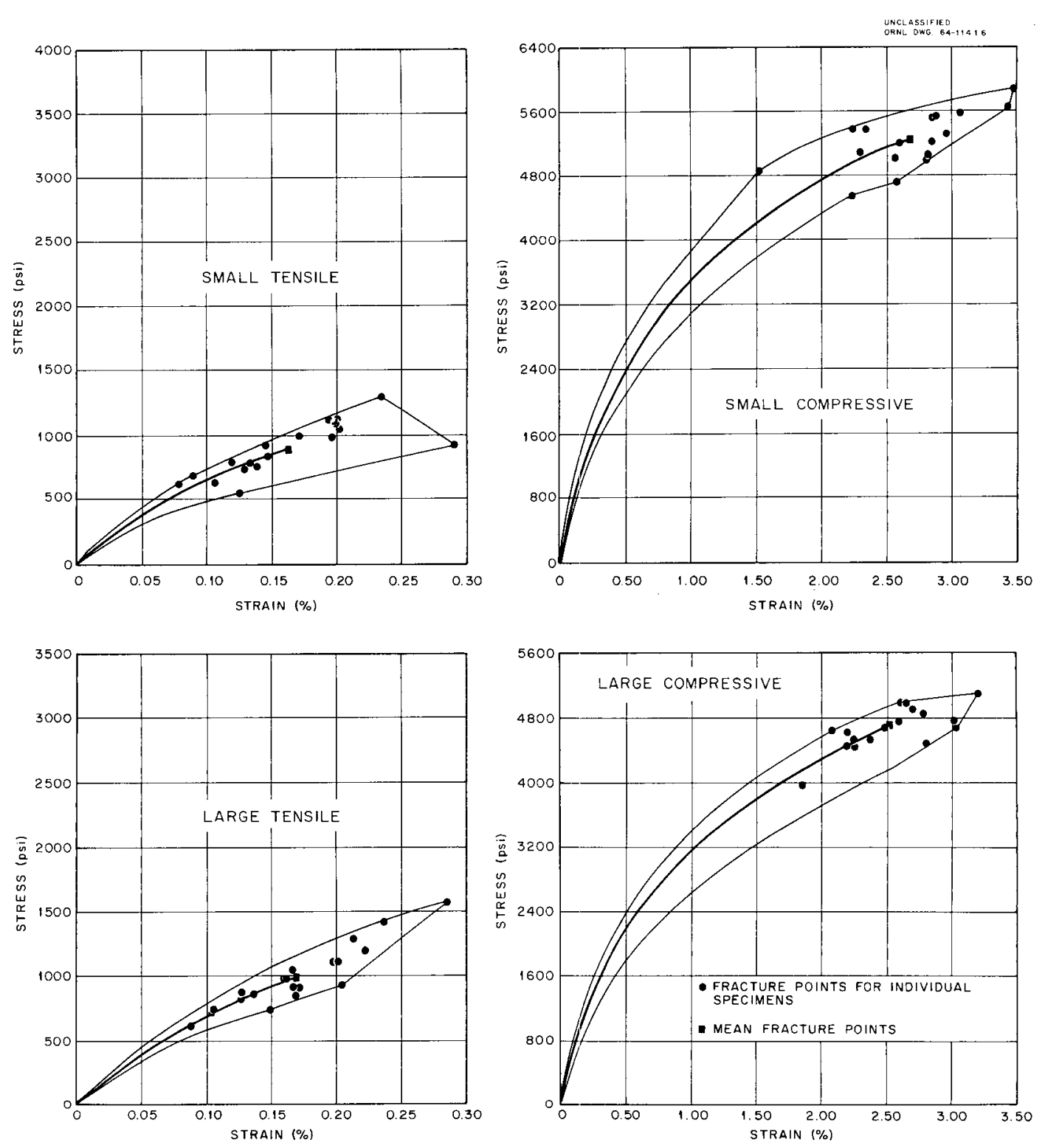

Fig. 7. Mean Stress-Strain Curves, Ranges of the Data, and Fracture Points for Transverse Uniaxial Specimens.

strain reached the tensile failure strain and a longitudinal break resulted. To illustrate the type failures that occurred, a photograph of opposite sides of failed specimens that were cut both parallel and transverse to the extrusion direction is shown in Fig. 10. Strain ratio specimens were selected for this illustration because the initiating, longitudinal cracks are easily seen. Of course, once the initial crack was induced, the crushing action of the loading mechanism tended to destroy 

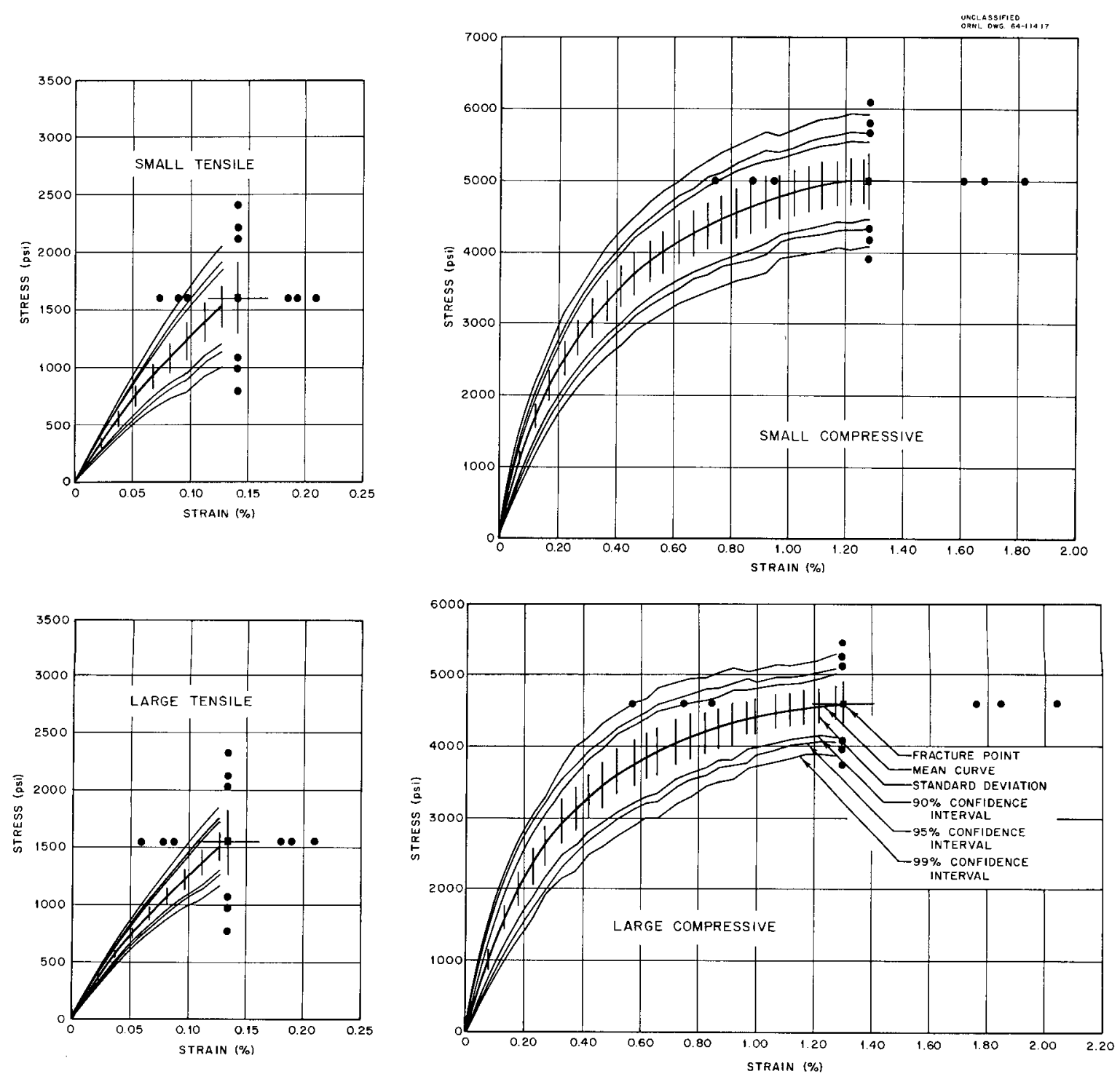

Fig. 8. Mean Stress-Strain Curves, Standard Deviations, and Confidence Intervals for Parallel Uniaxial Specimens.

the evidence of the actual failure mode. The transverse specimens shown in the photograph were cut from the parent stock so that the longitudinal axes were mutually perpendicular.

The representative stress-strain diagrams (mean curves) for each type of uniaxial specimen are shown in Fig. 11. The differences in behavior parallel to the extrusion axis and perpendicular to it may be readily seen. The tensile curves from the two sizes of specimens are nearly the same, and 

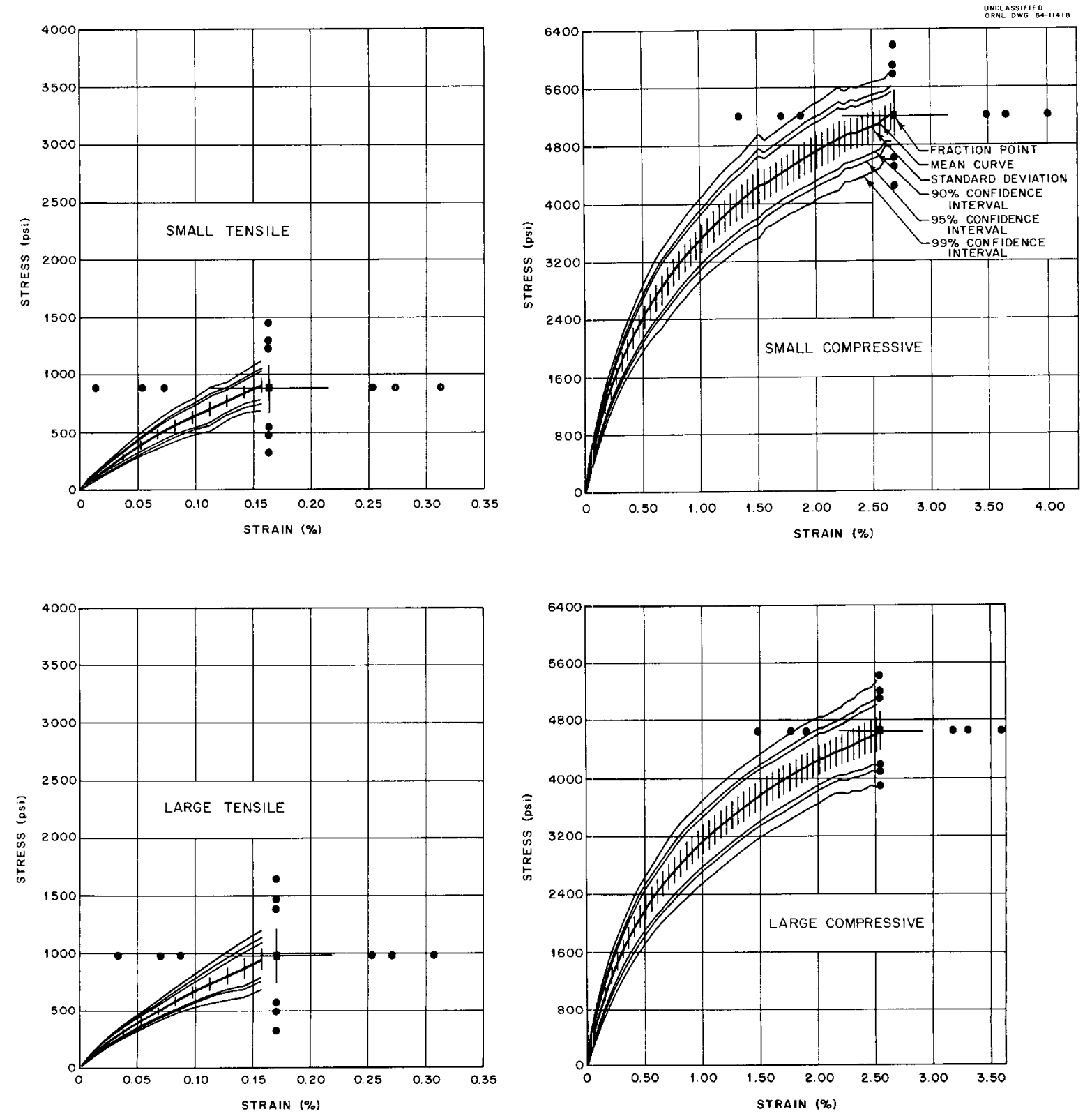

Fig. 9. Mean Stress-Strain Curves, Standard Deviations, and Confidence Intervals for Transverse Uniaxial Specimens.

no trend with size is seen. The curves for the smaller compressive specimens consistently show a greater stress for a given strain than do the curves for the larger ones. In an engineering sense, however, the curves are the same for the two sizes of specimens. Thus the uniaxial data from both the large and small specimens were combined to give the stress-strain diagrams of Figs. 12 and 13. The curves for the parallel direction are 


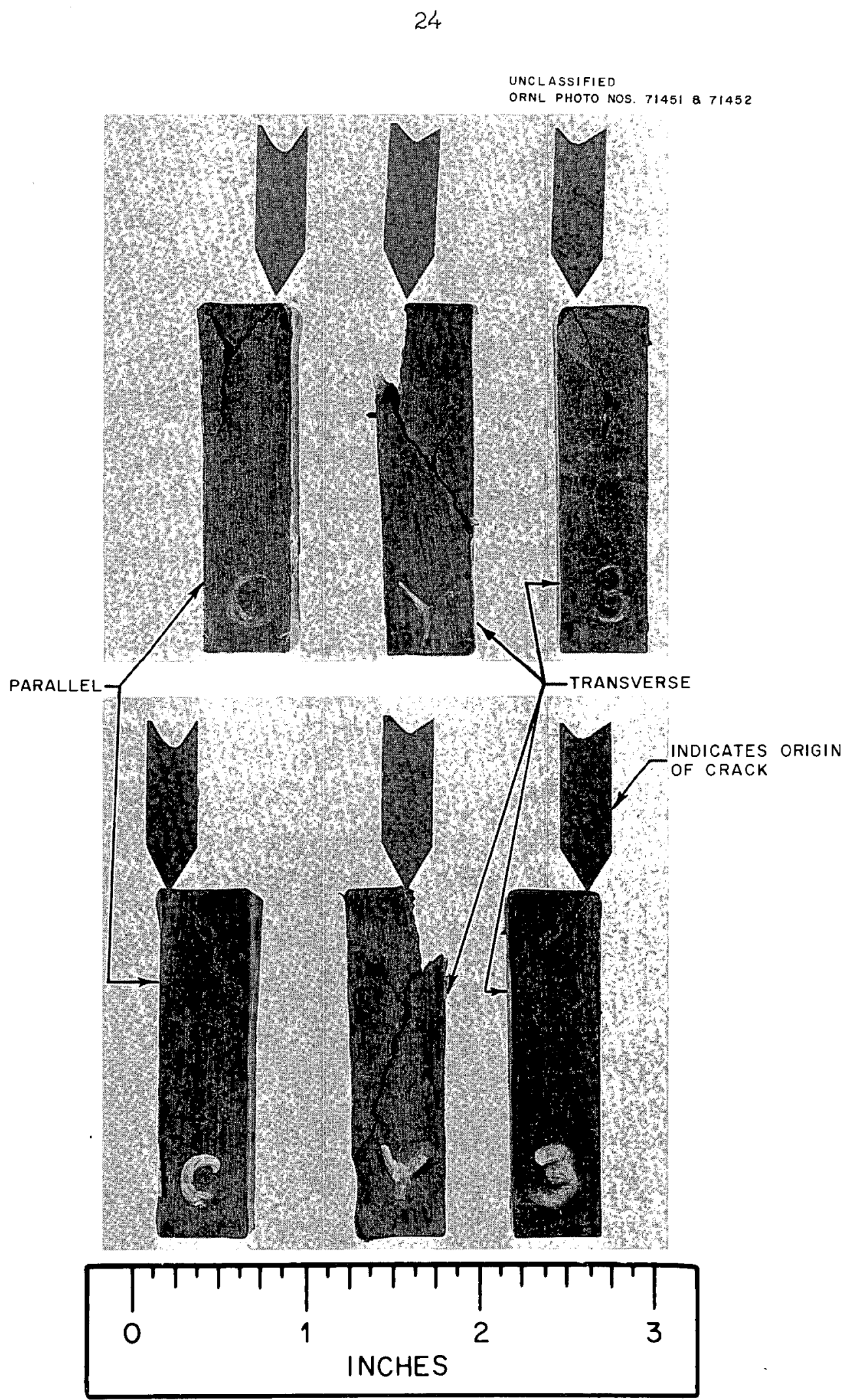

Fig. 10. Strain-Ratio Specimens Tested in Compression. 



Fig. 11. Stress-Strain Curves from Uniaxial Tests of EGCR-Type AGOT Graphite at Room Temperature.

plotted on one set of coordinates in Fig. 14 to better illustrate the differences in tensile and compressive behaviors. The moduli of elasticity and fracture results for the combined data are given in Table 3 .

Results of the tests on the area-effect specimens are given in Table 4. Specimens of eight sizes, ranging in diameter from 0.128 in. to 0.750 in., were tested. An instrumented 0.128-in.-diam specimen is shown in Fig. 15; the diameter of this specimen is equal to about four times the maximum particle size.

Since detectable strengthening resulted from instrumenting specimens of the two smaller sizes, only nine of the 18 specimens were strain gaged in each case, and the fracture stresses reported in the table were obtained entirely from the ungaged specimens. The increase in strength due to the gages was about $15 \%$ for the 0.128-in.-diam specimens and $7 \%$ for the $0.187-$ in.-diam ones. 


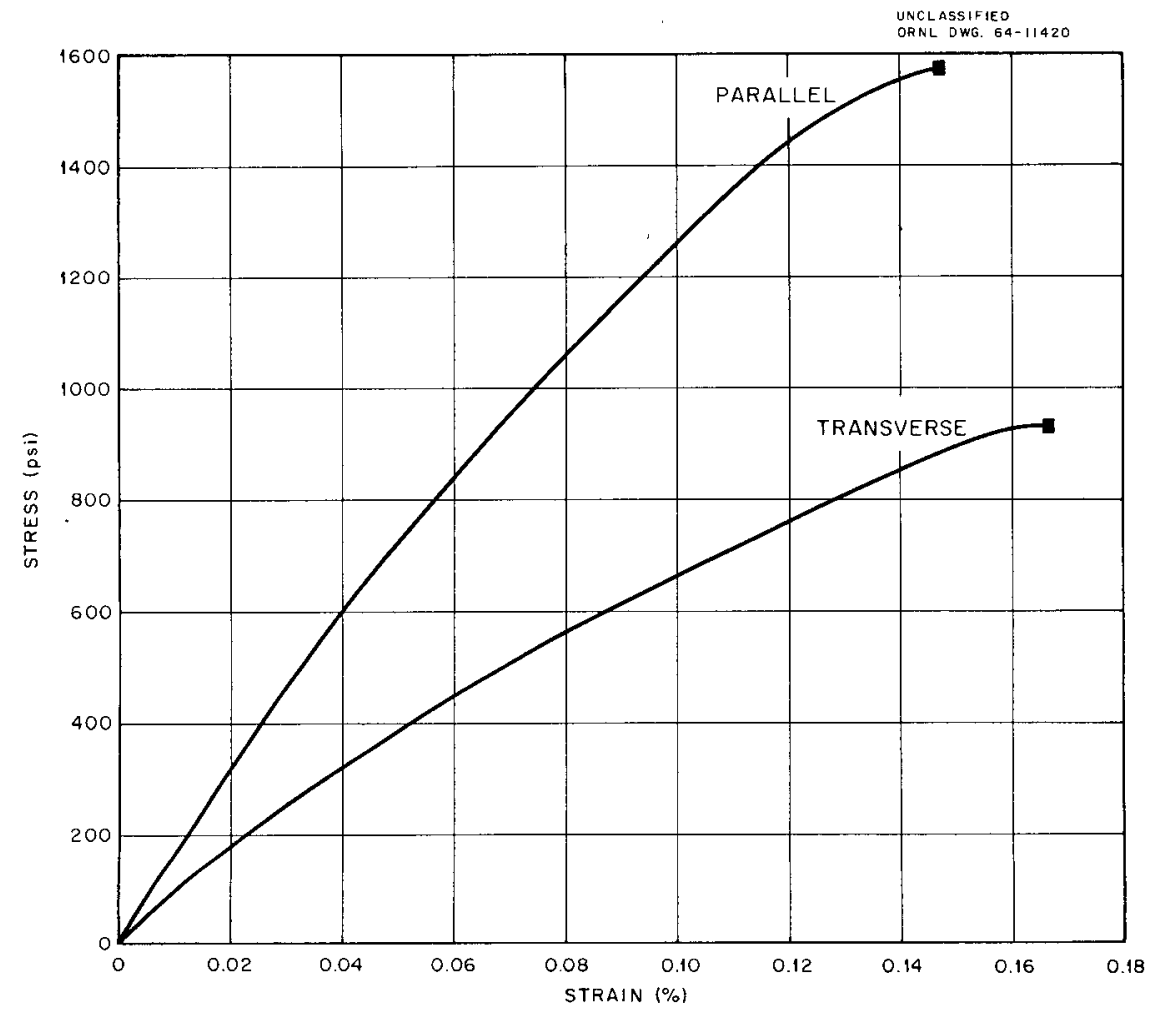

Fig. 12. Mean Stress-Strain Curves of Combined Large and Small Uniaxial Tensile Specimens.

Table 4. Tensile Strength Data for Area-Effect Specimens

\begin{tabular}{ccccc}
\hline $\begin{array}{c}\text { Diameter } \\
\text { (in.) }\end{array}$ & $\begin{array}{c}\text { Number of } \\
\text { Specimens }\end{array}$ & $\begin{array}{c}\text { Average Stress } \\
\text { (psi) }\end{array}$ & $\begin{array}{c}\text { Average Strain } \\
(\%)\end{array}$ & $\begin{array}{c}\text { Average Modulus } \\
\text { (psi) }\end{array}$ \\
\hline & & & & \\
0.128 & 9 & $1482(14.8)^{\mathrm{a}}$ & $0.112(24.1)$ & $\times 10^{6}$ \\
0.187 & 9 & $1493(14.2)$ & $0.159(20.1)$ & \\
0.250 & 18 & $1403(20.7)$ & $0.124(30.6)$ & $1.69(11.3)$ \\
0.318 & 20 & $1260(19.8)$ & $0.113(29.2)$ & $1.62(12.0)$ \\
{$[0.3125]^{\mathrm{b}}$} & {$[31]$} & {$[1610(20.0)]$} & {$[0.141(19.0)]$} & {$[1.67(11.0)]$} \\
0.375 & 20 & $1473(17.7)$ & $0.150(18.0)$ & $1.60(9.6)$ \\
0.500 & 19 & $1468(19.1)$ & $0.132(23.5)$ & $1.78(8.1)$ \\
0.625 & 20 & $1687(13.0)$ & $0.153(15.7)$ & $1.84(7.9)$ \\
{$[0.625]$} & {$[30]$} & {$[1540(18.0)]$} & {$[0.135(20.0)]$} & {$[1.79(6.0)]$} \\
0.750 & 20 & $1552(13.5)$ & $1.138(19.6)$ & $1.71(6.1)$ \\
\hline
\end{tabular}

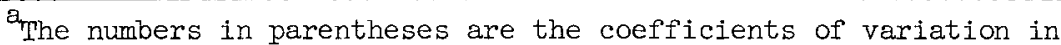
percent.

$\mathrm{b}_{\text {The numbers in }}$ brackets are for the volume-effect specimens. 
UNCLASSIFIED

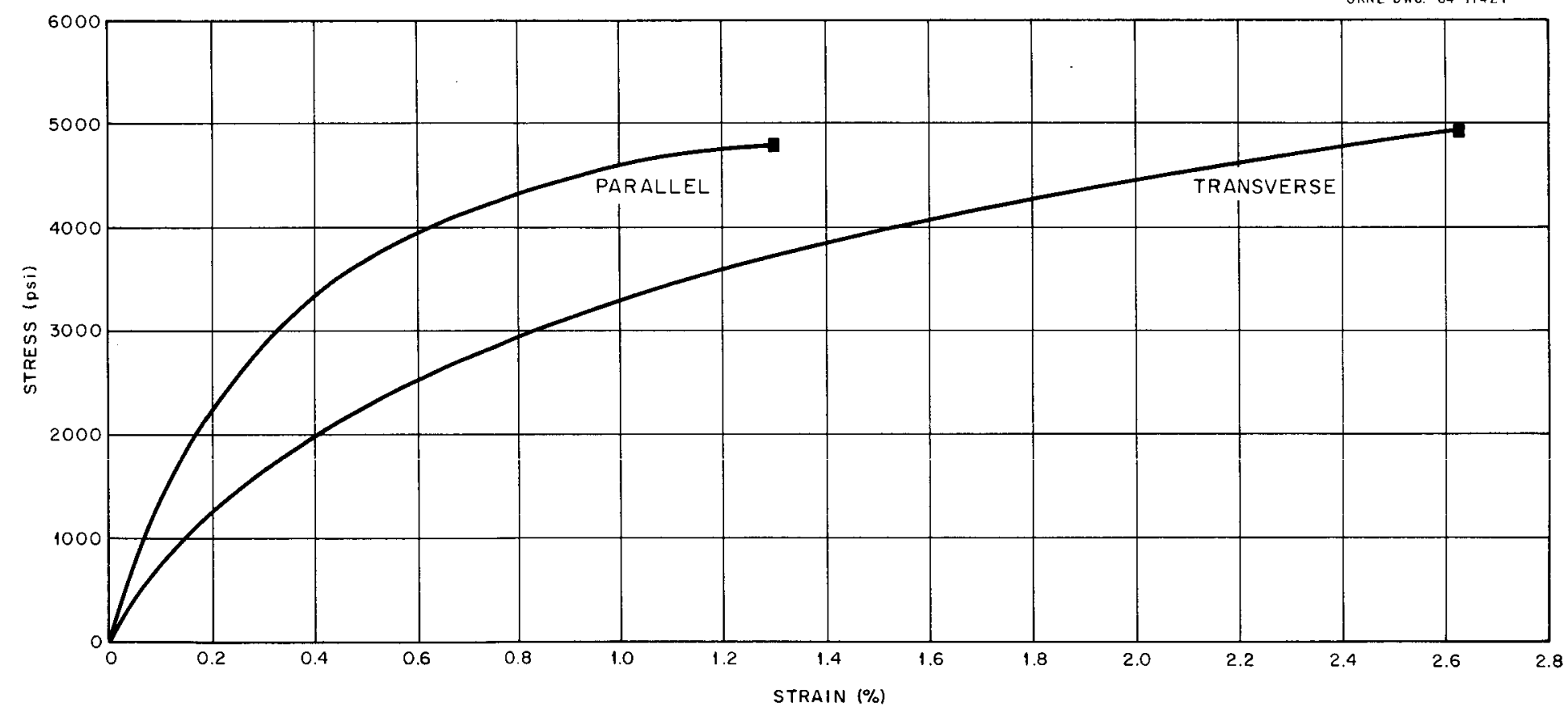

Fig. 13. Mean Stress-Strain Curves of Combined Large and Small Uniaxial Compressive Specimens. 


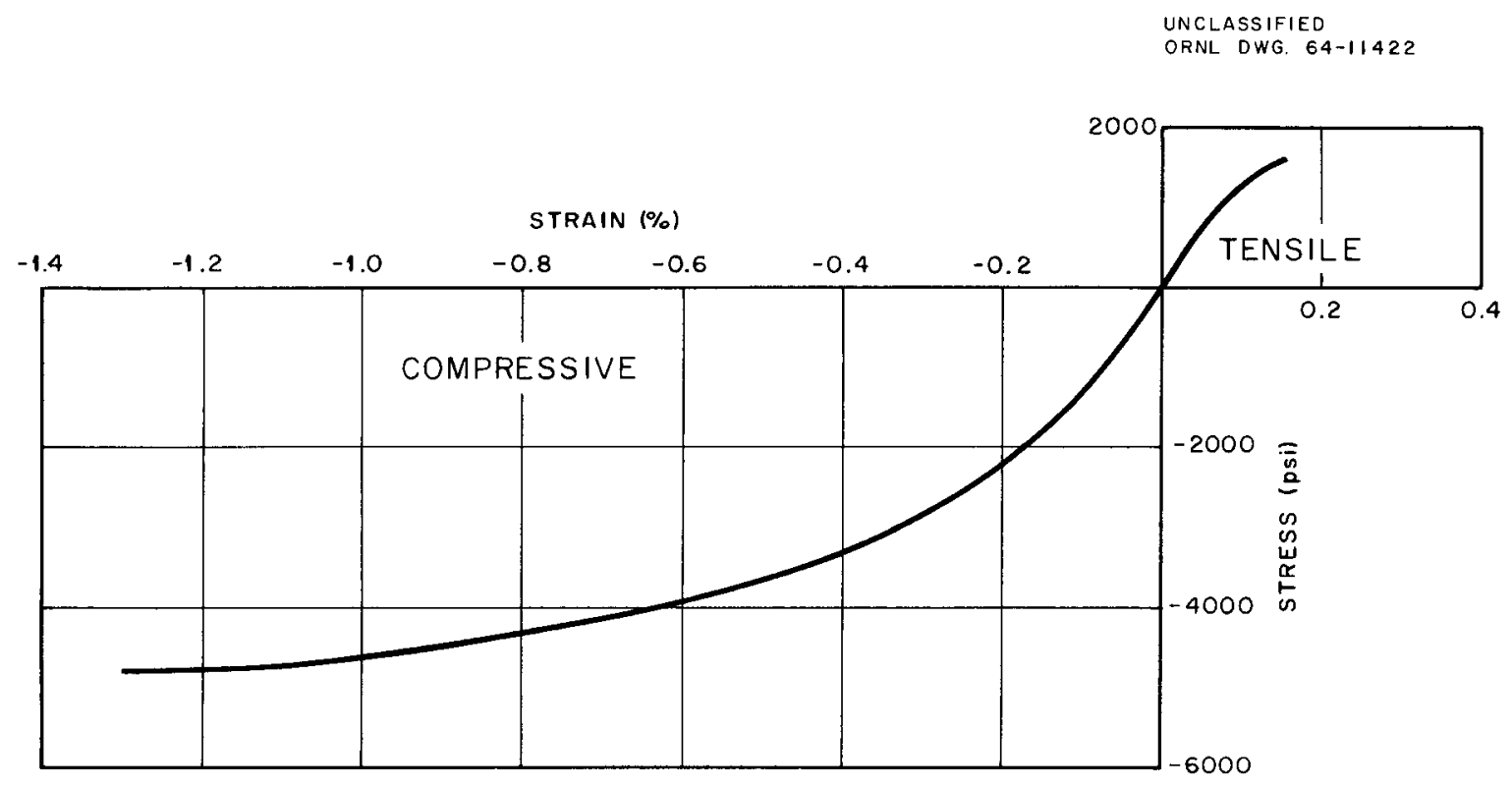

Fig. 14. Complete Uniaxial Stress-Strain Curve Parallel to Extrusion Direction.

From these data, the fracture stress, fracture strain, and modulus of elasticity do not show any trends with minimum diameter or crosssectional area. In addition, the data given in Table 3 for the volumeeffect specimens agree well with the data in Table 4. The applicable data from the volume-effect specimens are shown in brackets in Table 4. The area-effect specimens did not always fail at the minimum cross section, but all failures did occur within a small band on either side of the minimum. The area at the average breaking distance from the minimum was within $3 \%$ of the nominal minimum area. The details of the variations in areas at the positions of fracture are shown in Table 5. The maximum variations, as in the strength variations found throughout the test program, were obtained from isolated specimens.

Flexural Tests

Flexural tests were conducted on two sizes of specimens with longitudinal axes parallel to the extrusion axis. These were described earlier, along with the methods for obtaining stress-strain diagrams. As in the case of the uniaxial tests, the stress-strain curves displayed are based 


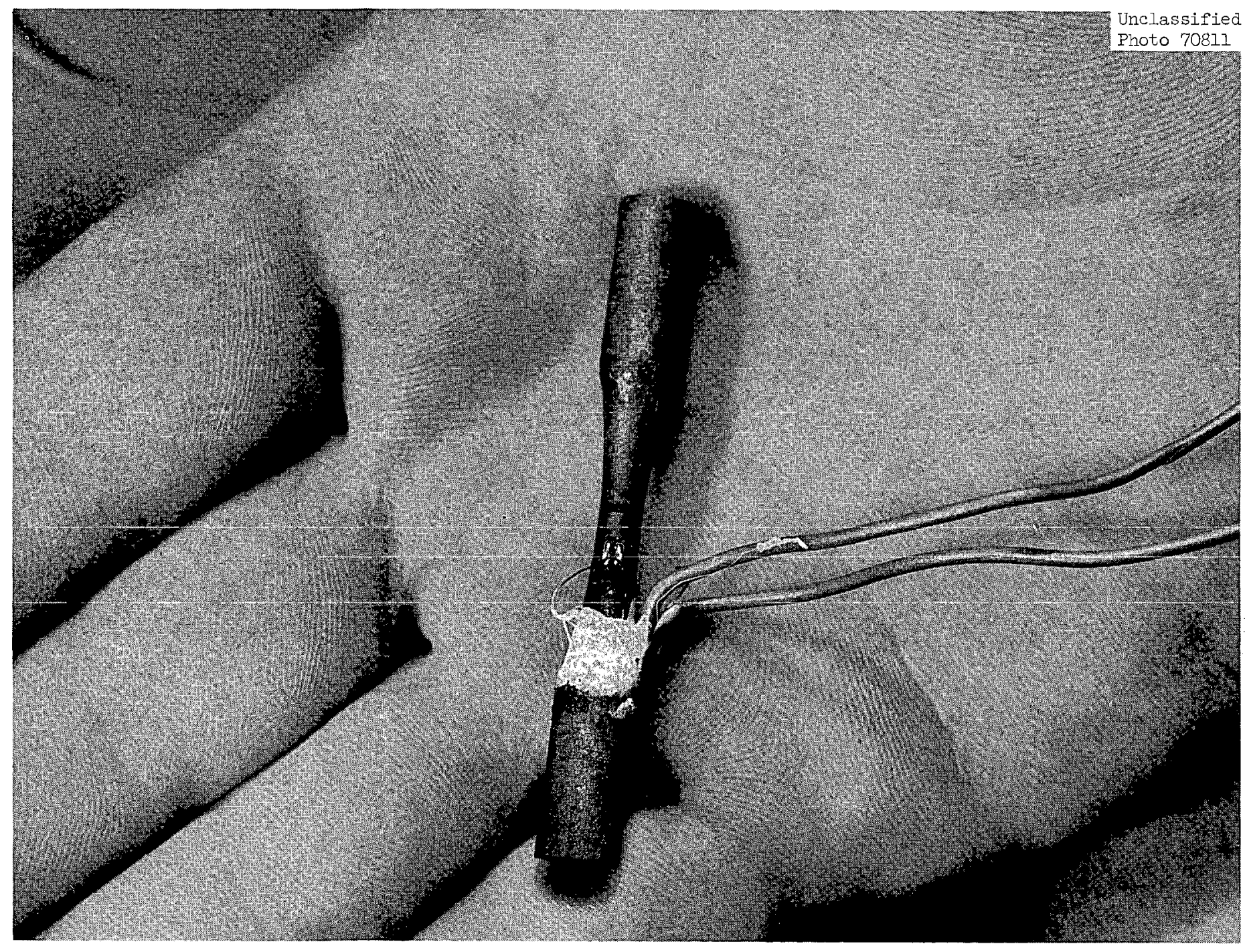

Fig. 15. Instrumented 0.128-in.-diam Tensile Specimen. 
Table 5. Variations in Area at Positions of Fracture for Area-Effect Specimens

\begin{tabular}{llccc}
\hline $\begin{array}{l}\text { Nominal } \\
\text { Diameter } \\
(\text { in. })\end{array}$ & $\begin{array}{c}\text { Nominal } \\
\text { Area } \\
\left(\text { in. }^{2}\right)\end{array}$ & $\begin{array}{c}\text { Average } \\
\text { Fracture Area } \\
\left(\text { in. }^{2}\right)\end{array}$ & $\begin{array}{c}\text { Average In- } \\
\text { crease in Area } \\
(\%)\end{array}$ & $\begin{array}{c}\text { Maximum } \\
\text { Fracture Area } \\
\left(\text { in. }{ }^{2}\right)\end{array}$ \\
\hline 0.128 & 0.0129 & 0.0131 & 1.5 & 0.0201 \\
0.187 & 0.0275 & 0.0278 & 1.1 & 0.0302 \\
0.250 & 0.0491 & 0.0495 & 0.8 & 0.0511 \\
0.318 & 0.0794 & 0.0814 & 2.5 & 0.0935 \\
0.375 & 0.1104 & 0.1116 & 1.1 & 0.1225 \\
0.500 & 0.1964 & 0.1979 & 0.7 & 0.2359 \\
0.625 & 0.3068 & 0.3078 & 0.3 & 0.3207 \\
0.750 & 0.4418 & 0.4441 & 0.5 & 0.4657 \\
\hline
\end{tabular}

on data taken at particular strain intervals. Calculations for the curves presented were done entirely on the digital computer. Using Eqs. (I) and (2) the analog and digital computers produced curves that were in excellent agreement. This is illustrated by Fig. 16 where the two curves for a single small flexural specimen are superposed.

The representative or mean curves based on the stresses calculated from Eqs. (1) and (2) and the strain readings are shown in Fig. 17, where the envelopes that contain all the curves are shown, as well as all fracture points. The "fracture points" shown for the compressive sides of the beams are merely the points corresponding to failures on the tensile sides of the specimens. The standard deviations and the confidence intervals at 90, 95, and 99\%, together with the mean curves, are shown in Fig. 18. Here again the 's are used to show the confidence limits on the fracture stress and strain in each case. The mean curves for the two specimen sizes are shown in Fig. 19. Since these mean curves nearly coincide, these data could be combined to produce the curve of Fig. 20.

The strength data from the flexural specimens are given in Table 6; the compressive data listed are the quantities corresponding to the points of tensile fracture, as noted in the table. The stresses at fracture calculated from elementary beam theory are also given for comparison. It may 
Table 6. Strength Data From Flexural Tests on EGCR-Type AGOr Graphite

\begin{tabular}{|c|c|c|c|c|c|}
\hline Type of Specimen & $\begin{array}{l}\text { Number of } \\
\text { Specimens Tested }\end{array}$ & $\begin{array}{l}\text { Stress at } \\
\text { Fracture } \\
\quad \text { (psi) }\end{array}$ & $\begin{array}{l}\text { Strain at } \\
\text { Fracture } \\
\quad(\%)\end{array}$ & $\begin{array}{l}\text { Modulus of } \\
\text { Elasticity } \\
\quad(p s i)\end{array}$ & $\begin{array}{c}\text { Ultimate Strain } \\
\text { Energy } \\
\left(\text { in.-lb/in. }{ }^{3}\right)\end{array}$ \\
\hline & & & & $\times 10^{6}$ & \\
\hline Small parallel flexural - tension & 29 & $2120(13)^{\mathrm{a}}$ & $0.181(19)$ & $1.72(13)$ & $2.21(32)$ \\
\hline $\begin{array}{l}\text { Small parallel flexural - compression } \\
\text { (data at tensile fracture) }\end{array}$ & 29 & $2220(13)$ & $0.173(19)$ & $1.83(10)$ & $2.21(32)$ \\
\hline Small parallel flexural & 29 & $2360(13)^{\mathrm{b}}$ & & & \\
\hline Large parallel flexural - tension & 24 & $1960(15)$ & $0.186(14)$ & $1.47(13)$ & $2.05(26)$ \\
\hline $\begin{array}{l}\text { Large parallel flexural - compression } \\
\text { (data at tensile fracture) }\end{array}$ & 24 & $2130(14)$ & $0.174(15)$ & $1.58(12)$ & $2.05(26)$ \\
\hline Large parallel flexural & 24 & $2180(13)^{b}$ & & & \\
\hline All parallel flexural - tension & 53 & $2050(14)$ & $0.183(17)$ & $1.61(15)$ & $2.14(30)$ \\
\hline $\begin{array}{l}\text { All parallel flexural - compression } \\
\text { (data at tensile fracture) }\end{array}$ & 53 & $2180(14)$ & $0.174(17)$ & $1.72(13)$ & $2.14(30)$ \\
\hline All parallel flexural & 53 & $2280(14)^{\mathrm{b}}$ & & & \\
\hline
\end{tabular}

a Numbers in parentheses are coefficients of variation.

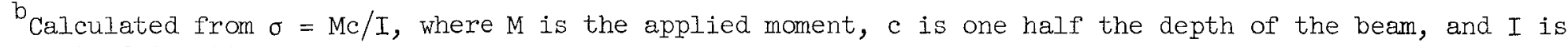
the moment of inertia. 


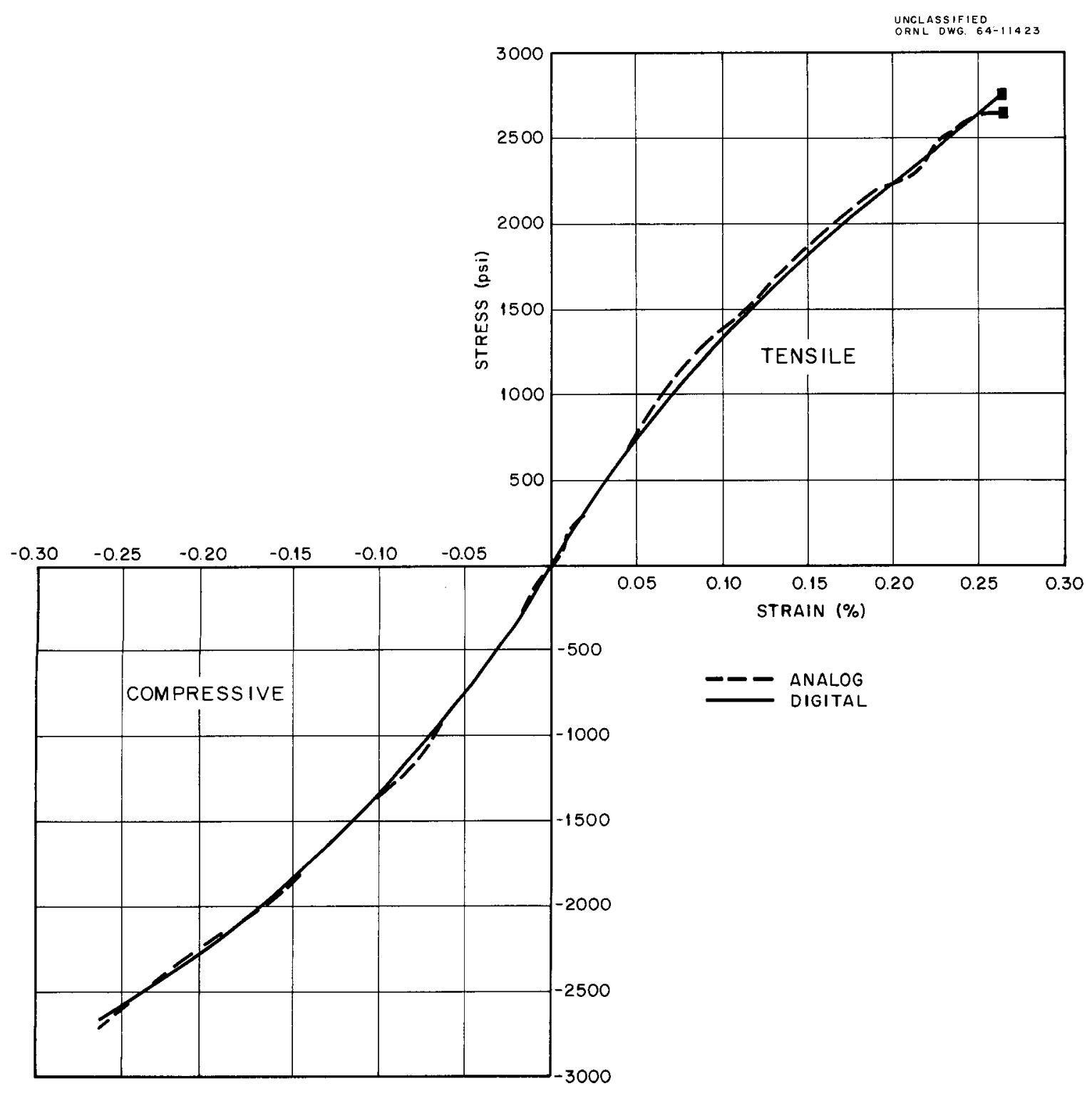

Fig. 16. Comparison of Stress-Strain Curves for Flexural Test Produced by Analog and Digital Computers.

be seen that ordinary beam theory gives higher stresses than those obtained using Eqs. (1) and (2), especially in tension. The compressive moduli are consistently higher than the tensile moduli, but the strain energies at tensile fracture are identical. The modulus of elasticity and fracture results for the combined data are also given.

The position of the neutral surface (i.e., the longitudinal plane in the specimen that is not strained) is an index to the relative resistances 

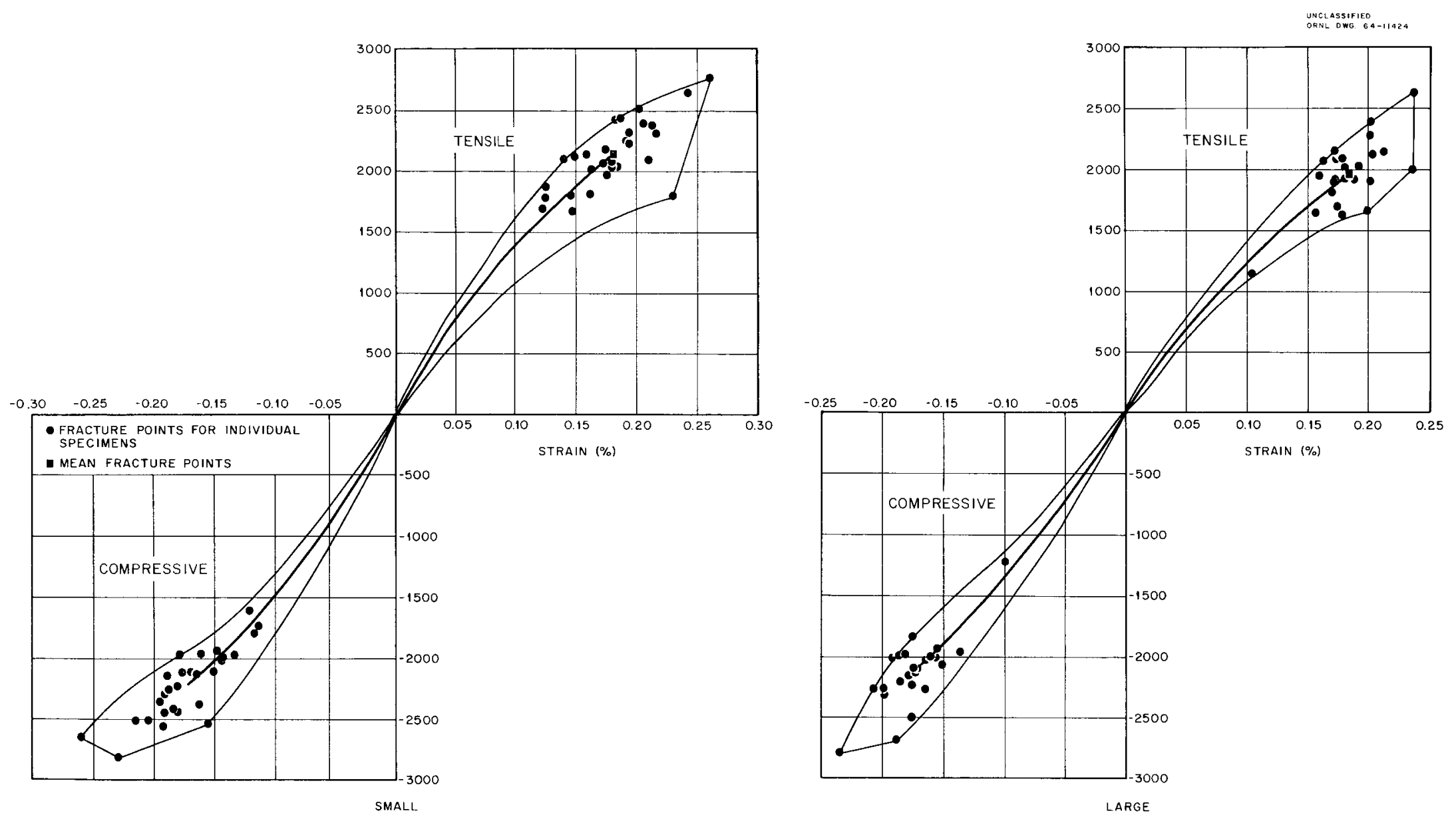

Fig. 17. Mean Stress-Strain Curves, Ranges of the Data, and Fracture Points for Parallel Bend Specimens. 


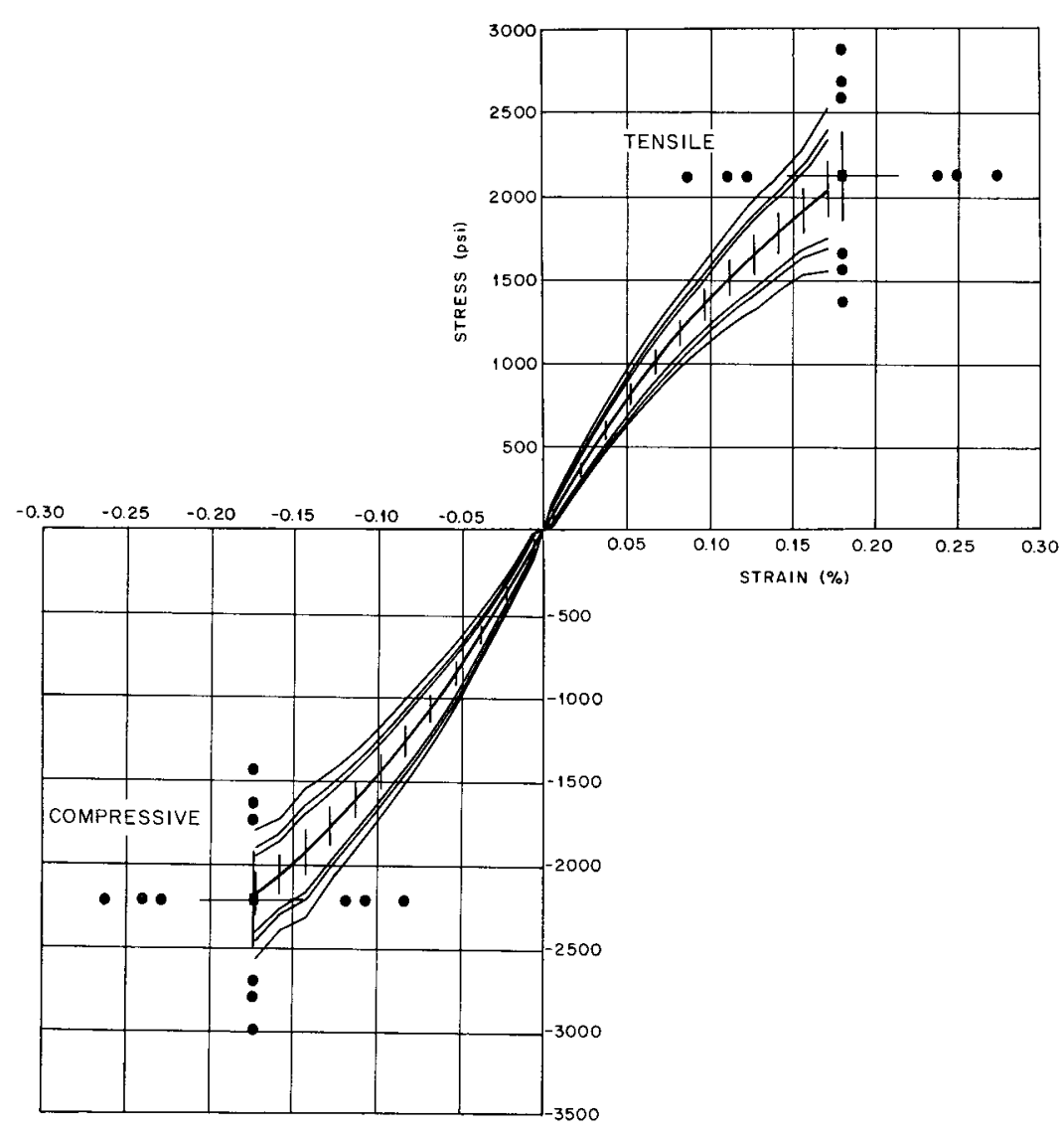

SMALL

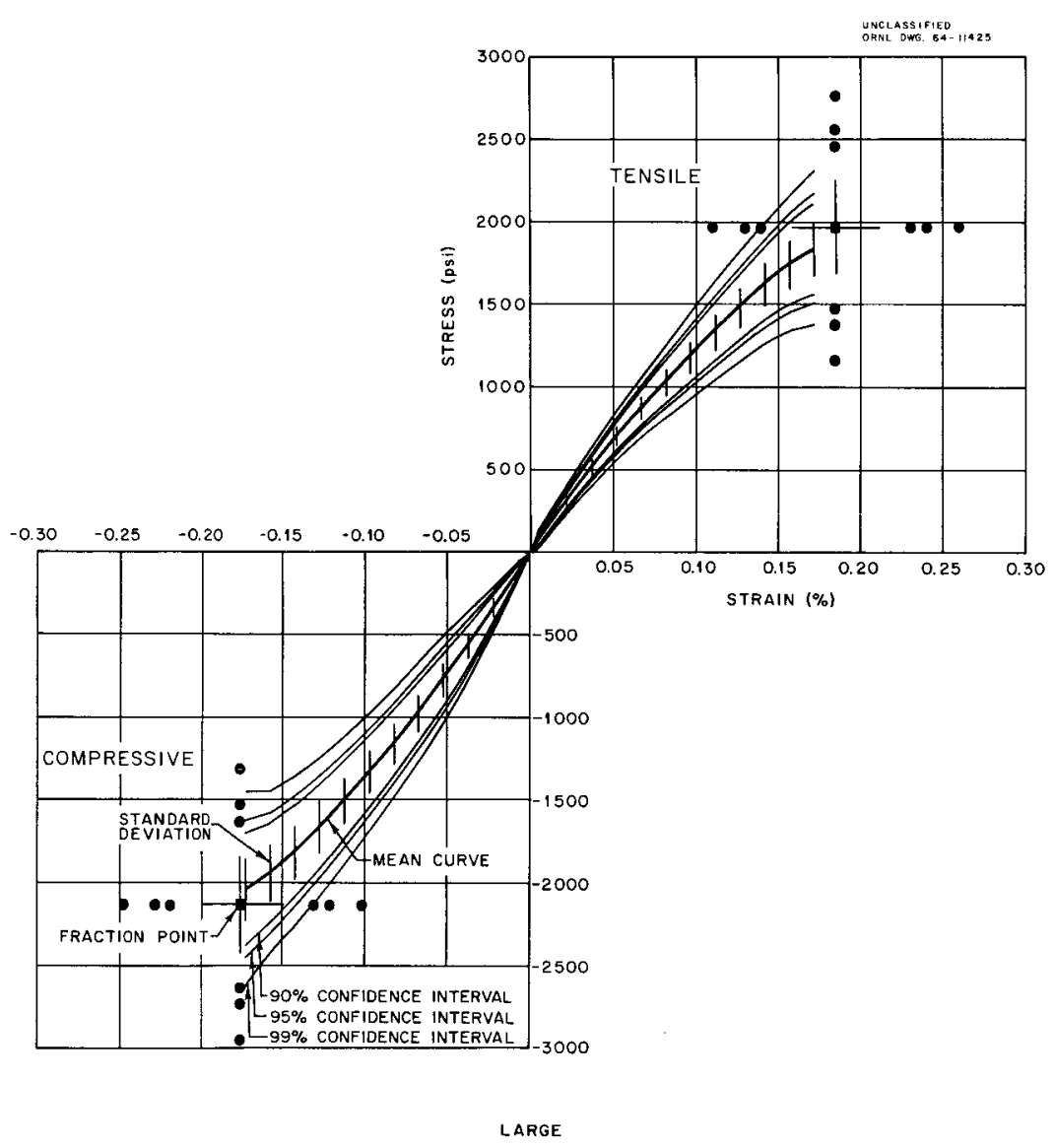

Fig. 18. Mean Stress-Strain Curves, Standard Deviations, and Confidence Intervals for Parallel Flexural Specimens. 




Fig. 19. Comparison of Mean Stress-Strain Curves for Large and Small Flexural Specimens.

to deformation in tension and in compression. When the compressive resistance is greater than that in tension, the neutral surface is shifted toward the compressive side of the specimen. The expression for this displacement from the neutral surface is given by Eq. (4). From this relationship and the computer results, the displacements of the neutral surfaces, 


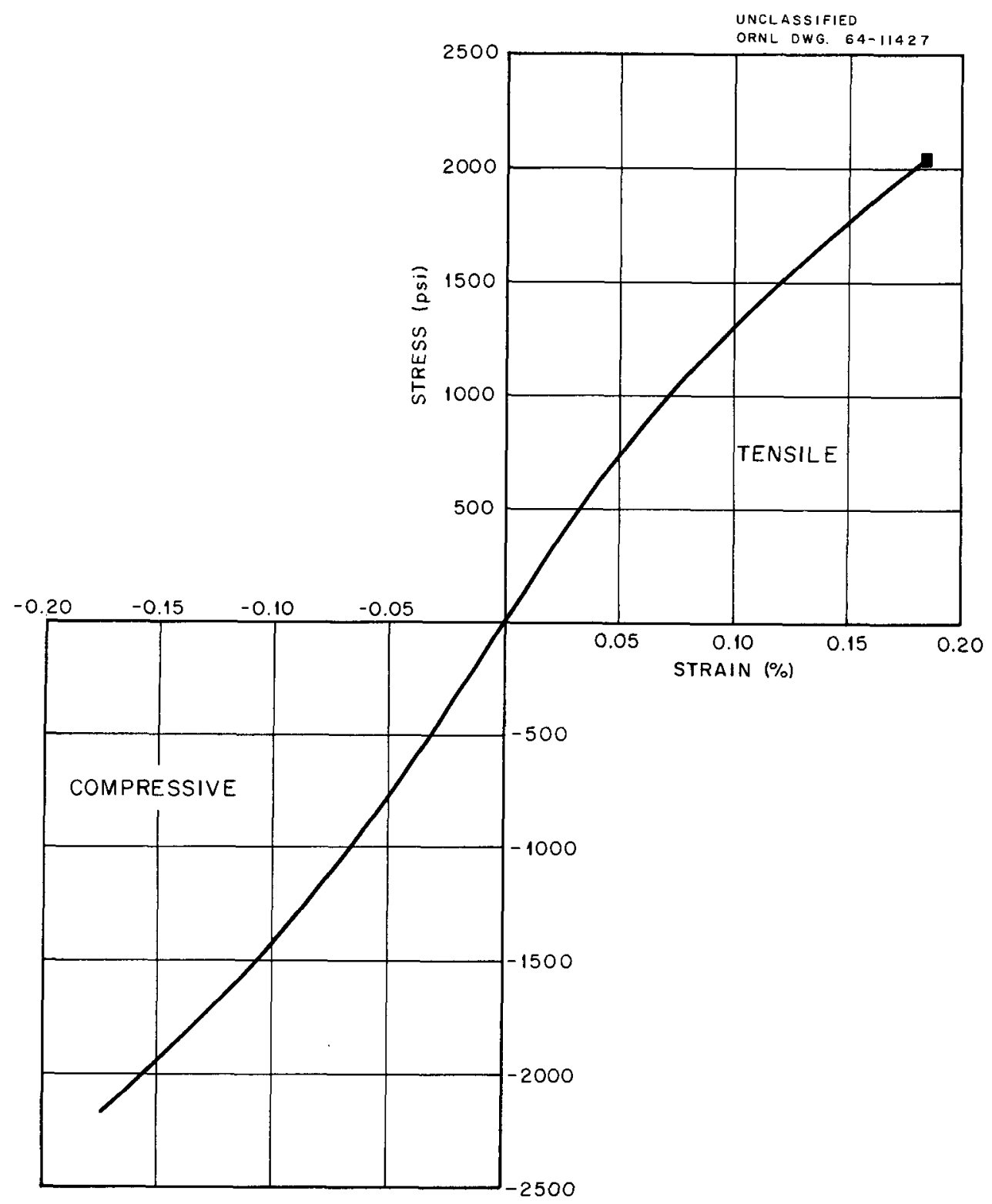

Fig. 20. Mean Stress-Strain Curve of Combined Large and Small Parallel Flexural Specimens.

as based on the mean curves, for each of the two sizes of flexural specimens are shown in Fig. 21. As indicated in the figure, the data were not sufficiently accurate to perform neutral surface calculations for strains less than $200 \mu \mathrm{in}$. To further illustrate this behavior, of the 53 flexural specimens tested only eight exhibited a neutral shift toward the tensile side of the specimen. The position of the neutral surface varied from $6 \%$ 


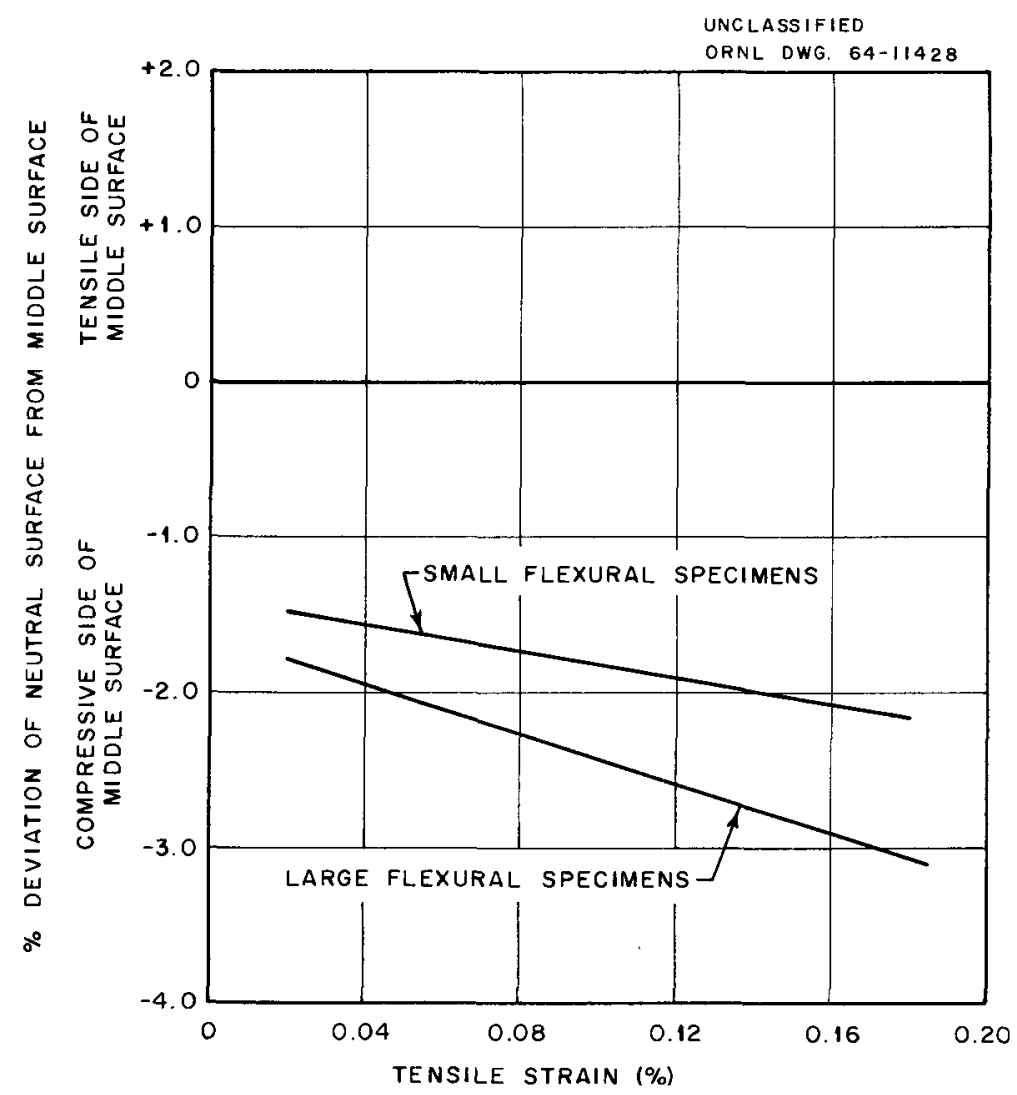

Fig. 21. Mean Variation of Position of Neutral Surface During Loading of Flexural Specimens.

of the thickness toward the compressive side of the specimen to $2 \%$ in the opposite direction.

Comparison of Uniaxial and Flexural Specimens

A comparison of the stress-strain diagrams obtained from flexural specimens and from uniaxial specimens is shown in Fig. 22. In this comparison and those that follow, the data used are those representative of each specimen type; that is, the mean values. Only portions of the compressive diagrams from the uniaxial tests are shown. Although the curves are essentially the same, the differences between tensile fracture points for the uniaxial tests and those for the flexural tests are obvious. Because of the importance of understanding graphite behavior in other than uniaxial tests, the underlying reasons for these differences were examined 


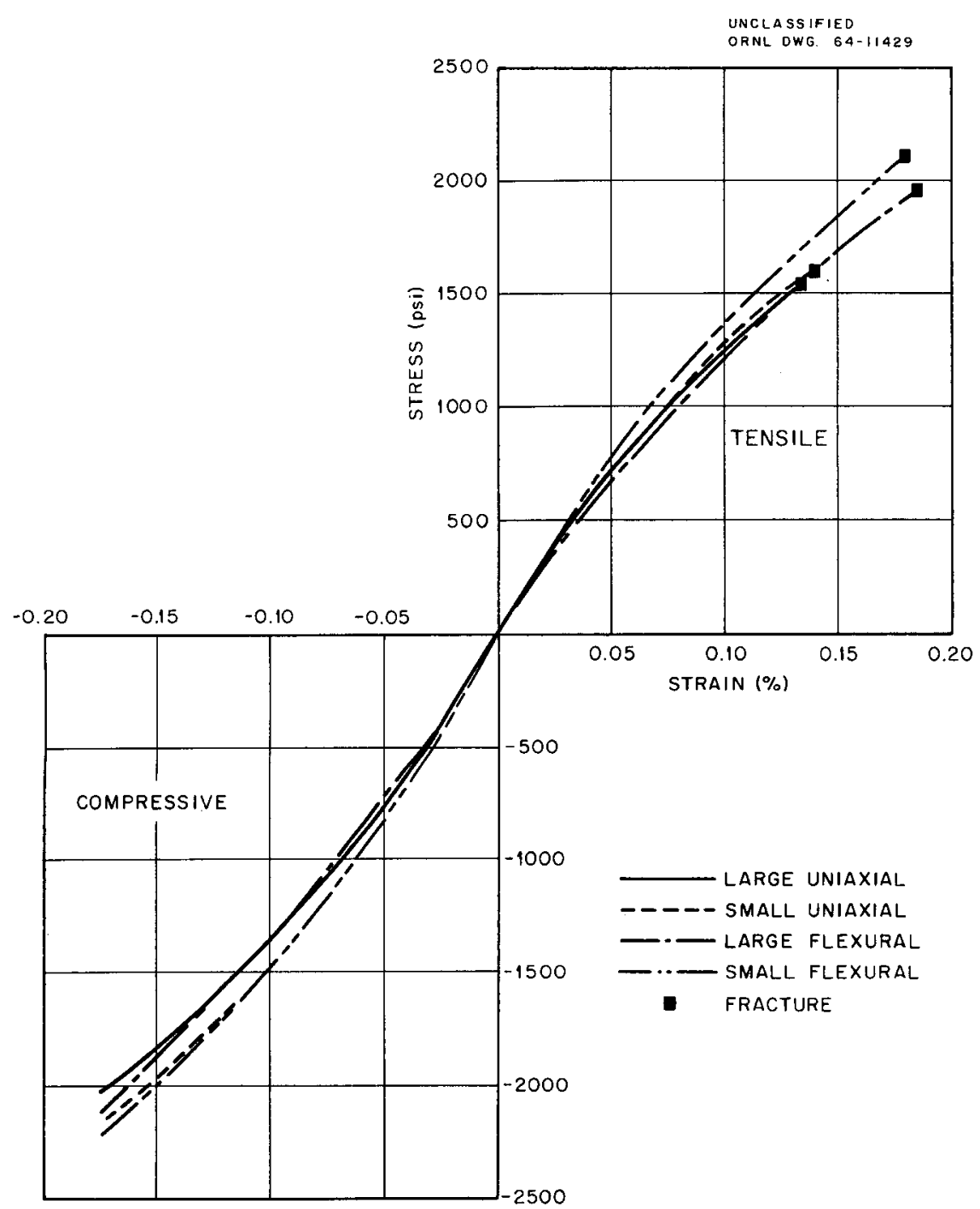

Fig. 22. Comparison of Room-Temperature Flexural and Uniaxial StressStrain Diagrams for EGCR Graphite Parallel to the Extrusion Axis.

in detail. The particulars of this investigation and the results are discussed below.

Point-to-point variations in strain on the surface of a tensile specimen are made up of two components: one due to factors such as nonhomogeneity and the other from bending. On the other hand the differences in strain on the extreme surfaces of flexural specimens are caused only by the inherent properties of the material, such as nonhomogeneity. The fracture strains recorded for the tensile specimens were the average of two diametrically opposed gages. Thus both strain variations within a 
cross section, that is, flexural strains and strain variations along the length of the specimen, were not recorded. For large samples the average stress-strain relationships are obtained; however, the strains are not appropriate for making valid comparisons with the flexural data. In order to make valid comparisons between these different sets of data, it was necessary first to estimate the difference between the peak strains and the average strains for a tensile specimen and then to separate the differences into bending and nonhomogeneous material components. The peak strains were determined using specially instrumented tensile specimens, and the portions of the strain due to nonhomogeneous characteristics of the material were determined using specially instrumented flexural specimens.

To determine the relationship of the maximum strain to the average strain for the tensile specimens, seven special tensile specimens were gaged as shown in Fig. 23. Six gages were uniformly spaced around the specimen, in addition to the two routinely used diametrically opposed gages.

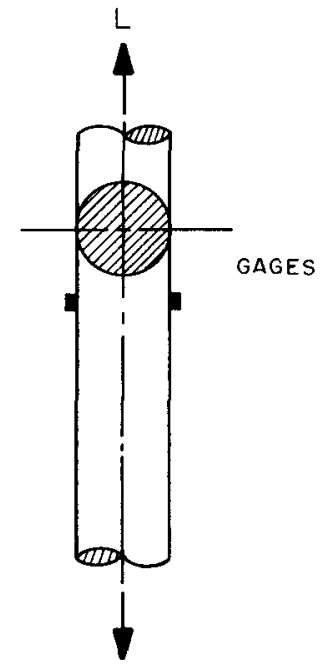

(a) GAGE POSITIONS FOR UNIAXIAL TENSILE TESTS

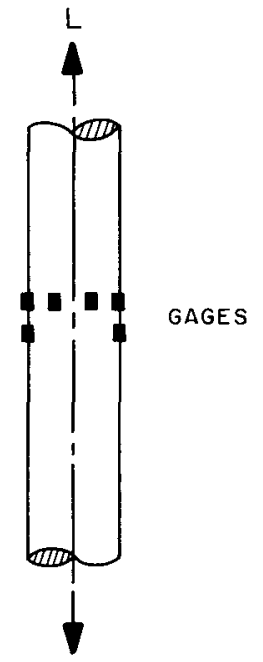

(b) GAGE POSITIONS FOR SPECIAL TENSILE TESTS

Fig. 23. Gage Positions for Uniaxial Specimens. 
Six flexural specimens, three large and three small, were instrumerted on the tensile surface, as shown in Fig. 24. For a completely homogeneous material the strains obtained from the gages on a single beam would be the same. A control specimen of aluminum, similarly instrumented and loaded, showed less than a $1 \%$ variation from the average strain along the length of the surface.

These tests showed that the strain variations common to both specimen types accounted for about $9 \%$ of the total for tensile specimens, leaving a bending component of about $20 \%$ to be added to the reported fracture strains. The stress should also be increased as dictated by the stress-strain diagram.

An additional investigation was made to evaluate friction effects in the flexural tests. During third-point bending, friction between the supports and the beam produces a moment that is opposite to the applied moment. The amount of error that results from ignoring this factor was experimentally determined. It was concluded from the tests that the friction at the

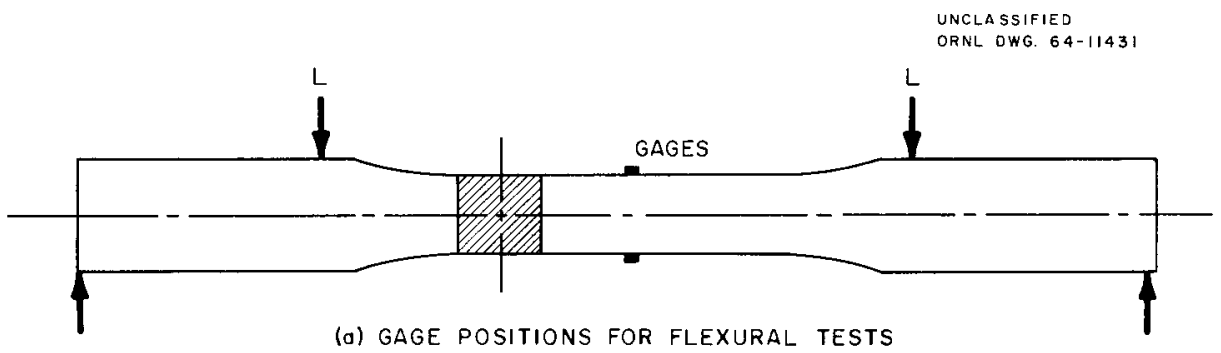

(a) GAGE POSITIONS FOR FLEXURAL TESTS

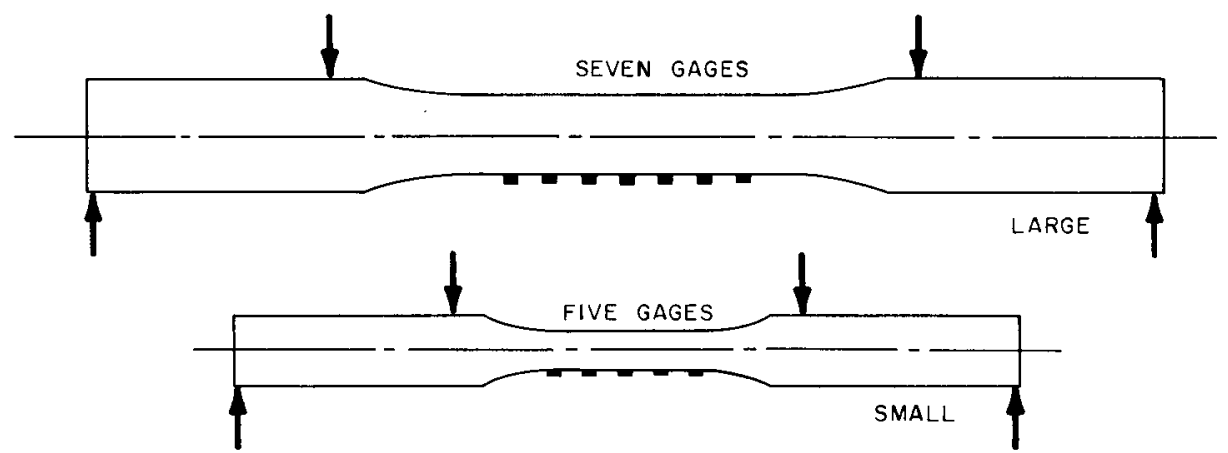

(b) GAGE POSITIONS FOR SPECIAL FLEXURAL TESTS

Fig. 24. Gage Positions for Flexural Specimens. 
supports was constant. The maximum stresses from the flexural tests were estimated to be $2 \%$ high for the small specimens and $3 \%$ high for the large ones.

When the tensile fracture points are adjusted and the flexural stresses are reduced by the respective percentages, the fracture points are essentially the same for the two types of tests. Thus, in an engineering sense, there are no differences.

In order to illustrate the agreement between the uniaxial and flexural tests, the fracture stresses, fracture strains, moduli, and ultimate strain energies were normalized to the results from the small tensile specimens. The calculated ratios are given in Table 7 .

Further comparisons of data may be seen in Figs. 25 and 26 . In these cases the data were not adjusted as discussed above. Figure 25 shows that an envelope extending $71 / 2 \%$ on either side of the combined mean encompasses the mean curves in both tension and compression for the two sizes of uniaxial and the two sizes of flexural specimens. Figure 26 shows the tensile and compressive curves plotted using absolute values of stress and strain. Here, an interval of $12.5 \%$ on either side of the mean encompasses all the curves. It is significant that the envelope of the standard deviations of each individual curve almost covers the envelope shown in Fig. 25. A mean curve for all the parallel tensile data, both uniaxial and flexural, is shown in Fig. 27.

Strain-Ratio Tests

Strain-ratio data were taken for $1 / 2$-in.-square specimens 2 in. Iong oriented as shown in Fig. 28 so that all six of the strain ratios could be measured independently. The ratio of lateral strain to longitudinal strain, $\epsilon_{\mathrm{T}} / \epsilon_{\mathrm{L}}$, was measured on each of two adjacent sides of the specimen as the load was applied along the axis.

The mean curves, $\mu_{i j}=\epsilon_{\mathrm{T}} / \epsilon_{\mathrm{L}}$, for both tensile and compressive loadings are shown in Fig. 29 as a function of $\epsilon_{L}$. The subscripts $i$ and $j$ refer to the orientation of the specimen and the direction of the lateral strain, respectively. Approximately ten specimens of each orientation were 
Table 7. Comparison of Parallel Uniaxial and Flexural Data Normalized to the Uniaxial Tensile Results for the Small Parallel Specimens

\begin{tabular}{|c|c|c|c|c|c|c|c|c|}
\hline \multirow{2}{*}{ Type of Specimen } & \multicolumn{2}{|c|}{$\begin{array}{l}\text { Fracture Stress } \\
\text { (psi) }\end{array}$} & \multicolumn{2}{|c|}{$\underset{(\%)}{\text { Fracture Strain }}$} & \multicolumn{2}{|c|}{$\begin{array}{l}\text { Modulus of Elasticity } \\
\text { (psi) }\end{array}$} & \multicolumn{2}{|c|}{$\begin{array}{l}\text { Ultimate Strain Energy } \\
\left(\text { in. }-1 \mathrm{~b} / \text { in. }^{3}\right)\end{array}$} \\
\hline & Original & Corrected & Original & Corrected & Original & Corrected & Original & Corrected \\
\hline & & & & & $\times 10^{6}$ & $\times 10^{6}$ & & \\
\hline Basis of normalization & 1610 & 1800 & 0.141 & 0.169 & 1.67 & 1.67 & 1.21 & 1.77 \\
\hline \multicolumn{9}{|l|}{ Uniaxial } \\
\hline Parallel small tensile & 1.00 & 1.00 & 1.00 & 1.00 & 1.00 & 1.00 & 1.00 & 1.00 \\
\hline Parallel large tensile & 0.96 & 0.98 & 0.96 & 0.96 & 1.07 & 1.07 & 0.92 & 0.92 \\
\hline \multicolumn{9}{|l|}{ Flexural } \\
\hline Parallel small tensile & 1.32 & 1.15 & 1.28 & 1.07 & 1.03 & 1.01 & 1.83 & 1.23 \\
\hline Parallel large tensile & 1.22 & 1.06 & 1.32 & 1.10 & 0.88 & 0.85 & 1.69 & 1.12 \\
\hline
\end{tabular}




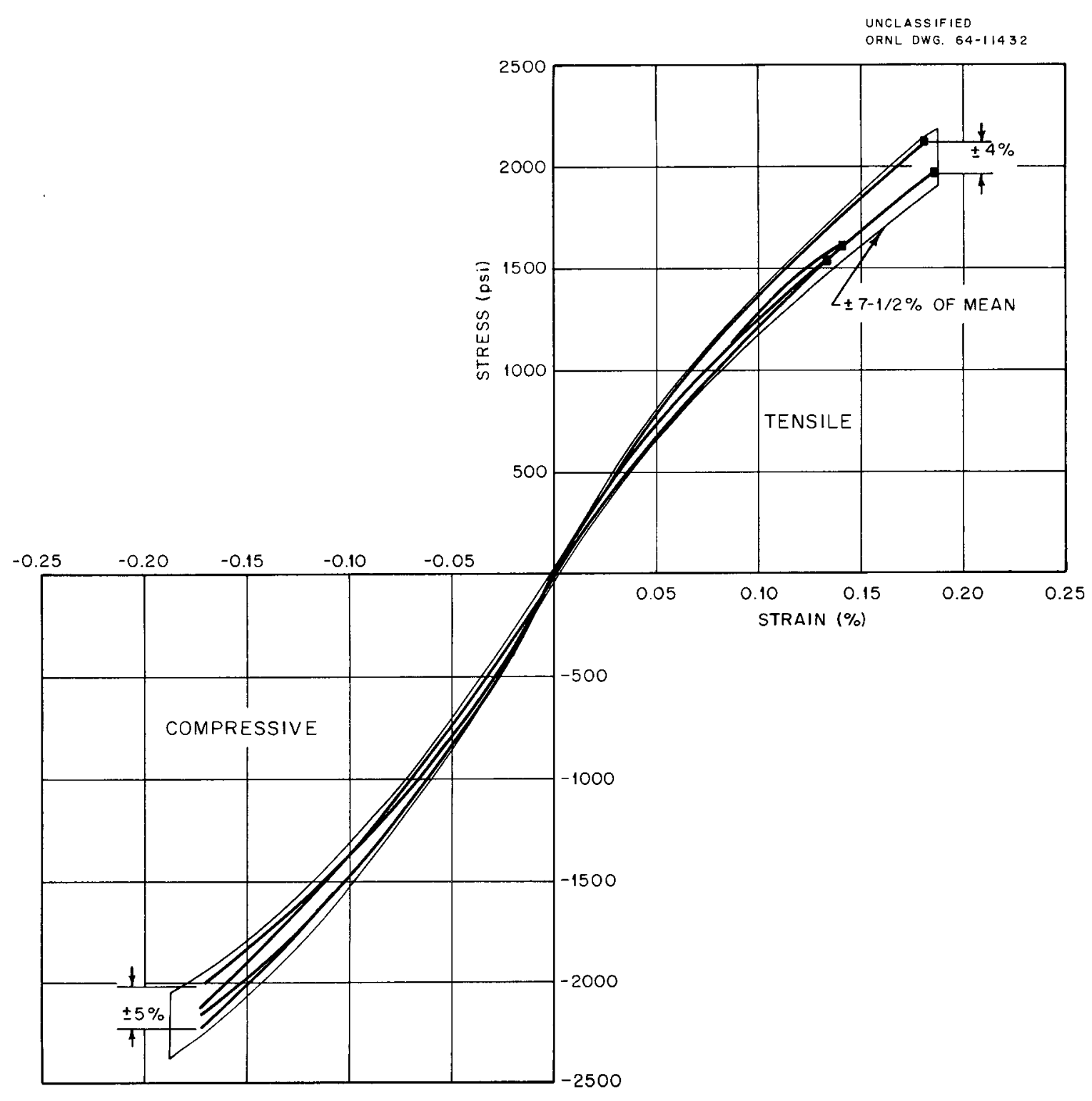

Fig. 25. Variation of Experimental Data from the Mean.

tested to failure in tension and a like number in compression. The vertical bars in Fig. 29 are the standard deviation of the data.

In keeping with the assumption of transverse isotropy, the data for $\mu_{12}$ and $\mu_{21}$, for $\mu_{31}$ and $\mu_{32}$, and for $\mu_{13}$ and $\mu_{23}$ were combined to form the curves shown in Fig. 30. The variation in the data is such that combining these data is justified. Theoretical curves based on the classical plasticity laws for anisotropic materials are also shown. ${ }^{5,6}$ The apparent deviation of the data from the theoretical curves reflects a volume change in 


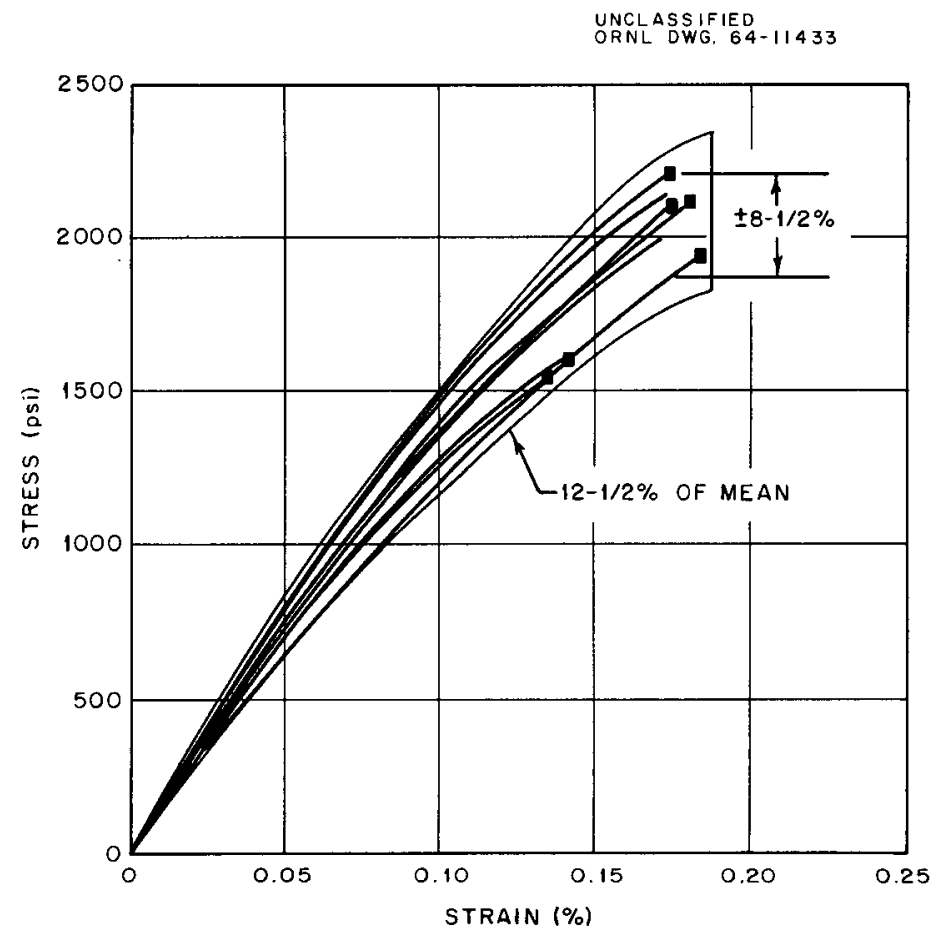

Fig. 26. Variation of Combined Tensile and Compressive Experimental Data from the Mean.

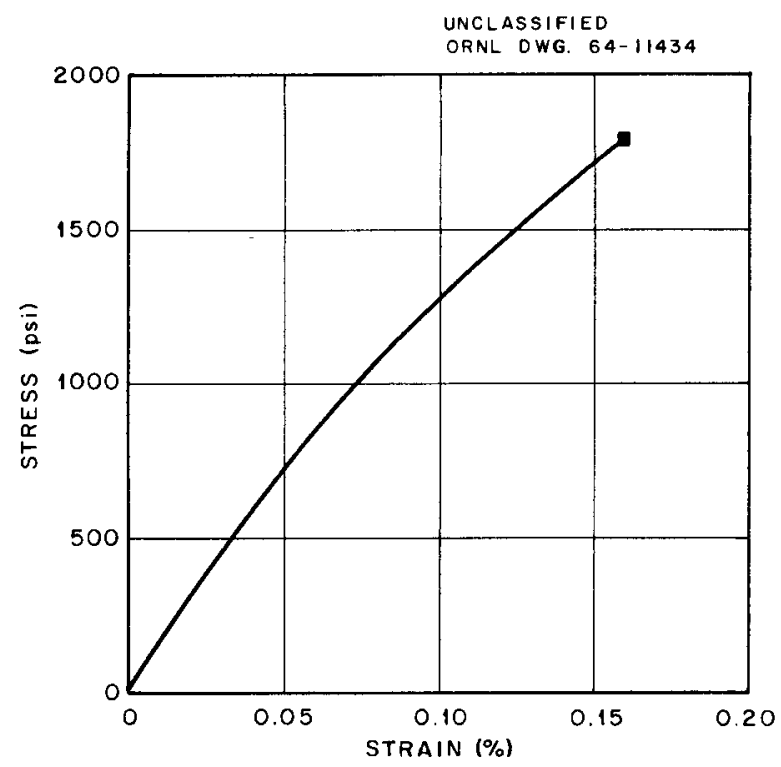

Fig. 27. Mean Stress-Strain Curve for All Flexural and Uniaxial Tensile Data. 


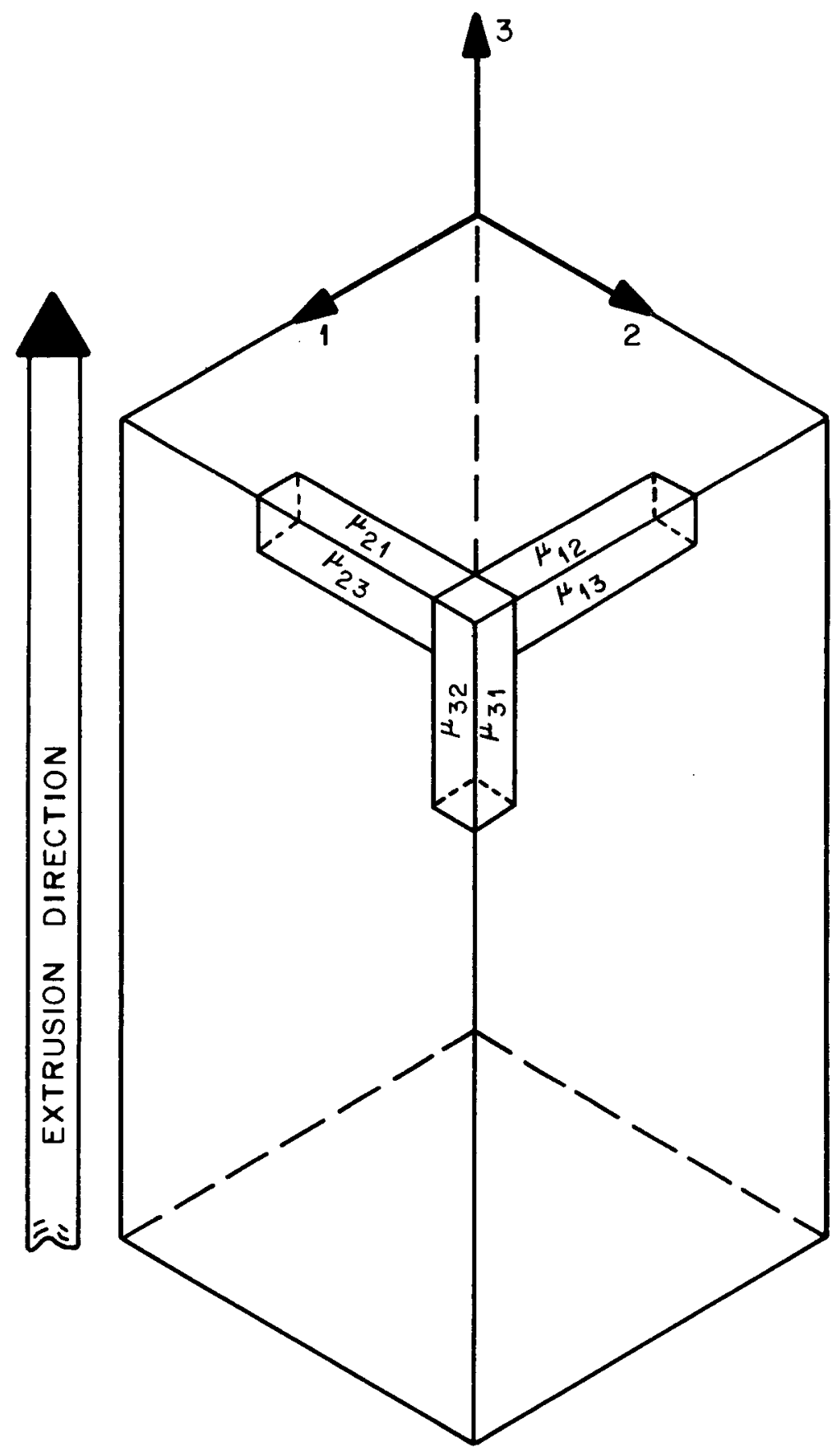

Fig. 28. Orientation of Strain-Ratio Specimens. 

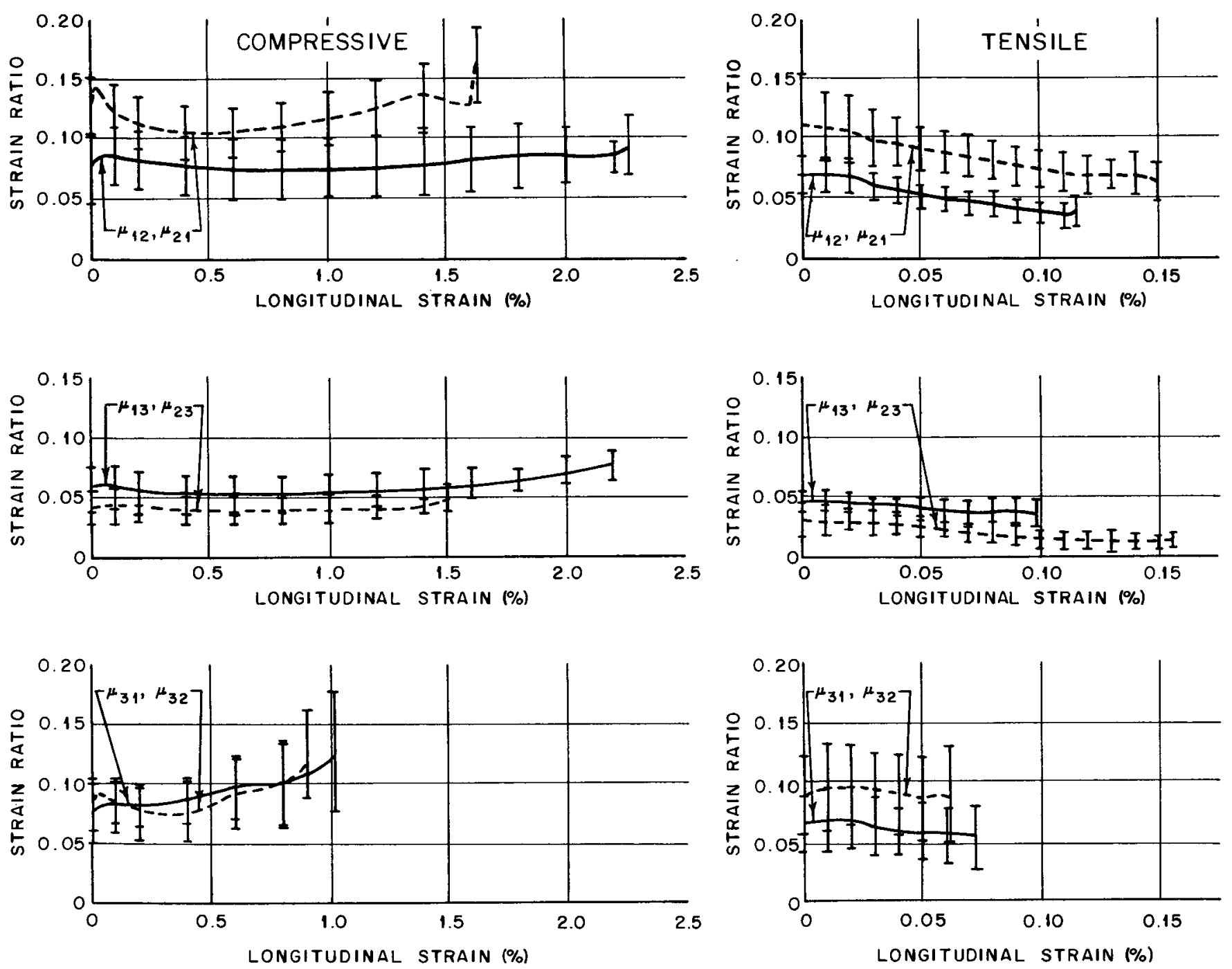

Fig. 29. Strain-Ratio Data. 

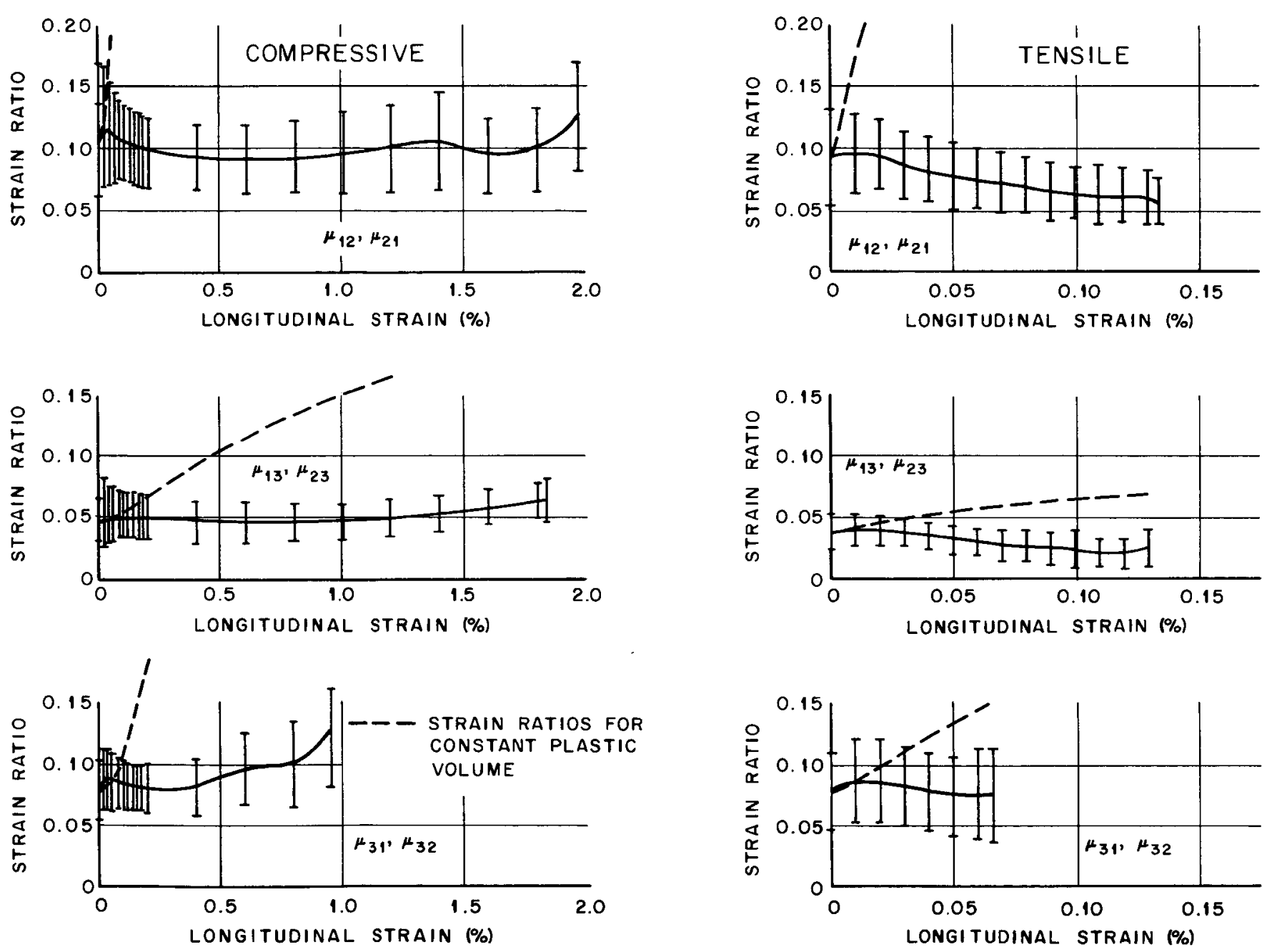

Fig. 30. Strain-Ratio Data Based on Transverse Isotropy. 
the nonelastic strains. This is different from the behavior of metals and indicates a need for nonelastic strain laws more appropriate to graphite.

The elastic strain ratios (i.e., Poisson's ratios), $v_{i j}$, are the initial values of the $\mu_{i j}$ curves at zero strain. These values, together with the coefficients of variation in parentheses, are given in the following table.

Table 8. Poisson's Ratios

\begin{tabular}{lccc}
\hline$v_{i j}$ & Tension & Compression & Mean \\
\hline$v_{31}$ & $0.0784(39)^{\mathrm{a}}$ & $0.0790(30)$ & $0.0786(36)$ \\
$v_{13}$ & $0.0385(37)$ & $0.0491(36)$ & $0.0442(38)$ \\
$v_{12}$ & $0.0936(41)$ & $0.1003(38)$ & $0.0969(39)$ \\
\hline
\end{tabular}
variation.

It is of particular interest to see how well the data of Table 8 conform to the transverse isotropic model for elastic behavior. The theoretical relation between $\nu_{13}$ and $v_{31}$ is

$$
v_{31}=\frac{E_{3}}{E_{1}} v_{13}
$$

Average values of the elastic moduli taken from the uniaxial tests in tension and compression were used to calculate $v_{31}$. The resulting theoretical values are given below:

$$
\begin{array}{ll}
v_{31} \text { (tension) } & 0.0697 \\
v_{31} \text { (compression) } & 0.0911 \\
v_{31} \text { (mean value) } & 0.0810
\end{array}
$$

The values for tension and compression are within 15\% of the experimental values, while the mean value is within $3 \%$. 
Examination of Data Distributions

Stress Distributions for a Given Strain

Since all the statistical studies of the data were based on the assumption that the data were normally distributed, the validity of this assumption should be demonstrated. In this section the distributions of stresses determined at specified values of strain are investigated. The data distribution at fracture will be examined in the next section.

The normality of a data distribution may be examined by determining the two statistics, skewness and kurtosis. Skewness is the quality of a frequency distribution being bunched together on one side of the mean and tailing out on the other side. It is measured by a statistic based on the sum of the third powers of deviations from the mean. ${ }^{7}$ This statistic is usually denoted by $g_{1}$. A positive $g_{1}$ indicates an excess in the number of items smaller than the mean and a negative value indicates an excess of items larger than the mean.

Kurtosis is the quality of a frequency distribution being relatively flat or peaked as compared with the normal curve. It is measured by a statistic based on the sum of the fourth powers of deviations from the mean. ${ }^{7}$ This statistic is usually denoted by $g_{2}$. A positive $g_{2}$ indicates an excess of items near the mean and far from it, with a corresponaing depletion of the flanks of the distribution. Negative values of $g_{2}$ result from flat-topped distribution curves. The student-t test ${ }^{8}$ may be used to determine the significance of both $g_{1}$ and $g_{2}$.

The values of $g_{1}$ and $g_{2}$ for the distributions of stress values at certain values of strain are given in Table 9. The distributions for the ten basic types of specimens tested and for pertinent combinations of the specimen types were investigated. The values of the student-t statistics and the probabilities (in percent) that the data will deviate in the specified manner from the normal distribution are also given in the table. A probability of $95 \%$ or greater is (statistically) "significant." 9 In seven of the ten sets of data from individual specimen types, the skewness is not significant and in eight of the ten cases the kurtosis is not significant. In the four combined sets, there is neither significant skewness nor kurtosis. The combined sets of specimens have a much larger sample size; 
Table 9. Skewness and Kurtosis of the Stress Distributions at Certain Values of Strain

\begin{tabular}{|c|c|c|c|c|c|c|c|c|}
\hline \multirow[b]{2}{*}{ Type of Specimen } & \multirow[b]{2}{*}{$\begin{array}{l}\text { Number of } \\
\text { Specimens }\end{array}$} & \multirow[b]{2}{*}{$\begin{array}{l}\text { Strain } \\
(\%)\end{array}$} & \multicolumn{3}{|c|}{ Skewness } & \multicolumn{3}{|c|}{ Kurtosis } \\
\hline & & & $\mathrm{g}_{1}$ & $\begin{array}{l}t_{1} \\
(a)\end{array}$ & $\begin{array}{c}\text { Probability of } \\
\text { Real Difference } \\
(\%)\end{array}$ & $g_{2}$ & $\begin{array}{l}t_{2} \\
(a)\end{array}$ & $\begin{array}{c}\text { Probability of } \\
\text { Real Difference } \\
(\%)\end{array}$ \\
\hline \multicolumn{9}{|l|}{ Single groups of specimens } \\
\hline \multicolumn{9}{|l|}{ Parallel uniaxial } \\
\hline Small tensile & 31 & 0.0825 & 0.579 & 1.38 & 85 & -1.070 & 1.31 & 85 \\
\hline Large tensile & 29 & 0.0825 & -1.463 & 3.38 & $99 \cdot 9$ & 2.717 & 3.22 & 99.9 \\
\hline Small compressive & 29 & 0.5250 & -0.760 & 1.76 & 92 & 0.222 & 0.26 & 30 \\
\hline Large compressive & 29 & 0.5250 & 0.836 & 1.93 & 95 & 0.874 & 1.04 & 70 \\
\hline \multicolumn{9}{|l|}{ Transverse uniaxial } \\
\hline Small tensile & 18 & 0.0825 & -0.628 & 1.17 & 80 & -0.134 & 0.13 & 20 \\
\hline Small compressive & 17 & 0.5250 & 0.369 & 0.67 & 50 & -0.226 & 0.21 & 20 \\
\hline Large compressive & 17 & 0.5250 & -0.757 & 1.38 & 85 & 0.354 & 0.34 & 30 \\
\hline \multicolumn{9}{|l|}{ Parallel flexural } \\
\hline Small tensile & 29 & 0.0825 & -1.090 & 2.52 & 99 & 2.689 & 3.20 & $99 \cdot 9$ \\
\hline Large tensile & 24 & 0.0825 & 0.240 & 0.51 & 40 & -1.249 & 1.37 & 85 \\
\hline \multicolumn{9}{|c|}{ Combined groups of specimens } \\
\hline Parallel tensile & 113 & 0.0825 & -0.003 & 0.01 & 10 & -0.378 & 0.84 & 60 \\
\hline Parallel compressive & 111 & 0.0825 & 0.268 & 1.17 & 80 & 0.162 & 0.36 & 30 \\
\hline Transverse tensile & 38 & 0.0825 & -0.525 & 1.37 & 85 & 0.406 & 0.54 & 50 \\
\hline Transverse compressive & 34 & 0.5250 & -0.025 & 0.06 & 10 & 0.030 & 0.03 & 10 \\
\hline
\end{tabular}

$a_{\text {Student-t statistic. }}$ 
thus these results are somewhat more meaningful. Since in the majority of cases it has not been shown that the skewness and kurtosis are significant at the $95 \%$ level, the assumption of normality of the stress distributions for a given strain is justified.

Histograms and frequency curves were plotted for various sets of the data referred to in Table 9. Typical plots are shown in Fig. 31. Here the distributions for all the parallel tensile results and compressive results at a strain of $0.0825 \%$ are displayed.

Statistical Examination of Fracture Stress Data

One of the most widely discussed theories of failure that treats the statistical nature of observed fracture is that proposed by Weibull. ${ }^{10}$ Weibull postulates that within every volume of material there are a number of flaws distributed at random, both in severity and position, that cause the material to be weaker at some locations than at others. The natural consequence of this postulate is that the larger the volume of material subjected to stress, the higher the likelihood of failure. This is the size effect. It was noted that two parameters, namely the mean and variance, were insufficient to characterize failure of brittle materials. Weibull therefore constructed a three-parameter probability function based on the intuitively appealing assumption that failure is caused by tensile stresses alone. A fracture probability function was postulated of the following form:

$$
P\left(\sigma_{x}<\sigma\right)=1-\exp \left[-\int_{V}\left(\frac{\sigma_{t}(v)-\sigma_{u}}{\sigma_{0}}\right)^{m} d V\right],
$$

where

$$
\begin{aligned}
& \sigma \quad=\text { stress in psi, } \\
& \sigma_{\mathrm{x}}=\text { maximum stress at failure, } \\
& \sigma_{t}(\mathrm{~V})=\text { tensile stress distribution in the volume, } \\
& \sigma_{\mathrm{u}}=\text { minimum failure stress or location parameter, } \\
& \mathrm{m} \quad=\text { scatter parameter, } \\
& \sigma_{0} \quad=\text { scale parameter. }
\end{aligned}
$$


UNCLASSIFIED

ORNL OWG 64-11438
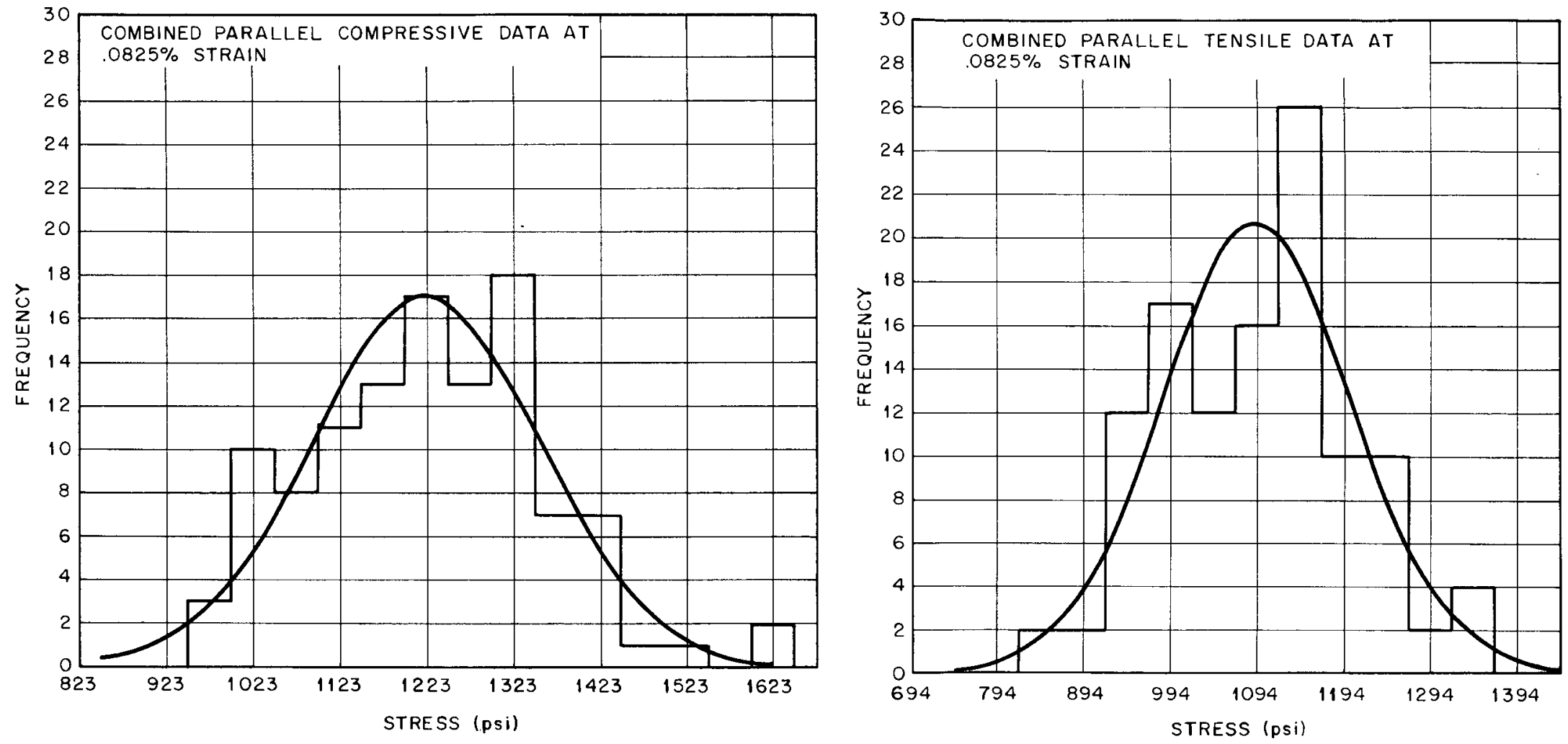

Fig. 31. Typical Frequency Curves and Histograms. 
According to the theory, the three parameters $m, \sigma_{u}$, and $\sigma_{0}$ are constants that are different for each material. These constants must be determined from a statistical sample of fractured specimens.

Equation (9) can be written in terms of the maximum stress $\sigma_{x}$ and a stress distribution constant $\mathrm{k}$ :

$$
P\left(\sigma_{x}<\sigma\right)=1-\exp \left[-\mathrm{kV}\left(\frac{\sigma_{x}-\sigma_{u}}{\sigma_{0}}\right)^{m}\right],
$$

where

$$
k=\frac{1}{V} \int_{V}\left[\frac{\sigma_{t}(V)-\sigma_{u}}{\sigma_{x}-\sigma_{u}}\right]^{m} d V
$$

The probability density function ( $p d f$ ) of $\sigma_{x}$ corresponding to the histogram is usually easier to work with than the probability function. The Weibull paf is

$$
f\left(\sigma_{x}\right)=\frac{m}{\theta}\left(\frac{\sigma_{x}-\sigma_{u}}{\theta}\right)^{m-1} \exp \left[-\left(\frac{\sigma_{x}-\sigma_{u}}{\theta}\right)^{m}\right],
$$

where the scale parameter takes the form

$$
\theta=\sigma_{0}(\mathrm{kV})^{-1 / \mathrm{m}}
$$

The mean of the distribution $\overline{\sigma_{X}}$ is given by

$$
\overline{\sigma_{x}}=\sigma_{u}+\theta \Gamma\left(1+\frac{1}{m}\right)
$$

where $\Gamma$ is the complete gamma function; and the variance $a^{2}$, where " $a$ " is the standard deviation, is

$$
a^{2}=\theta^{2}\left[\Gamma\left(1+\frac{2}{m}\right)-\Gamma^{2}\left(1+\frac{1}{m}\right)\right] \text {. }
$$


Elaborations of the theory take into consideration surface area and statistical nonhomogeneity. These refinements, however, will not be considered here.

The problem in statistics is that of estimating the parameters $m$, $\sigma_{u}$, and $\theta$. The related problem in mechanics was to determine whether or not EGCR-type AGOT graphite obeys the preceding formulation. The latter problem is more inclusive than the former and required a testing program elaborate enough to examine the effect of volume and stress distribution. The four tests of parallel specimens, large tensile, small tensile, large flexural, and small flexural, were considered to be adequate for this purpose, provided independent estimates of the parameters could be obtained. The volumes of the larger specimens were $0.92 \mathrm{in.}^{3}$, that is, eight times the volumes of the smaller specimens, 0.115 in. $^{3}$

The usual method for estimating the parameters from a set of data is the maximum likelihood method. However, this method results in nonlinear equations for the WeibulI distribution. Closed-form solutions to these equations are not available; therefore other less efficient methods were used. Estimates by two of these methods, McClintock's method and a leastsquares-fit method, ${ }^{11}$ were used for the EGCR-type AGOT graphite tested. In order to calculate $\sigma_{0}, k$ must be determined, since

$$
\sigma_{0}=\theta(\mathrm{kV})^{1 / \mathrm{m}}
$$

For the tensile specimens, $\mathrm{k}=1$ [see Eq. (11)]. For the flexural specimens, assuming a linear stress distribution in the beam,

$$
k=\frac{1}{2(m+1)}\left(\frac{\sigma_{x}-\sigma_{u}}{\sigma_{x}}\right) \text {. }
$$

In particular, $k$ is a function of $\sigma_{x}$. However, if $k$ is evaluated at the mean stress $\overline{\sigma_{X}}$, then

$$
\overline{\mathrm{k}}=\frac{1}{2(\mathrm{~m}+1)}\left(\frac{\overline{\sigma_{\mathrm{x}}}-\sigma_{\mathrm{u}}}{\overline{\sigma_{\mathrm{x}}}}\right) \text {. }
$$


These estimates and the residuals resulting from the fit are given in Table 10 .

An examination of Table 10 shows that both methods gave reasonably consistent values for $\mathrm{m}$, except for the large flexural specimen data, in which case neither method yielded good estimates. The least-squares method failed to fit, as evidenced by the large residual, and the McClintock method produced a negative value for $\sigma_{u}$, which is inadmissible under the assumptions of the theory. This could possibly be attributed to the smaller number of samples for the large flexural tests. At any rate, any conclusions based on large flexural data alone would be questionable.

If the estimates from the three tests, small tensile, large tensile, and small flexural, can be considered fairly accurate, the theoretical results may be compared with the experimental results. According to the theory, all three of the parameters $m, \sigma_{u}$, and $\sigma_{o}$ should be the same for all three tests. Only the estimates for $m$ are completely consistent. The $\sigma_{u}$ estimates are consistent for the two tensile tests but differ by a factor of 2 or 3 for the small flexural test. The $\sigma_{0}$ parameter differs widely for all three tests. Of note is the consistent behavior of the $\theta$ estimates.

Table 11 and Fig. 32 show the expected values of the means and standard deviations based on the least-squares estimates for the small tensile data and the corresponding experimental values. These estimates were used as a standard for comparison because the residual was smallest and the product $(\mathrm{kV})$ was intermediate.

It is concluded that the data do not support the theory, even though the fracture data for each specimen type appear to be distributed according to a Weibull pdf. The experimental values in Table 11 indicate that the variance is uniform for all tests, but the means are uniform only within the type of loading, that is, small tension with large tension and small flexure with large flexure. From Eqs. (14) and (15) it may be seen that the variance is influenced by $\theta$ but not by $\sigma_{u}$, whereas the mean is influenced by both parameters. The conclusions are that the scale parameter $\theta$ is not a function of either volume or stress distribution and that the minimum fracture or location parameter $\sigma_{u}$ is influenced by stress distribution but not by volume. 
Table 10. Estimates of the Weibull Parameters for EGCR-Type AGOT Graphite

\begin{tabular}{|c|c|c|c|c|c|c|c|c|}
\hline $\begin{array}{c}\text { Specimen } \\
\text { Type } \\
\text { (all parallel) }\end{array}$ & $\begin{array}{l}\text { Number of } \\
\text { Samples }\end{array}$ & $\begin{array}{l}\text { Method of } \\
\text { Estimation }\end{array}$ & $\begin{array}{l}\text { Residual } \\
\left(\text { times } 10^{3}\right)\end{array}$ & $\mathrm{m}$ & $\sigma_{u}$ & $\theta$ & $\begin{array}{l}\mathrm{k} \\
(\mathrm{a})\end{array}$ & $\sigma_{0}$ \\
\hline Small tensile & $\begin{array}{l}32 \\
32\end{array}$ & $\begin{array}{l}\text { Least squares } \\
\text { McClintock }\end{array}$ & $\begin{array}{r}-0.0610 \\
0.1945\end{array}$ & $\begin{array}{l}2.752 \\
3.439\end{array}$ & $\begin{array}{l}702.463 \\
602.363\end{array}$ & $\begin{array}{l}1006.49 \\
1046.695\end{array}$ & $\begin{array}{l}1 \\
1\end{array}$ & $\begin{array}{l}458.851 \\
558.098\end{array}$ \\
\hline Large tensile & $\begin{array}{l}30 \\
30\end{array}$ & $\begin{array}{l}\text { Least squares } \\
\text { McClintock }\end{array}$ & $\begin{array}{r}-0.1221 \\
1.0496\end{array}$ & $\begin{array}{l}3.284 \\
4.078\end{array}$ & $\begin{array}{l}603.965 \\
514.164\end{array}$ & $\begin{array}{l}1044.78 \\
1129.419\end{array}$ & $\begin{array}{l}1 \\
1\end{array}$ & $\begin{array}{l}1018.59 \\
1106.56\end{array}$ \\
\hline Small flexural & $\begin{array}{l}29 \\
29\end{array}$ & $\begin{array}{l}\text { Least squares } \\
\text { Mcclintock }\end{array}$ & $\begin{array}{l}0.8239 \\
1.3786\end{array}$ & $\begin{array}{l}2.836 \\
2.989\end{array}$ & $\begin{array}{l}1483.46 \\
1521.93\end{array}$ & $\begin{array}{r}984.468 \\
1005.870\end{array}$ & $\begin{array}{l}0.0483 \\
0.0497\end{array}$ & $\begin{array}{l}157.52 \\
178.94\end{array}$ \\
\hline Large flexural & $\begin{array}{l}24 \\
24\end{array}$ & $\begin{array}{l}\text { Least squares } \\
\text { McClintock }\end{array}$ & $\begin{array}{r}137.817 \\
0.1453\end{array}$ & $\begin{array}{r}6.678 \\
16.360\end{array}$ & $\begin{array}{c}0 \\
-1590.4\end{array}$ & $\begin{array}{l}2336.76 \\
3458.802\end{array}$ & $\begin{array}{l}0.0599 \\
0.0498\end{array}$ & $\begin{array}{r}153.29 \\
2864.40\end{array}$ \\
\hline
\end{tabular}

$\mathrm{a}_{\mathrm{k}}$ for the flexural specimens is $\overline{\mathrm{k}}$ as defined in Eq. (17). 
UNCLASSIFIED

ORNL DWG. $64-11439$

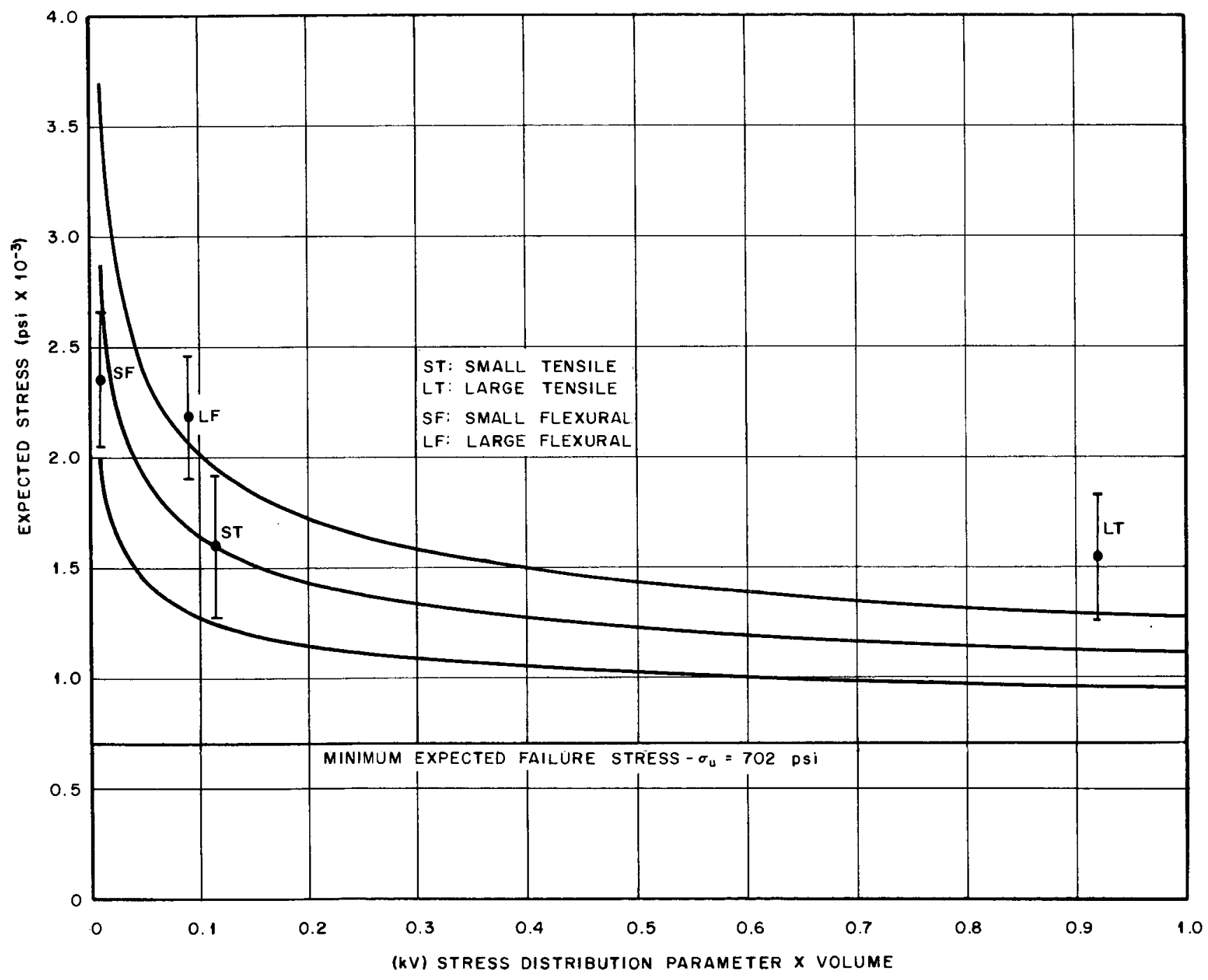

Fig. 32. Expected Mean Failure Stress and Expected Standard Deviation Versus (kV) Based on Small Tensile Data. 
Table 11. Theoretical and Experimental Values of the Mean Fracture Stress and the Standard Deviation

\begin{tabular}{|c|c|c|c|c|}
\hline \multirow[b]{2}{*}{$\begin{array}{c}\text { Specimen } \\
\text { Type } \\
\text { (all parallel) }\end{array}$} & \multicolumn{2}{|c|}{ Expected Values ${ }^{a}$} & \multicolumn{2}{|c|}{ Experimental Values } \\
\hline & $\begin{array}{c}\text { Mean Stress, } \\
\bar{\sigma} \\
(\text { psi) }\end{array}$ & $\begin{array}{c}\text { Standard } \\
\text { Deviation, } \\
\sqrt{\mathrm{a}^{2}}\end{array}$ & $\begin{array}{c}\text { Mean Stress, } \\
\bar{\sigma} \\
(\operatorname{psi})\end{array}$ & $\begin{array}{c}\text { Standard } \\
\text { Deviation, } \\
\sqrt{a^{2}}\end{array}$ \\
\hline Small tensile & 1597.94 & 351.597 & 1594.31 & 318.917 \\
\hline Large tensile & 1123.35 & 165.25 & 1539.00 & 282.53 \\
\hline Small flexural & 2773.13 & 813.25 & 2357.07 & 305.35 \\
\hline Large f'lexural & 1675.85 & 382.29 & 2179.46 & 283.65 \\
\hline
\end{tabular}

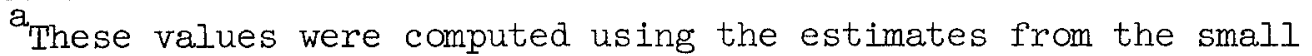
tensile data.

In summary, further work is needed both theoretically and experimentally. Additional theoretical work is required in the statistics of the Weibull pdf. More efficient methods of parameter estimation and parameter testing are necessary. The number of specimens required to constitute an adequate sample size and the errors that can be expected from smaller sample sizes must be studied. Last and most important, sufficient experimental data must be generated in support of theoretical developments.

Analytical Representations of the Stress-Strain Relationships

Since EGCR-type AGOT graphite exhibits a nonlinear stress-strain diagram, analytical methods expressing the relationship between stress and strain should be developed. Such methods would define parameters that characterize the particular curve or curves being investigated. The various analytical relationships discussed in this section are given by Eqs. (5) through (8), and the properties of these formulations are discussed on page 17. Both the totality of data from all tests on each type of specimen and the mean data for the set were fit, where possible, but only the results from fitting the mean data are presented. This was done because there was a wide scatter of characterizing parameters for those formulations requiring nonlinear techniques when the totality of data was fit. Also 
the series formulations tend to oscillate with increased number of coefficients when such sets of data are fit. Although fits were obtained using Eqs. (6) and (8), these relationships were shown to be less valuable for characterizing the data, and these results are not depicted. The exponents obtained by fitting $\mathrm{Eq}$. (6) to the data were very large and the solutions often diverged. For Eq. (8), suitable convergence of the coefficients did not occur.

The parameters obtained from fitting the various sets of data by Eq. (5) are given in Table 12. The results obtained by fitting the uniaxial

Table 12. Parameters Obtained by Fitting the Mean of the Various Sets of Data With the Formula $\epsilon=\frac{\sigma}{\mathrm{E}}+\left(\frac{\sigma}{\mathrm{A}}\right)^{\mathrm{n}}$

\begin{tabular}{|c|c|c|c|}
\hline \multirow{2}{*}{ Type of Specimen } & \multirow{2}{*}{$\begin{array}{c}E \\
(p s i)\end{array}$} & \multicolumn{2}{|c|}{ Parameters } \\
\hline & & A & $\mathrm{n}$ \\
\hline & $\times 10^{6}$ & & \\
\hline \multicolumn{4}{|l|}{ Uniaxial } \\
\hline Parallel small tensile & 1.67 & 42,700 & 2.37 \\
\hline Parallel large tensile & 1.79 & 56,400 & 2.13 \\
\hline Parallel small compressive & 1.77 & 15,000 & 4.30 \\
\hline Parallel large compressive & 1.58 & 11,700 & 4.99 \\
\hline Transverse small tensile & 0.90 & 23,600 & 2.27 \\
\hline Transverse large tensile & 1.00 & 30,900 & 2.10 \\
\hline Transverse small compressive & 0.91 & 18,300 & 3.08 \\
\hline Transverse large compressive & 0.82 & 18,000 & 2.89 \\
\hline \multicolumn{4}{|l|}{ Flexural } \\
\hline Parallel small tensile & 1.72 & 42,900 & 2.47 \\
\hline Parallel large tensile & 1.47 & 50,900 & $2 \cdot 31$ \\
\hline Parallel small compressive & 1.83 & 41,300 & $2 \cdot 58$ \\
\hline Parallel large compressive & 1.59 & 51,200 & 2.43 \\
\hline
\end{tabular}


compressive data should not be compared with those of the tensile data, since the fracture points greatly differ. Also the moduli for the uniaxial compressive data were obtained using 500- $\mu$ in. intervals and are not the same as the values given in Table 3. Taking this into account, a very good degree of consistency in parameters exists among the various tests. For instance, the range of $\mathrm{A}$ for the parallel tensile results in Table 12 is from 42,700 to 56,400, while the range for $\mathrm{n}$ is from 2.13 to 2.47 . Similar agreement was found for parameters determined from the parallel uniaxial compressive data. The parameters determined by fitting the transverse data may be similarly characterized.

The mean of the various sets of mean data was fitted using Eq. (5), and the results are shown in Fig. 33. The pertinent mean curves are also plotted. The agreement is excellent for both sets of tensile data; how'ever, for the compressive data, less agreement exists. In these results, flexural data, together with uniaxial data, were used only in the fit of the parallel tensile data. The characterizing parameters are given in Table 13.

Table 13. Characterizing Parameters Obtained by Fitting the Mean Data With the Formula $\epsilon=\frac{\sigma}{\mathrm{E}}+\left(\frac{\sigma}{\mathrm{A}}\right)^{\mathrm{n}}$

\begin{tabular}{lllll}
\hline \multirow{2}{*}{ Type of specimen } & $\mathrm{E}$ & \multicolumn{2}{c}{ Parameters } \\
\cline { 5 - 6 } & (psi) & A & $\mathrm{n}$ \\
\hline Parallel tensile (flexural and uniaxial data) & 1.67 & 45,800 & 2.34 \\
Parallel compressive (uniaxial data only) & 1.68 & 13,200 & 4.63 \\
Transverse tensile (uniaxial data only) & 0.95 & 27,400 & 2.17 \\
Transverse compressive (uniaxial data only) & 0.863 & 18,500 & 2.95 \\
\hline
\end{tabular}

The similarity between Eq. (5) and Jenkins' equation, 12

$$
\epsilon=\frac{\sigma}{E}+B \sigma^{2},
$$



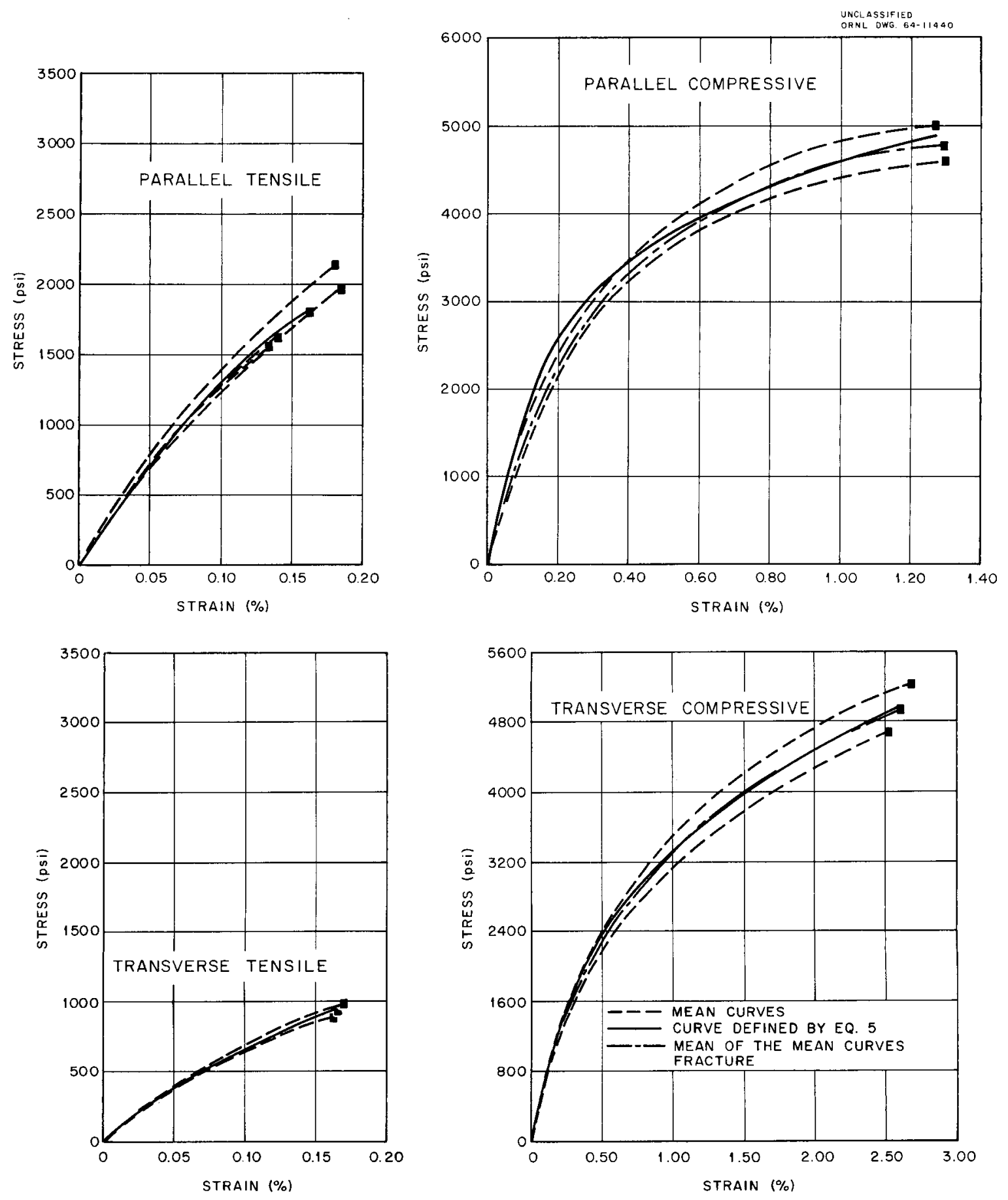

Fig. 33. Comparison of the Mean Curves With the Fit of the Mean of These curves Using $\epsilon=\frac{\sigma}{E}+\left(\frac{\sigma}{A}\right)^{\mathrm{n}}$. 
should be noted. Jenkins' equation was derived for PGA graphite under small compressive stresses on the basis of a rheological model consisting of friction blocks and springs. If $\mathrm{n}=2$, then $\mathrm{Eq} .(5)$ and Jenkins' equation are identical. It is significant that for the tensile tests, the flexure tests, and the combined tensile results, the value of $\mathrm{n}$ is fairly close to 2 .

The various sets of data were fit using Eq. (7), and the parameters are given in Table 14. It was found that only three parameters are necessary to characterize the tensile data; however, this number is not adequate for the compressive data. For these cases, all the data were fit arbitrarily, using eight coefficients. In most cases the first parameter is the dominating one.

Contrary to the results obtained using Eq. (5), a good degree of consistency between parameters from Eq. (7), which characterize similar data, does not exist. Thus, the characterizing parameters are taken as those defined by the mean curve for all the mean curves pertinent to a particular type of data; for instance, all the tensile data. The parameters so determined are given in Table 15. Comparison of the fitted results with the mean curves is shown in Fig. 34. In all cases the agreement is excellent. Comparisons of the characterizing curves determined by Eqs. (5) and (7) are shown in Fig. 35. The tensile curves are in excellent agreement, except near fracture. This is because $\mathrm{Eq}$. (5) does not necessarily pass through the fracture point. Less agreement exists for the compressive curves.

In summary, Eqs. (5) and (7) are amenable for characterizing the data. Equation (5) is probably more easily handled in analyses but is less accurate for compression than Eq. (7). Equation (7) can be made to fit the data accurately and has the additional advantage of going through the fractúre points. In many applications the formula to be used would probably be dictated by whether the analysis was simpler using stress as a function of strain or strain as a function of stress. 
Table 14. Parameters Obtained by Fitting the Mean of the Various Sets of Data With the Formula $\sigma=E \epsilon+\left(\frac{\sigma_{f}-E \epsilon_{f}}{\epsilon_{f}^{2}}\right) \epsilon^{2}+\epsilon \sum_{j=1}^{k} a_{j} \sin \frac{j \pi \epsilon}{\epsilon_{f}}$

\begin{tabular}{|c|c|c|c|c|c|c|c|c|c|c|c|}
\hline \multirow{2}{*}{ Type of Specimen } & \multirow{2}{*}{$\begin{array}{c}E \\
(p s i)\end{array}$} & \multirow{2}{*}{$\begin{array}{l}\varepsilon_{f} \\
(\phi)\end{array}$} & \multirow{2}{*}{$\begin{array}{c}\sigma_{f} \\
(p s i)\end{array}$} & \multicolumn{8}{|c|}{ Parameters } \\
\hline & & & & $a_{1}$ & $a_{2}$ & $a_{3}$ & $a_{4}$ & $a_{5}$ & $a_{6}$ & $a_{7}$ & $a_{8}$ \\
\hline & $\times 10^{6}$ & & & & & & & & & & \\
\hline \multicolumn{12}{|l|}{ Uniaxial } \\
\hline Parallel small tensile & 1.67 & 0.141 & 1610 & $-31,800$ & 310 & 18,900 & & & & & \\
\hline Parallel large tensile & 1.79 & 0.135 & 1540 & $-98,400$ & $-7,790$ & 6,690 & & & & & \\
\hline Parallel small compressive & 1.77 & 1.286 & 5000 & $-468,000$ & $-119,000$ & $-45,800$ & $-21,900$ & $-8,080$ & -4820 & -1200 & -1230 \\
\hline Parallel large compressive & 1.58 & 1.311 & 4600 & $-398,000$ & $-91,100$ & $-36,300$ & $-16,100$ & $-7,460$ & -2410 & -1330 & -12 \\
\hline Transverse small tensile & 0.90 & 0.164 & 880 & $-36,900$ & $-4,460$ & 14,700 & & & & & \\
\hline Transverse large tensile & 1.00 & 0.171 & 980 & $-89,200$ & $-18,100$ & $-2,750$ & & & & & \\
\hline Transverse small compressive & 0.91 & 2.703 & 5210 & $-288,000$ & $-92,700$ & $-46,000$ & $-24,400$ & $-13,800$ & -7400 & -4600 & -1220 \\
\hline Transverse large compressive & 0.82 & 2.553 & 4650 & $-258,000$ & $-81,000$ & $-39,100$ & $-20,300$ & $-12,200$ & -6370 & -3750 & -979 \\
\hline \multicolumn{12}{|l|}{ Flexural } \\
\hline Parallel small tensile & 1.72 & 0.181 & 2120 & $-39,000$ & 13,300 & $-5,890$ & & & & & \\
\hline Parallel large tensile & 1.47 & 0.186 & 1960 & $-33,700$ & 2,090 & 3,030 & & & & & \\
\hline Parallel small compressive & 1.83 & 0.173 & 2220 & $-24,800$ & 7,270 & -812 & & & & & \\
\hline Parallel large compressive & 1.59 & 0.174 & 2130 & $-22,300$ & 4,240 & $-11,600$ & & & & & \\
\hline
\end{tabular}


Table 15. Characterizing Parameters Obtained by Fitting the Mean Data With the

$$
\text { Formula } \sigma=E \epsilon+\left(\frac{\sigma_{f}-E \epsilon_{f}}{\epsilon_{f}^{2}}\right) \epsilon^{2}+\epsilon \sum_{j=1}^{k} a_{j} \sin \frac{j \pi \epsilon}{\epsilon_{f}}
$$

\begin{tabular}{|c|c|c|c|c|c|c|c|c|c|c|c|}
\hline \multirow{2}{*}{ Type of Specimen } & \multirow{2}{*}{$\begin{array}{c}E \\
(p s i)\end{array}$} & \multirow{2}{*}{$\begin{array}{l}\epsilon_{\mathrm{f}} \\
(\%)\end{array}$} & \multirow{2}{*}{$\begin{array}{c}\sigma_{f} \\
(p s i)\end{array}$} & \multicolumn{8}{|c|}{ Parameters } \\
\hline & & & & $a_{1}$ & $a_{2}$ & $a_{3}$ & $a_{4}$ & $a_{5}$ & $a_{6}$ & $a_{7}$ & $a_{8}$ \\
\hline & $\times 10^{6}$ & & & & & & & & & & \\
\hline $\begin{array}{l}\text { Parallel tensile } \\
\text { (flexural and uniaxial data) }\end{array}$ & 1.67 & 0.164 & 1790 & $-39,400$ & $-7,670$ & 21,600 & & & & & \\
\hline $\begin{array}{l}\text { Parallel uniaxial compressive } \\
\text { (uniaxial data only) }\end{array}$ & 1.68 & 1.299 & 4800 & 431,000 & $-104,000$ & $-40,500$ & $-20,900$ & $-10,400$ & -5980 & -2420 & 374 \\
\hline $\begin{array}{l}\text { Transverse uniaxial tensile } \\
\text { (uniaxial data only) }\end{array}$ & 0.95 & 0.167 & 930 & $-63,400$ & $-11,700$ & 6,250 & & & & & \\
\hline $\begin{array}{l}\text { Transverse uniaxial compressive } \\
\text { (uniaxial data only) }\end{array}$ & 0.86 & 2.628 & 4930 & $-273,000$ & $-87,100$ & $-42,300$ & $-22,700$ & $-12,700$ & -7170 & -4120 & -1220 \\
\hline
\end{tabular}


UNCLASSIFIED
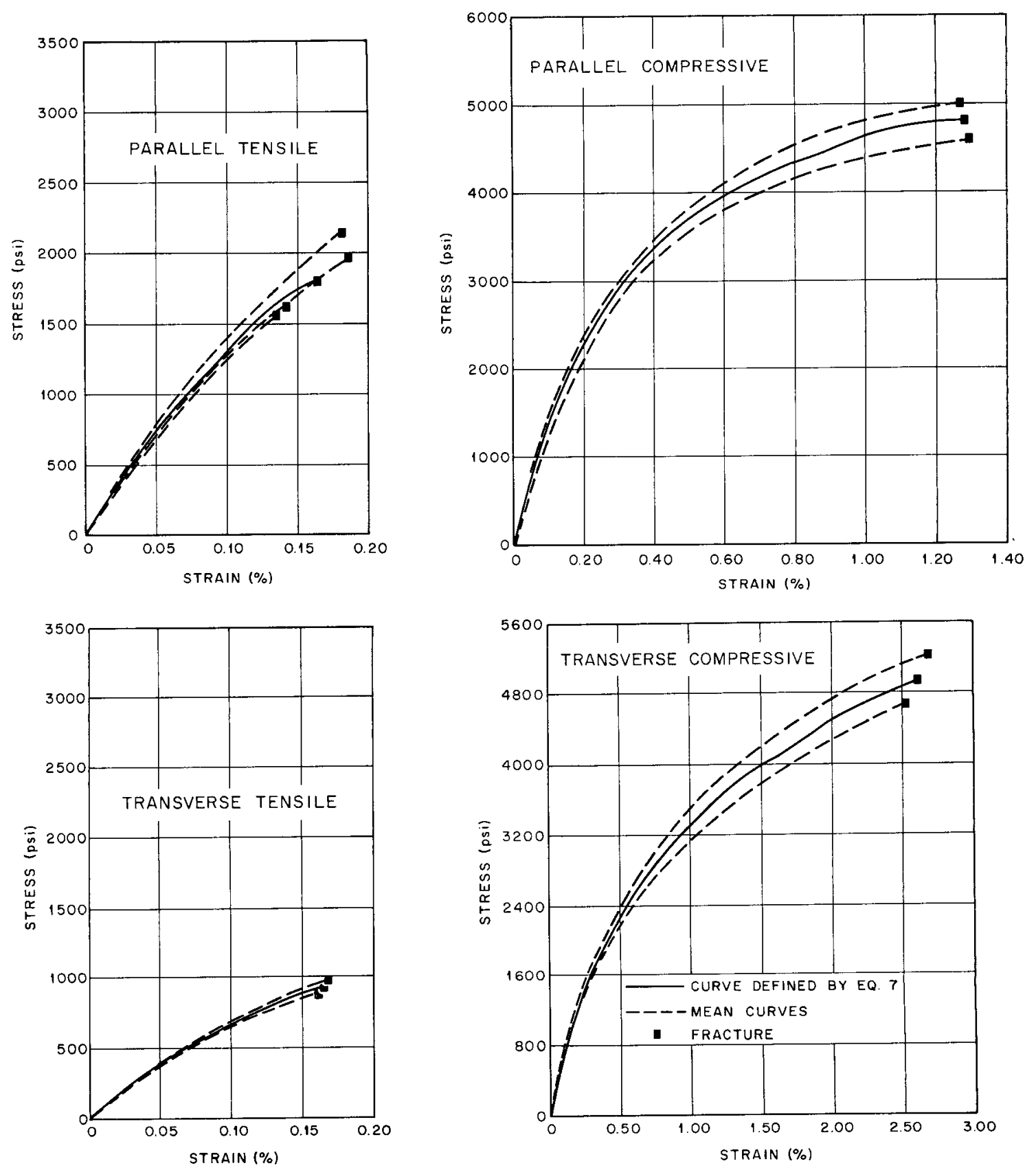

Fig. 34. Comparison of the Mean Curves With the Fit of the Mean of These Curves Using $\sigma=\Xi \epsilon+\left(\frac{\sigma_{f}-E \epsilon_{f}}{\epsilon_{f}^{2}}\right) \epsilon^{2}+\epsilon \sum_{j=1}^{k} a_{j} \sin \frac{j \pi \epsilon}{\epsilon_{f}}$. 

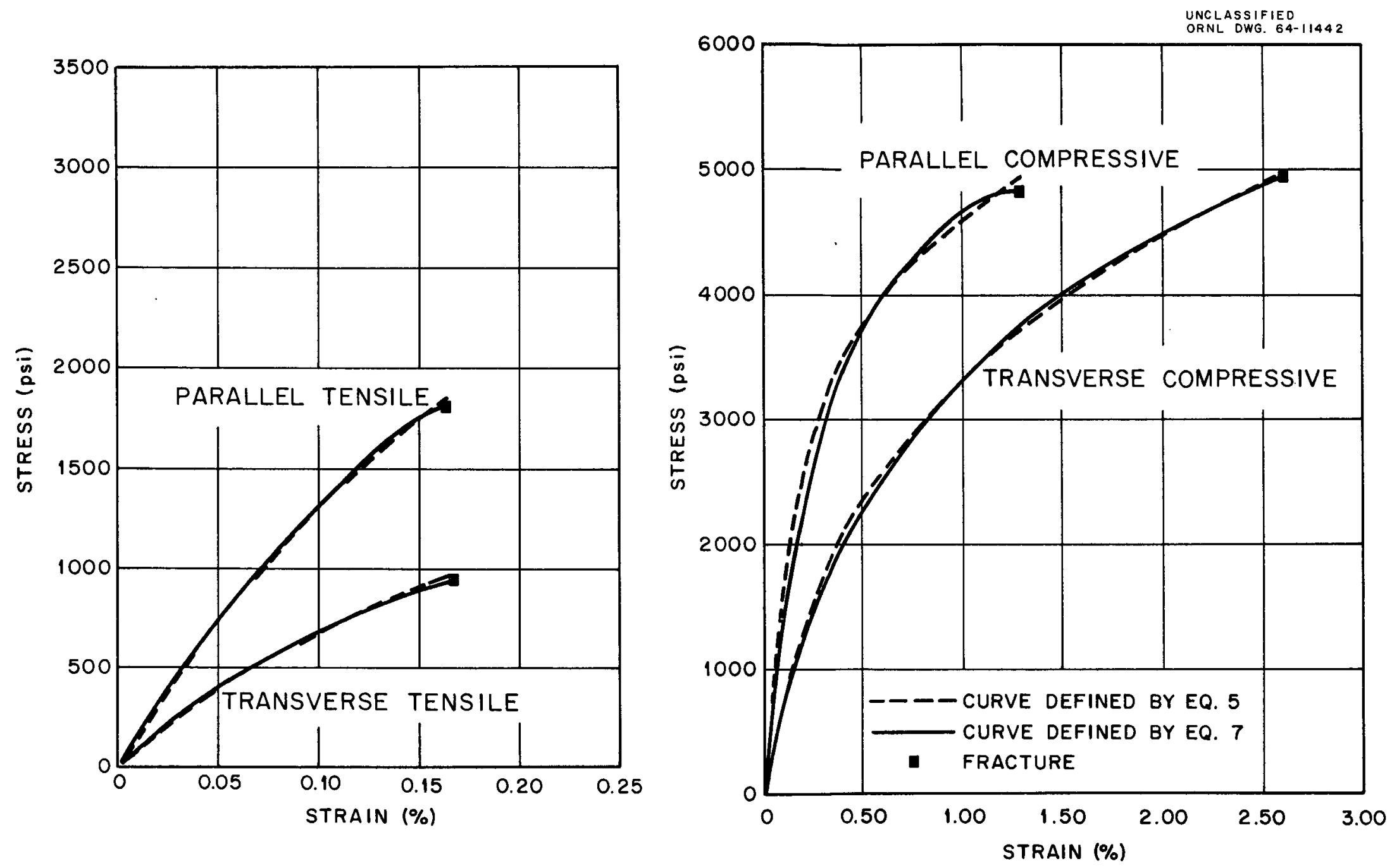

Fig. 35. Comparison of the Curves Obtained by Fitting the Means of the Related Mean Curves. 


\section{Summary}

The most important conclusions reached as a result of these investigations are that

1. Size effects, including volume and cross-sectional area, are small or nonexistent for EGCR-type AGOT graphite specimens within the size range investigated, and

2. The behavior of graphite is the same in flexural and in uniaxial tests, and the stress-strain diagrams do not differ in an engineering sense.

Thus the first step in establishing failure criteria for EGCR-type AGOT graphite has been completed.

EGCR-type AGOT graphite exhibits a considerable degree of anisotropy, and the mechanical properties conform fairly well with the assumption of transverse isotropy. In the plane transverse to the extrusion direction, the ratio of the strain induced normal to the direction of the applied load to the strain in the direction of the load is about the same regardless of whether the load is applied in the direction parallel or transverse to the extrusion axis. The tensile fracture strains are about the same for both the parallel and transverse directions, but the transverse compressive fracture strains exceed the parallel compressive fracture strains substantially. During compressive tests the specimens apparently fail in tension. Taking into account the scatter of the data and the small number of strain-ratio tests performed, the lateral tensile strains are close enough to the failure strains for the tensile tests to suggest a maximum strain criteria for failure. However, to verify such criteria, apparent discrepancies in the uniaxial test results must be resolved and multiaxial stress states must be examined.

The stress-strain diagrams from both the tensile and compressive tests in a given direction agree fairly well up to the tensile fracture strain, even though the average values of the elastic moduli differ. The functional relationship between stress and strain in tension can be adequately represented by a two-parameter function. The characterizing exponent parameter is fairly close to that set forth by Jenkins. ${ }^{12}$ 
The distribution of stresses at a given strain does not deviate significantly from the normal distribution. The fracture stresses appear to be distributed as a Weibull function; however, the Weibull theory of failure is not applicable in its present form.

A significant aspect regarding the testing of graphite such as EGCRtype AGOT is that because of variations in the material alone, uniaxial tests cannot be conducted without internally induced bending. The presence of self-induced bending in certain types of loadings will significantly affect the performance of graphite components. 
Appendix

Hooke's Law for a Transversely Isotropic Material

While graphite does not exhibit elastic properties over even a small range of stress, elastic analyses are often very useful tools for determining nominal stress and strain distributions in graphite components. In such analyses, stress is proportional to strain and independent of time. Thus, the mechanical properties pertinent to elastic analyses must be known. These properties and the relationships between them are discussed below.

Any stress on a volume element can be resolved into nine stress components, as shown in Fig. Al. There are three normal stresses perpendicular to the three faces of the cube and six tangential stresses or shear

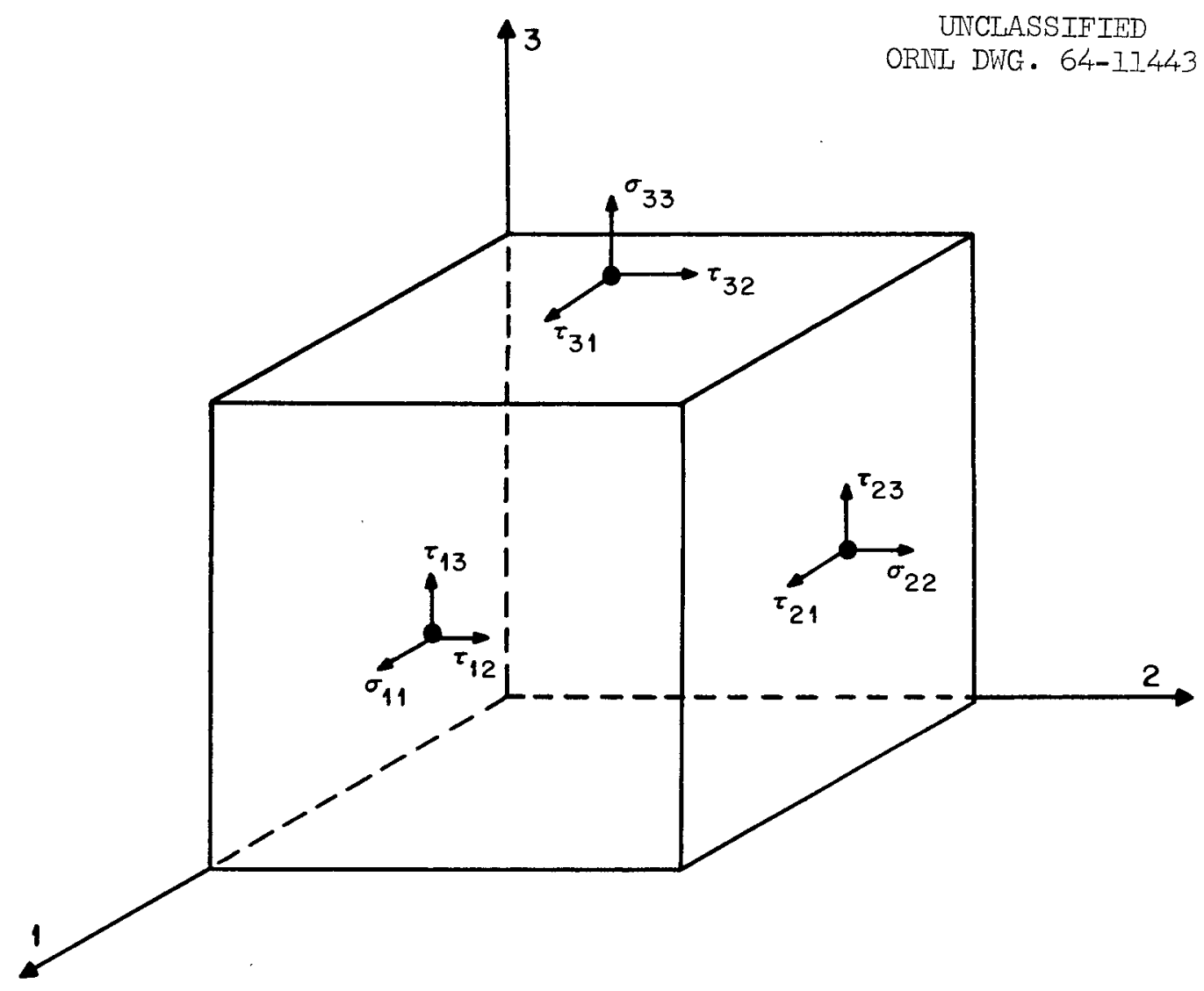

Fig. Al. The Distribution of Stresses Acting on a Volume Element. 
stresses. By considering the equilibrium of the element, the following equalities can be shown to hold: $\tau_{21}=\tau_{12}, \tau_{23}=\tau_{32}$, and $\tau_{13}=\tau_{31}$. Thus the stress can be completely specified by only six independent components, which are three normal stresses, $\sigma_{1}, \sigma_{2}, \sigma_{3}$, and three tangential stresses, $\tau_{12}, \tau_{23}, \tau_{31}$.

For each stress component there is a corresponding strain component. Thus there are three normal strains, $\epsilon_{1}, \epsilon_{2}, \epsilon_{3}$, and three shear strains, $\gamma_{12}, \gamma_{23}$, and $\gamma_{31}$. The linear relations between stress and strain components are the generalized form of Hooke's law and are given by the following set of equations:

$$
\begin{aligned}
& \sigma_{1}=c_{11} \epsilon_{1}+c_{12} \epsilon_{2}+c_{13} \epsilon_{3}+c_{14} \gamma_{23}+c_{15} \gamma_{31}+c_{16} \gamma_{12} \\
& \sigma_{2}=c_{21} \epsilon_{1}+c_{22} \epsilon_{2}+c_{23} \epsilon_{3}+c_{24} \gamma_{23}+c_{25} \gamma_{31}+c_{26} \gamma_{12} \\
& \sigma_{3}=c_{31} \epsilon_{1}+c_{32} \epsilon_{2}+c_{33} \epsilon_{3}+c_{34} \gamma_{23}+c_{35} \gamma_{31}+c_{36} \gamma_{12} \\
& \tau_{23}=c_{41} \epsilon_{1}+c_{42} \epsilon_{2}+c_{43} \epsilon_{3}+c_{44} \gamma_{23}+c_{45} \gamma_{31}+c_{46} \gamma_{12} \\
& \tau_{31}=c_{51} \epsilon_{1}+c_{52} \epsilon_{2}+c_{53} \epsilon_{3}+c_{54} \gamma_{23}+c_{55} \gamma_{31}+c_{56} \gamma_{12} \\
& \tau_{12}=c_{61} \epsilon_{1}+c_{62} \epsilon_{2}+c_{63} \epsilon_{3}+c_{64} \gamma_{23}+c_{65} \gamma_{31}+c_{66} \gamma_{12}
\end{aligned}
$$

These equations may be written in matrix form as:

$$
\left[\begin{array}{c}
\sigma_{1} \\
\sigma_{2} \\
\sigma_{3} \\
\tau_{23} \\
\tau_{31} \\
\tau_{12}
\end{array}\right]=\left[\begin{array}{llllll}
c_{11} & c_{12} & c_{13} & c_{14} & c_{15} & c_{16} \\
c_{21} & c_{22} & c_{23} & c_{24} & c_{25} & c_{26} \\
c_{31} & c_{32} & c_{33} & c_{34} & c_{35} & c_{36} \\
c_{41} & c_{42} & c_{43} & c_{44} & c_{45} & c_{46} \\
c_{51} & c_{52} & c_{53} & c_{54} & c_{55} & c_{56} \\
c_{61} & c_{62} & c_{63} & c_{64} & c_{65} & c_{66}
\end{array}\right]\left[\begin{array}{c}
\epsilon_{1} \\
\epsilon_{2} \\
\epsilon_{3} \\
\gamma_{23} \\
\gamma_{31} \\
\gamma_{12}
\end{array}\right]
$$

The c's are called stiffness constants and the square matrix is called the stiffness matrix.

It can be shown thermodynamically ${ }^{13}$ that the stiffness matrix is symmetrical about the principal diagonal. Thus, the matrix becomes: 


$$
\left[\begin{array}{llllll}
c_{11} & c_{21} & c_{31} & c_{41} & c_{51} & c_{61} \\
c_{21} & c_{22} & c_{32} & c_{42} & c_{52} & c_{62} \\
c_{31} & c_{32} & c_{33} & c_{43} & c_{53} & c_{63} \\
c_{41} & c_{42} & c_{43} & c_{44} & c_{54} & c_{64} \\
c_{51} & c_{52} & c_{53} & c_{54} & c_{55} & c_{65} \\
c_{61} & c_{62} & c_{63} & c_{64} & c_{65} & c_{66}
\end{array}\right]
$$

where there are only 21 independent constants.

It is assumed that graphite is isotropic in the plane perpendicular to the extrusion axis (i.e., it is transversely isotropic). Under this assumption the stiffness matrix has only five independent elements. By choosing the 3-direction as the direction of extrusion, the matrix reduces to:

$\left[\begin{array}{cccccc}c_{11} & c_{12} & c_{13} & 0 & 0 & 0 \\ c_{12} & c_{11} & c_{13} & 0 & 0 & 0 \\ c_{13} & c_{13} & c_{33} & 0 & 0 & 0 \\ 0 & 0 & 0 & c_{44} & 0 & 0 \\ 0 & 0 & 0 & 0 & c_{44} & 0 \\ 0 & 0 & 0 & 0 & 0 & 1 / 2\left(c_{11}-c_{12}\right)\end{array}\right]$

The five stiffness constants may be related to five independent material constants that can be determined experimentally. These material constants are given in Table A.I.

The relationships between the stiffness constants and the material constants are:

$$
\begin{aligned}
& c_{11}=1 / 2\left(\xi_{1}+2 G_{1}\right), \\
& c_{12}=1 / 2\left(\xi_{1}-2 G_{1}\right), \\
& c_{13}=v_{13} \xi_{3},
\end{aligned}
$$


Table A.l. Material Constants

\begin{tabular}{|c|c|c|c|}
\hline Symbol & Name & Method of Measurement & Formula \\
\hline$E_{1}$ & $\begin{array}{l}\text { Modulus of } \\
\text { Elasticity }\end{array}$ & $\stackrel{\text { Extrusion }}{\Longrightarrow}$ & $E_{1}=\sigma / \epsilon$ \\
\hline$E_{3}$ & $\begin{array}{l}\text { Modulus of } \\
\text { Elasticity }\end{array}$ & 4 & $\mathrm{E}_{3}=\sigma / \epsilon$ \\
\hline $\mathrm{G}_{4}$ & Shear Modulus & & $G_{1}=T_{13}$ \\
\hline$v_{12}$ & Poisson's Ratio & & $v_{12}=-\frac{2}{\epsilon}$ \\
\hline$v_{13}$ & Poisson's Ratio & & $v_{13}=-\frac{}{\epsilon_{I}}$ \\
\hline
\end{tabular}




$$
\begin{aligned}
& c_{33}=\left(1-v_{12}\right) \xi_{3}, \\
& c_{44}=G_{4},
\end{aligned}
$$

where

$$
\begin{aligned}
& \xi_{1}=\frac{E_{1}}{\left(1-v_{12}\right)-2 \frac{E_{3}}{E_{1}} v_{13}^{2}}, \\
& \xi_{3}=\frac{E_{3}}{\left(1-v_{12}\right)-2 \frac{E_{3}}{E_{1}} v_{13}^{2}},
\end{aligned}
$$

or

$$
\xi_{3}=\frac{E_{3}}{E_{1}} \xi_{1},
$$

and

$$
G_{1}=\frac{E_{1}}{2\left(1+v_{12}\right)} .
$$

Thus, Hooke's law takes the following form:

$$
\begin{gathered}
\epsilon_{1}=\frac{1}{E_{1}}\left[\sigma_{1}-v_{12} \sigma_{2}-\nu_{13} \sigma_{3}\right], \\
\epsilon_{2}=\frac{1}{E_{1}}\left[\sigma_{2}-\nu_{13} \sigma_{3}-v_{12} \sigma_{1}\right], \\
\epsilon_{3}=\frac{1}{E_{3}}\left[\sigma_{3}-\frac{E_{3}}{E_{1}} \nu_{13}\left(\sigma_{1}+\sigma_{2}\right)\right], \\
r_{23}=\frac{1}{G_{4}} \tau_{23},
\end{gathered}
$$




$$
\begin{gathered}
r_{31}=\frac{1}{G_{4}} T_{31}, \\
r_{12}=\frac{2\left(1+v_{12}\right)}{E_{1}} T_{12} .
\end{gathered}
$$

By setting $\sigma_{1}=\sigma_{2}=0$ in the above expression for $\epsilon_{1}$ it follows that

$$
\epsilon_{1}=\frac{1}{E_{1}}\left(-v_{13} \sigma_{3}\right)
$$

It also follows from the definition of Poisson's ratio $v_{31}, v_{31}=-\frac{\epsilon_{1}}{\epsilon_{3}}$, that

$$
\epsilon_{1}=\frac{1}{E_{3}}\left(-v_{31} \sigma_{3}\right)
$$

Thus the following relationship is implied:

$$
v_{31}=\frac{E_{3}}{E_{1}} v_{13} .
$$

This expression may be derived directly using the principles of superposition and conservation of energy. 
Bibliography

1. C. R. Kennedy, Mechanical Properties of Graphite, pp. 287-290, GCRP Semiann. Progr. Rept. Sept. 30, 1962, USAEC Report ORNL-3372, Oak Ridge National Laboratory.

2. Experimental Gas-Cooled Reactor Final Hazards Summary Report, Vol. I, Description and Hazards Evaluation, USAEC Report ORO-586, Oak Ridge Operations Office, Oct. 10, 1962.

3. Allis-Chalmers Manufacturing Company, Material Specification, Core Graphite, Specification No. RC-2, Revision I (NR), March 9, 1960.

4. The calculation of stress-strain curves from flexural tests is discussed in J. W. Baldwin and C. E. Kesler, The Behavior in Tension, Torsion, and Flexure of Members Made of Brittle Materials, TAM Report 179, University of Illinois, 1960, and A. Nadai, Theory of Flow and Fracture of Solids, Vol. I, pp. 357-359, McGraw-Hill, New York, 1950.

5. J. D. Lubahn and R. P. Felgar, Plasticity and Creep of Metals, Wiley, New York, 1961.

6. L. W. Hu, Studies on Plastic Flow of Anisotropic Metals, J. Appl. Mech., 21: 444-450 (1956).

7. G. W. Snedecor, Statistical Methods Applied to Experiments in Agriculture and Biology, 5th ed., pp. 199-202, The Iowa state University Press, Ames, Iowa, 1956.

8. Ibid., pp. 45-47.

9. D. S. Villars, Statistical Design and Analysis of Experiments for Development Research, p. 4, Wm. C. Brown Company, Dubuque, Iowa, 1951.

10. W. Weibull, "The Phenomenon of Rupture in Solids," Ingeniörsvetenskapsakademiens, Handlingar, NR 153, 1939.

11. C. E. Spruill, Structural Reliability of Components Using Brittle Materials Strength, Report AST/EIR-13431, Vaught Astronautics, October 1961.

12. G. M. Jenkins, Analysis of the Stress-Strain Relationship in Reactor Grade Graphite, British Journal of Applied Physics, 13: 30-32 (1962).

13. A. E. H. Love, A Treatise on the Mathematical Theory of Elasticity, 4th ed., Dover Publications, New York, 1944. 


$$
\text { : }
$$
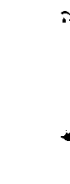

$\bullet$

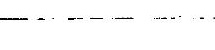
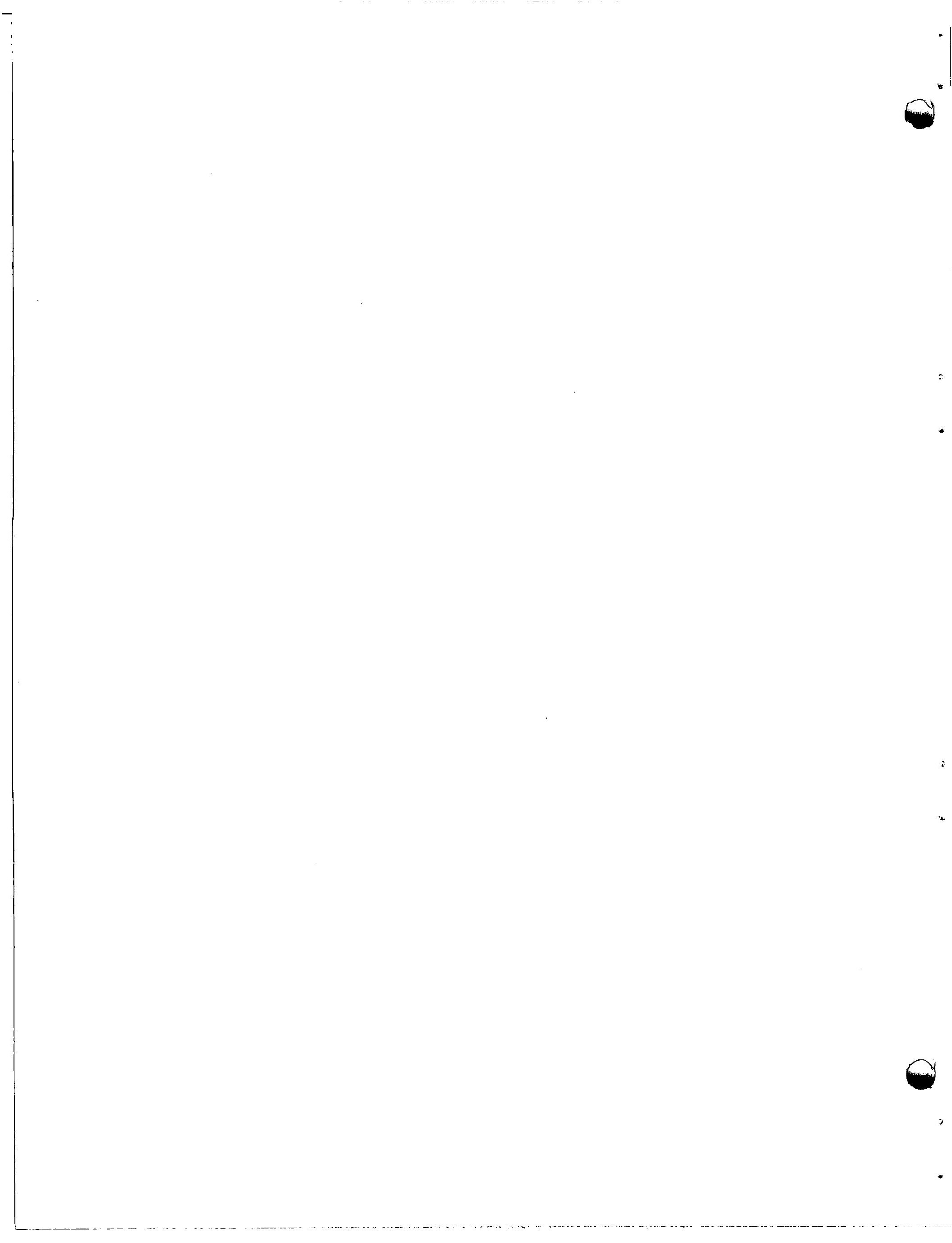


$$
\begin{gathered}
\text { ORNL-3728 } \\
\text { UC-80 - Reactor Technology } \\
\text { TID-4500 (36th ed.) }
\end{gathered}
$$

\section{Internal Distribution}

1. S. E. Beall
2. J. A. Burka
3. F. I. Carlsen, Jr.
4. W. I. Carter
5. C. E. Center (K-25)
6. W. H. Cook
7. I. T. Dudley
8. A. P. Fraas
9-18. B. L. Greenstreet
19. W. D. Harman
20. C. E. Larson (K-25)
21. R. N. Lyon
22. H. G. MacPherson
23. D. L. McElroy
24. J. G. Merkle
25. S. E. Moore
26. F. H. Neill
27. P. Patriarca
28. I. R. Phillips
29. M. L. Picklesimer

\author{
30. A. W. Savolainen \\ 31. R. W. Schneider \\ 32. M. J. Skinner \\ 33. J. E. Smith \\ 34. J. R. Tallackson \\ 35. A. J. Taylor \\ 36-80. D. B. Trauger \\ 81. D. Vondy \\ 82. A. M. Weinberg \\ 83. J. R. Weir \\ 84-103. G. D. Whitman \\ 104. H. D. Willis \\ 105-144. F. J. Witt \\ 145-149. G. T. Yahr \\ 150-151. Central Research Library \\ 152-153. Document Reference Section \\ 154-158. Laboratory Records Depart- \\ ment \\ 159. Laboratory Records, RC
}

\section{External Distribution}

160. W. F. Banks, Allis-Chalmers, Washington, D.C.

161. E. O. Bergman, National Engineering Science Co., Pasadena, California

162. M. N. Burkett, National Carbon Co., New York

163. P. D. Bush, Kaiser Engineers, Oakland, California

164. D. R. Carver, Louisiana State University, Baton Rouge, Louisiana

165. A. I. Chalfant, Pratt \& Whitney Aircraft, Hartford, Connecticut

166. R. A. Charpie, Union Carbide Corp., New York

167-168. D. F. Cope, AEC, ORO

169. B. Y. Cotton, Carbide International, Ottawa, Ohio

170. W. E. Crowe, Los Alamos Scientific Laboratory

171. R. E. Dahl, Hanford Atomic Products Operation, Hanford, Washington

172. J. M. Davidson, Hanford Atomic Products Operations, Hanford, Washington

173. J. Dietz, Los Alamos Scientific Laboratory

174-175. F. J. Digesu, Southern Research Institute, Birmingham, Alabama

176. Herman Ellerbrock, NASA, Lewis Research Center, Cleveland, Ohio

177. R. M. Evan-Iwanowski, Syracuse University, Syracuse, New York

178. B. Fisher, Los Alamos Scientific Laboratory 
179. I. I. France, Westinghouse Astronuclear Laboratory, Pittsburgh, Pennsylvania

180. J.W. Helm, Hanforà Atomic Products Operation, Hanford, Washington

181-183. Harold Hessing, Los Alamos Scientific Laboratory

184. T. J. Higgins, University of Wisconsin, Madison, Wisconsin

185. L. E. Hulbert, Battelle Memorial Institute

186. J. I. Jackson, Hanford Atomic Products Operation, Hanford, Washington

187-188. L. H. Jackson, AEC, ORO

189. V. Kachur, Westinghouse Astronuclear Laboratory, Pittsburgh, Pennsylvania

190. S. Kaufman, NASA, Lewis Research Center, Cleveland, Ohio

191-192. P. G. Lafyatis, Union Carbide Corp. Carbon Products Div., Lawrenceburg, Tennessee

193. B. F. Langer, Bettis Plant, Westinghouse, Pittsburgh, Pennsylvania

194-195. J. D. Lubahn, Colorado School of Mines, Golden, Colorado

196. L. L. Lyon, Los Alamos Scientific Laboratory

197-198. M. Manjoine, Westinghouse Astronuclear Laboratory, Pittsburgh, Pennsylvania

199. W. D. Manly, Union Carbide Corporation, New York

200. S. S. Manson, NASA, Lewis Research Center, Cleveland, Ohio

201. R. L. Maxwell, University of Tennessee, Knoxville, Tennessee

202. W. J. McAfee, University of Tennessee, Knoxville, Tennessee

203. D. McMillan, Los Alamos Scientific Laboratory

204. R. V. Meghreblian, Jet Propulsion Laboratory, Pasadena, California

205. J. I. Mershon, U.S. Atomic Energy Commission, Washington, D.C.

206. R. I. Miller, Kaiser Engineers, Oakland, California

207. W. C. Morgan, Hanford Atomic Products Operation, Hanford, Washington

208-210. J. E. Morrissey, U.S. Atomic Energy Commission, Washington, D.C.

2ll. S. Mrowzowski, University of Buffalo, Buffalo, New York

212. J. V. Neely, Allis-Chalmers, Washington, D.C.

213-214. R. E. Nightingale, Hanford Atomic Products Operation, Hanford, Washington

215. C. H. Parr, Rohm and Haas Company, Huntsville, Alabama

216. Ernest Roberts, IIASA, Lewis Research Center, Cleveland, Ohio

217-219. J. C. Rowley, Los Alamos Scientific Laboratory

220. J. Seldin, Union Carbide Corp., Parma Research Center, Cleveland, Ohio

221. W. A. Shaw, Auburn University, Auburn, Alabama

222. I. R. Shobe, University of Tennessee, Knoxville, Tennessee

223. M. Smith, Los Alamos Scientific Laboratory

224-225. G. B. Spence, Union Carbide Corp., Parma Research Center, Cleveland, Ohio

226. C. H. Tarrant, AEC, Oak Ridge, Tennessee

227. N. R. Thielke, NASA, Lewis Research Center, Cleveland, Ohio

228. D. E. Thomas, Westinghouse Astronuclear Laboratory, Pittsburgh, Pennsylvania 
229. K. N. Tong, Syracuse University, Syracuse, New York

230. T. Vance, Los Alamos Scientific Laboratory

231. Tu-Lung Weng, Union Carbide Corp., Parma Research Center, Cleveland, Ohio

232. E. M. Woodruff, Hanford Atomic Products Operation, Hanford, Washington

233. H. H. Yoshikawa, Hanford Atomic Products Operation, Hanford, Washington

234. Division of Research and Development, AEC, ORO

235-852. Given distribution as shown in TID-4500 (36th ed.) under Reactor Technology category ( 75 copies - CFSTI) 